\title{
OPFERGRUBE DER HÜGELGRÄBERKULTUR IN DER GEMARKUNG VON MÉNFŐCSANAK SPIRALORNAMENT AUF EINEM TONFRIES EINES GEBÄUDES
}

\author{
G. ILON \\ Ungarisches Nationalmuseum - Nationalzentrum für Kulturerbe, II. Regionalbüro \\ Szófia u. 33-35, Pf. 12, H-9704 Szombathely, Ungarn \\ E-Mail: gabor.ilon@mnm-nok.gov.hu
}

\begin{abstract}
Bothros of the Tumulus culture found at the state administrational boundary of Ménföcsanak. Spiral decoration on the clay frieze of a building. The report focuses on only one feature of the preventive archaeological excavation performed on an area of $277,165 \mathrm{~m}^{2}$. In addition to the bones of cattle, domesticated pig, sheep and sheep/goat, as well as carp and pike in the pit, the skeleton of a child (aging between 5 and 8) identified as Inf. I/II was placed in a large bowl (pithos?). In addition to the fragments of two grinding stones with plant remains and phytoliths, as well as food remains and charcoal fragments referring to burning, and to many fractured vessels, such as storage vessels, dishes, knob-footed beaker, portable hearth (pyraunos?), the fragment of the clay frieze of a building was placed nearby the sacrificed child. The data processing by natural sciences was supplemented by two AMS 14C data. This feature can be dated to the second half of the Koszider Period. This report also describes the reconstruction of the building appliqué, the decoration motif of the clay plastic art, and its analogues, and particularly three transportation "corridors/ routes", through which this aesthetical innovation might have been exported.
\end{abstract}

Keywords: Carpathian Basin, Koszider Period, building appliqué, spiral decoration, pithos, child sacrifice

In Erinnerung an István Bóna und Ivan Ordentlich

Der Fundplatz Győr-Ménfőcsanak, Széles-földek (weitere Benennungen in der Fachliteratur: Szeles, Szeles-Flur, Széles-Flur) befindet sich in NW-Ungarn (Abb. 1), in der Ungarischen Kleinen Tiefebene, 6 km südwestlich von Györ entfernt, in der Gemarkung von Ménföcsanak. Der Fundort ist im Südosten durch die Hauptstraße Nr. 83 begrenzt, während die Autobahn M1 (Wien-Budapest) in NW-SO-Richtung ihn überquert. Die für Besiedlung geeigneten Teile - durch den Grundwasserspiegel beeinflusst - wurden ab dem Neolithikum bis ins Mittelalter bewohnt. Auf diese Weise entstand ein ausgedehnter, ca. 150 ha großer Fundplatzkomplex auf der SO-Terrasse der Raab. Ein Teil dessen ist die sog. Széles-Flur. Die Raab mündet in einer Entfernung von 6 km in die Donau.

Die neuesten archäologischen Forschungen wurden auf einer Fläche von $277165 \mathrm{~m}^{2}$ durchgeführt. Die Mitarbeiter des II. Regionalbüros für Kulturerbe (heute: UNM Nationalzentrum für Kulturerbe) dokumentierten 11506 Befunde zwischen Oktober 2009 und September 2011 unter der Leitung des Verfassers. Den aktuellen Gesetzen gemäß wurden die Grabungen vor den Bauarbeiten mit der finanziellen Unterstützung der Bauherren durchgeführt.

Das Fundmaterial wurde vollständig konserviert und mit meinen Mitarbeitern bereitete ich schon die Monographie der vorkeltischen Periode vor. Die vorliegende Studie befasst sich mit dem einzigartigen Fundensemble einer freigelegten Grube, dessen Besonderheiten einen vorläufigen Schnellbericht begründen. 
Der zu behandelnde Befund kam östlich des Baches Pándzsa, im Quadranten JD-231 (Abb. 1) zum Vorschein und wurde zwischen dem 30. Mai und dem 6. Juni 2011 freigelegt. Die Grube erhielt die stratigraphische Nummer 7765. Das auf der Grubensohle freigelegte Skelett eines Kindes wurde mit der stratigraphischen Nummer 7900 bezeichnet.

Die Grube erschien nach dem maschinellen Abtragen der Humusschicht als eine dunklere Verfärbung. Ihr Durchmesser betrug 170-180 cm. Die Grube verschmälerte sich nach der Sohle, ihre Tiefe betrug - vom Niveau der abgetragenen Humusschicht gemessen - 59,8 cm bzw. 37,6 cm (Abb. 2-3).

In der Ausfüllung kamen folgende Artefakte zum Vorschein:

Knochenreste von ausgewachsenen Rindern, Schweinen, Schafen, Schafen/Ziegen sowie Karpfen- und Hechtknochen. Unter den Tierknochen kamen der rechte Beckenknochen bzw. das Schulterblattbruchstück eines Kindes (Inf. I/II, 5-8 Jahre) ans Tageslicht. ${ }^{2}$ Im Weiteren wurden in der Grube Muschel (Unio crassus 2 St. rechte bzw. Unio pictorum 1 St. linke Schale) gefunden.

Unio crassus weist auf Fließgewässer hin, während Unio pictorum die Weiher bzw. die etwas schlammigere Umgebung der Flussufer bevorzugt. Die gesammelten Bruchstücke stammen wahrscheinlich aus demselben Süßgewässersystem, d. h. aus dem einstigen Ur-Marcal-Raab-Fluss. Keine Spuren einer möglichen Verarbeitung zum Schmuck oder Gerät konnten beobachtet werden, auch Verwendungsspuren fehlten. Sie wurden für Speiseoder Futterzwecke gesammelt.

Auf der Grubensohle wurden die folgenden Artefakte freigelegt (Abb. 2-3):

Bruchstücke von zwei Mahlsteinen, dekoriertes Gebäudeelement aus Lehm (Bruchstück eines Frieses Abb. 2: Beigabe Nr. 20), Gefäßfragmente sowie die Knochenreste des in den oberen Schichten bereits erwähnten, 5-8-jährigen Kindes, in Pithos-Form angeordnet. Auf einem der Wirbelknochen eines erwachsenen Schafes oder einer Ziege sind Schnittspuren zu sehen. Als weitere Beigaben (Nr. 15, 16, 17) kamen gebrannte Knochen von Kleinwiederkäuern und die rechte Schale einer Muschel (Unio crassus) zum Vorschein (Abb. 2: Beigabe Nr. 19). Die durch Flotation gewonnenen geringen Pflanzenreste der Ausfüllung waren von schlechter Qualität. Außer Gerste, Nacktweizen und Getreideteilen konnten auch Reste von Unkraut (weißer Gänsefuß) nachgewiesen werden. Es ist gut vorstellbar, dass die Speisereste auf eine brotartige Teigspeise hinweisen, auf eine Art Brei. ${ }^{3}$ Die große Menge der durch Flotation gewonnenen, feinen Holzkohlereste weist auf ein lokales Feuerereignis hin.

Das auf der Oberfläche der Mahlsteine präparierte Phytolithmaterial (Abb. 4.1) zeigt ein gemischtes Bild. Einerseits sind auf Getreide hindeutende pflanzliche Opalkörner vorhanden, andererseits konnten als Umweltindikator geltende andere Morphotypen, überwiegend zu Süßgräsern gehörende vegetative Formeln (z. B. Blatt, Stiel) identifiziert werden. Der einzige nicht Süßgras-Morphotyp (globular bulbous) kann gleicherweise als Umweltindikator betrachtet werden. ${ }^{4}$

Im Lichte der archäobotanischen Ergebnisse ist es schwer zu entscheiden, ob die in der Ausfüllung der Grube erscheinenden Getreidereste an einen Ritual zu knüpfen sind und ob das wenige Getreide mit Absicht oder zufällig in die Grube gelangte. Die Tatsache, dass der weiße Gänsefuß, das typische Unkraut der Getreidekulturen auch erscheint, könnte eventuell auch darauf hinweisen, dass durch Ernte und später durch Reinigung kein reiner Getreiderohstoff hergestellt werden konnte. Der zum Mahlen vorbereitete Grundstoff enthielt Hüllspelzen und Granne; auch die Phytolithe deuteten dies an.

${ }^{1}$ Die Grabungsfläche wurde in $20 \times 20$ m große Quadranten eingeteilt. Die geodätischen Arbeiten (Ausmessung, Nivellierung, Einmessung) wurden unter der Leitung von István Eke von den Geodäten des II. Regionalbüros durchgeführt, namentlich von Z. Áncsán, Á. Földi und Z. Kovács. Ihre Arbeit sei auch hiermit herzlich bedankt.

${ }^{2}$ G. TóTH: Bericht. Westtransdanubische Region: GyőrMénfőcsanak, Eperföldek/Szélesföldek. Szombathely, 15. 11. 2011., Archiv des UNM - Nationalzentrum für Kulturerbe; G. Tо́тн: Bericht. Westtransdanubische Region: Győr-Ménfőcsanak, Eperföldek/Szélesföldek. Szombathely, 30.12. 2011., Archiv des UNM - Nationalzentrum für Kulturerbe.
${ }^{3}$ S. JACOMET-CH. BROMBACHER-M. Dick: Archäobotanik am Zürichsee. Ackerbau, Sammelwirtschaft und Umwelt von neolithischen und bronzezeitlichen Seeufersiedlungen im Raum Zürich. Berichte der Züricher Denkmalpflege 7 (1989); F. GyULAI: Archaeobotany in Hungary. Seed, Fruit, Food and Beverage Remains in the Carpathian Basin from the Neolithic to the Late Middle Ages. Archaeolingua 21. Budapest 2010.

${ }^{4}$ Á. PETŐ-A. BARCZI: A Magyarországon előforduló meghatározó jelentőségű és gyakori talajtípusok fitolit profiljának katasztere. V: A vizsgált réti és öntéstalajok eredményei (Phytolith profile cadastre of the most significant and abundant soil types of Hungary. "V." Results of the examined meadow and alluvial soil profiles). Tájökológiai Lapok 10/1 (2012) 99-101. 


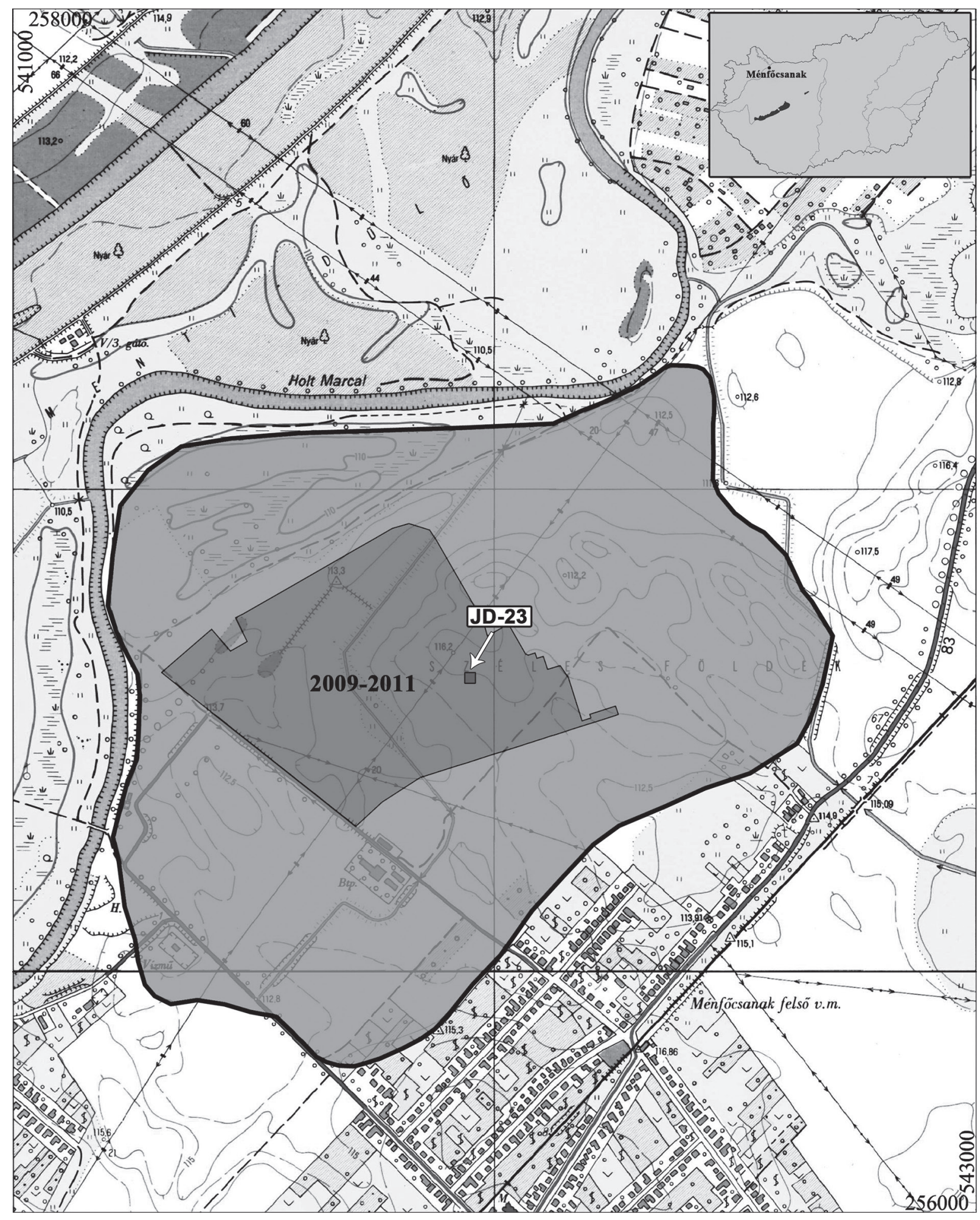

Abb. 1. 1: Die geographische Lage des Fundplatzes in Ungarn; 2: der freigelegte Teil des Fundplatzes auf der topographischen Karte (M 1:10000) (angefertigt von I. Eke) 


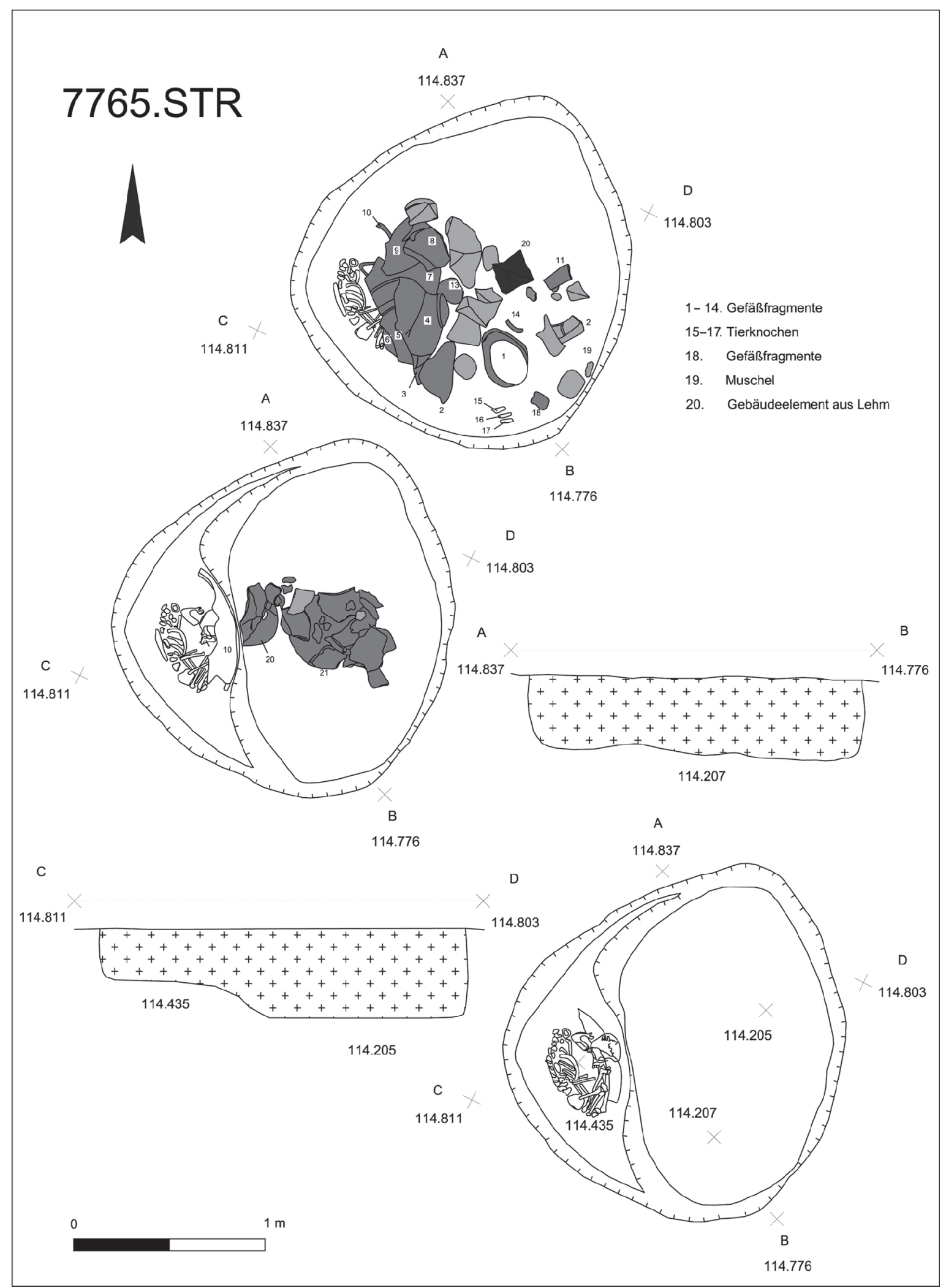

Abb. 2. Die Phasenzeichnungen der Grube (angefertigt von I. Eke, Z. Kovács) 

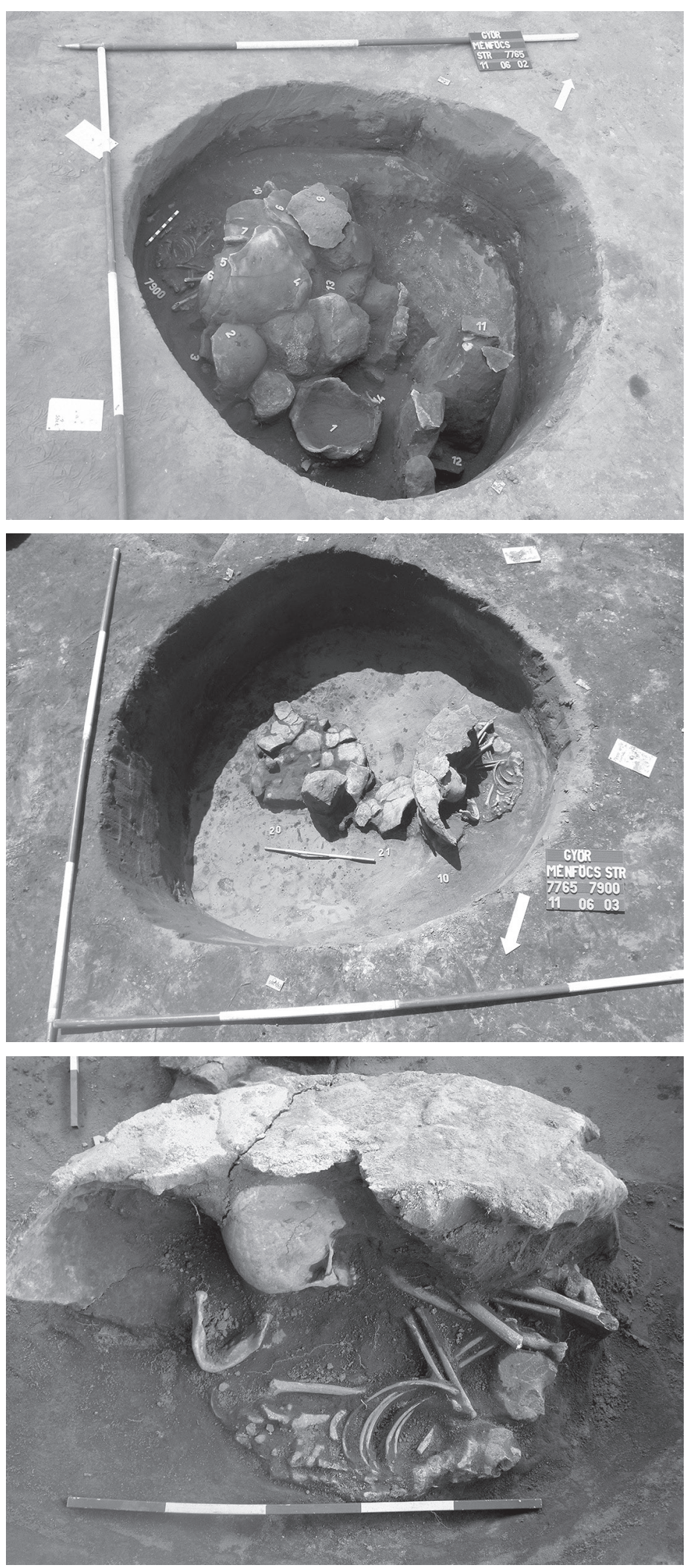

Abb. 3. Die Grabungsphasen der Grube (Foto: F. Halász) 

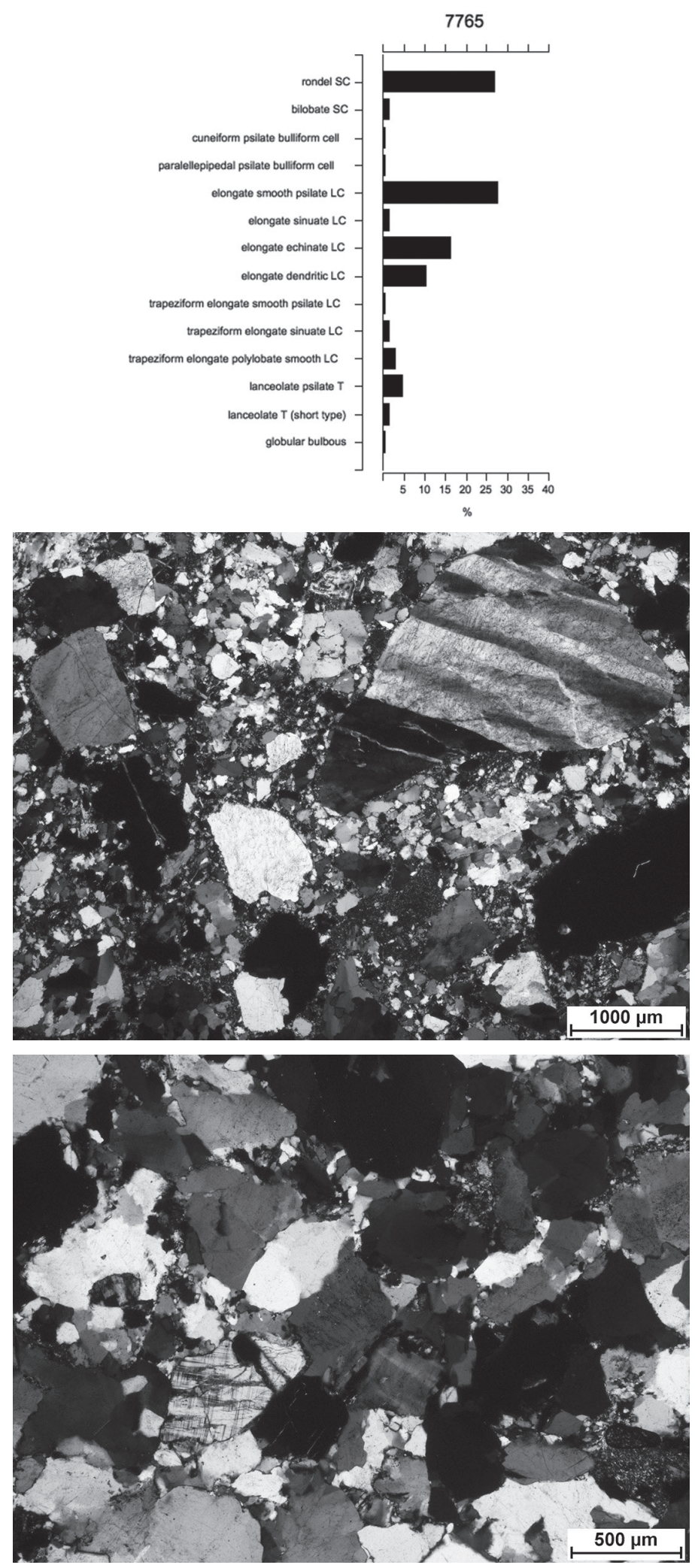

Abb. 4. 1: Diagramm der Phytolithreste der Mahlsteine (angefertigt von Á. Petö); 2a-b: Dünnschliffe der Mahlsteine (angefertigt von I. Oláh) 


\section{DIE BESCHREIBUNG DER FUNDE UND IHRE ANALOGIEN}

Kegelhalsgefäß. Außen sowie innen gelbgrau gefleckt und poliert, mit Sand und Kiesel gemagert. Der Rand ist horizontal abgeschnitten, der Körper ist doppelkegelstumpfförmig, der Unterteil stark nach unten verengt. Auf der Schulter saßen ursprünglich vier (heute nur noch drei) spitze Buckel. An der Freilegung wurde es als Beigabe Nr. 21 dokumentiert. H: $26 \mathrm{~cm}$; Dm. des Randes: $17 \mathrm{~cm}$; Dm. des Bodens: $12 \mathrm{~cm}$; Wanddicke: 0,9 cm. R.-Nr. 1.34305.7765.1. (Abb. 8.1; Abb. 17.1). Die nächsten und neuesten Parallelen kennen wir aus dem Grab A1 von Nagydém sowie aus dem Depotfund von Hegykő. 5

Oberteil eines großen Vorratsgefäßes. Außen dunkelbraun-grau, innen grau, mit Kies und Keramikgrus gemagert, auf dem Hals innen sowie außen poliert, der Bauch wurde mit Fingerstrichen geraut. Der Rand biegt nach außen, der Hals ist geschweift, der Körper eiförmig. Auf der Schulter sitzt ein Leistendekor, mit zwei (ursprünglich vielleicht vier) Buckeln. An der Freilegung mit Beigabennummer 7 und 8 dokumentiert. Maßangaben: $48 \times 51 \mathrm{~cm}$; Wanddicke: $1 \mathrm{~cm}$. R.-Nr. 1.34305.7765.3. (Abb. 8.2; Abb. 17.2). Seine weiterlebende Form ist von etwas unterschiedlichem Profil, senkrecht kanneliert, aber ebenfalls mit Leistendekor versehen. Sie kommt in mehreren Gruben der Siedlung von Veselé/Vígvár vor, wo sie in die späthügelgräberzeitliche Strachotín-Velké Hostěrádky-Phase datiert wurde. ${ }^{6}$

Oberer Teil eines Vorratsgefäßes. Innen und außen rotbraun und grau gefleckt, poliert, mit Sand und Kies gemagert. Der Rand ist schräg abgeschnitten und ausladend, der Hals geschweift, der Körper bauchig, auf der Schulter sitzen spitze Buckel. An der Freilegung erhielt es die Bezeichnung Beigabe Nr. 6. Maßangaben: $37 \times 44 \mathrm{~cm}$; Dm. des Randes: $38 \mathrm{~cm}$; Wanddicke: 0,9 cm. R.-Nr. 1.34305.7765.4. (Abb. 8.3; Abb. 17.4). Ein ähnliches Gefäß - zwar ohne Buckel - ist im Gefäßdepot von Veszprém-Kádárta-Gelemér bekannt. ${ }^{7}$ In der Ausformung ähnlich (stark ausladender Rand, spitze Buckel auf der Schulter und mit Henkel versehen) ist ein Gefäß in einem Grab von Znojmo-Pivovar, ${ }^{8}$ im Materialgut der Věteřov-Kultur bekannt.

Oberer Teil und Bauchbruchstücke eines großen Vorratsgefäßes. Außen hellbraun und grau gefleckt, poliert, innen gelb und grau gefleckt, mit Kies und Keramikgrus gemagert. Die Schulter ist stark eingezogen, der Körper doppelkegelstumpfförmig. Die Schulter ist mit spitzen Buckeln versehen, auf dem oberen Teil des Bauches sitzt ein Bandhenkel. An der Freilegung erhielt es die Bezeichnung Beigabe Nr. 3 und 10. Maßangaben des Bruchstücks: $36 \times 62 \mathrm{~cm}$; Breite des Henkels: $3,6 \mathrm{~cm}$; Wanddicke: $1,1 \mathrm{~cm}$. R.-Nr. 1.34305.7765.7. (Abb. 8.4; Abb. 17.6).

Hals-, Schulter- und Wandbruchstück eines Kegelhalsgefäßes. Außen braun und dunkelgrau gefleckt, innen grau und schwarz. Der Rohstoff des Gefäßes wurde mit Kies und Keramikgrus gemagert, der Hals ist innen wie außen poliert, die Schulter geglättet, der Bauch mit Fingerstrichen geraut. Maßangaben: $24 \times 23,5 \mathrm{~cm}$; Wanddicke: 1,1 cm. R.-Nr. 1.34305.7765.27. (Abb. 9.1).

Buckel eines großen Gefäßes. Der spitze Buckel löste sich von der Gefäßwand. Dunkelgrau und poliert, mit Kies gemagert. Breite der Buckel: 5 cm; Höhe: 1,8 cm. R.-Nr. 1.34305.7765.19. (Abb. 9.2). Die an der Gefäßwand applizierten Buckel erscheinen erst in dem in die Übergangsphase der Bz A2-Bz B1 datierten Retznei-Freidorf 1-Horizont in der Steiermark, und zwar gedellt, mit Zipfelschalen (ihre Beschreibung s. unten) und mit eingeritzten Motiven (s. die Beschreibung des nächsten Gefäßbruchstücks). ${ }^{9}$

Bauchbruchstück eines wahrscheinlich amphorenförmigen Gefäßes mit einem Bandhenkel. Außen braun, innen schwarz und poliert, mit grobem Kies gemagert. Auf dem Bauch, neben dem Henkel und unterhalb dessen senkrecht eingeritzte Linien (Kammstrich?). Maßangaben: 5,9 $\times 7,1 \mathrm{~cm}$; Breite des Henkels: 3,4 cm; Wanddicke: 0,9 cm. R.-Nr. 1.34305.7765.20. (Abb. 9.3).

Randbruchstück eines Gefäßes mit nach außen schweifendem Hals. Innen und außen gelbbraun und poliert, mit Sand gemagert. Dm. des Randes: $19 \mathrm{~cm}$; Wanddicke: 0,5 cm. R.-Nr. 1.34305.7765.21. (Abb. 9.4).

Randbruchstück eines Kegelhalsgefäßes. Außen und innen hellbraun und poliert, mit Sand und Keramikgrus gemagert. Dm. des Randes: $13 \mathrm{~cm}$; Wanddicke: 0,9 cm. R.-Nr. 1.34305.7765.22. (Abb. 9.5). Die Gefäßfragmente auf Abb. 9.6 und 9.7 haben eine ähnliche Randausbildung. Solche Fragmente kamen auch in dem Befund 1 der neulich publizierten Siedlung von Domaszék-Börcsök-tanya ${ }^{10}$ (Kom. Csongrád) zum Vorschein.

${ }^{5}$ ILON 1999, Taf. 1.1, 6.1.

${ }^{6}$ BARTíK 1996, 250, Obr. 3, F2; Tab. 8.3, 10.1, 12.6, 12.11.

${ }^{7}$ ILON 2012, Fig. 5.4.

\author{
${ }^{8}$ STUCHLÍ́ 2006, 144, Obr. 135.9 . \\ ${ }^{9}$ Tiefengraber 2007, 100-101, Abb. 15. \\ ${ }^{10}$ SÁNTA 2009, 262, Abb. 3.2. \\ Acta Archaeologica Academiae Scientiarum Hungaricae 65, 2014
}



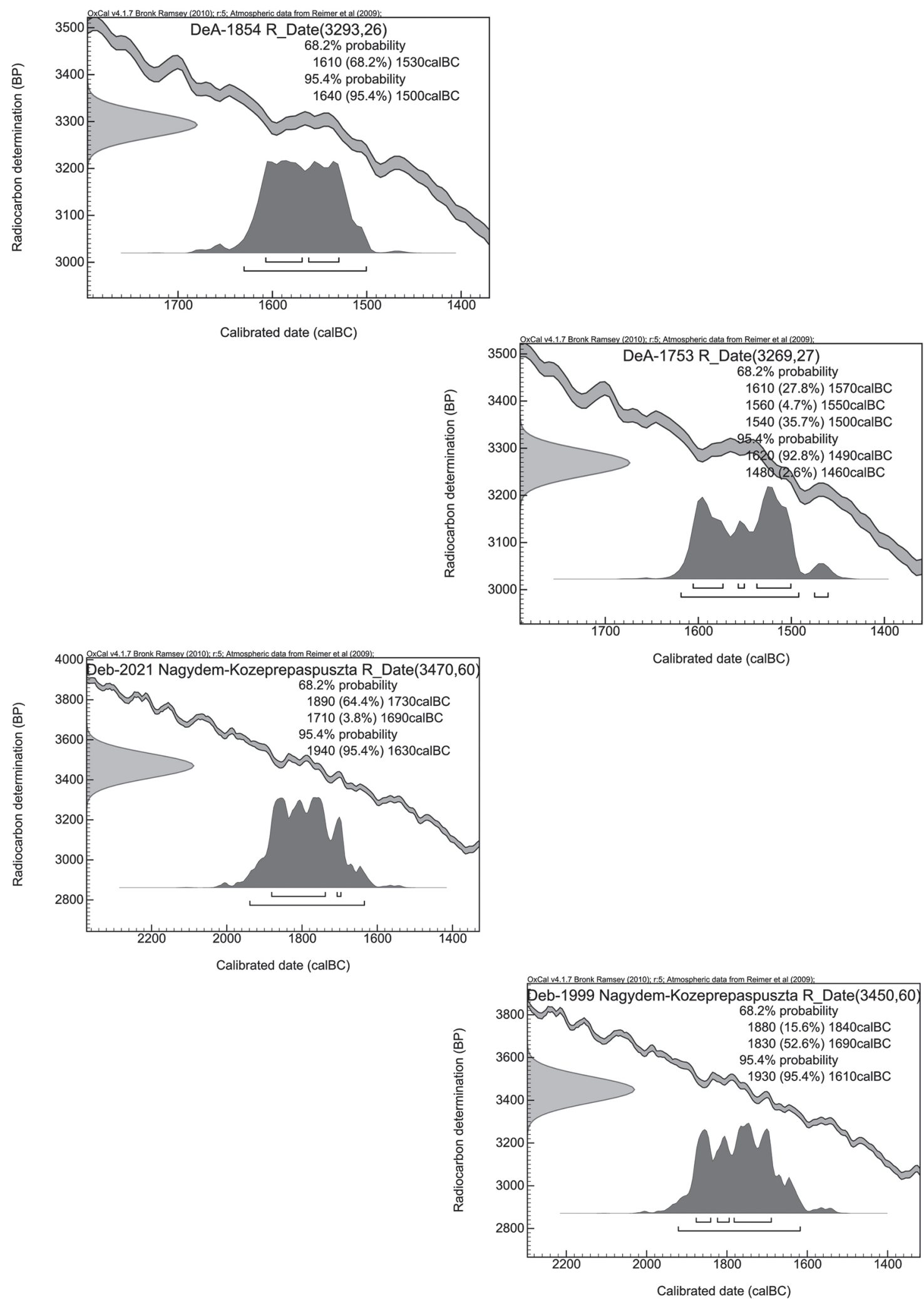

Abb. 5. Radiokarbondaten der Grube von Ménföcsanak und des Grabes 1A von Nagydém 


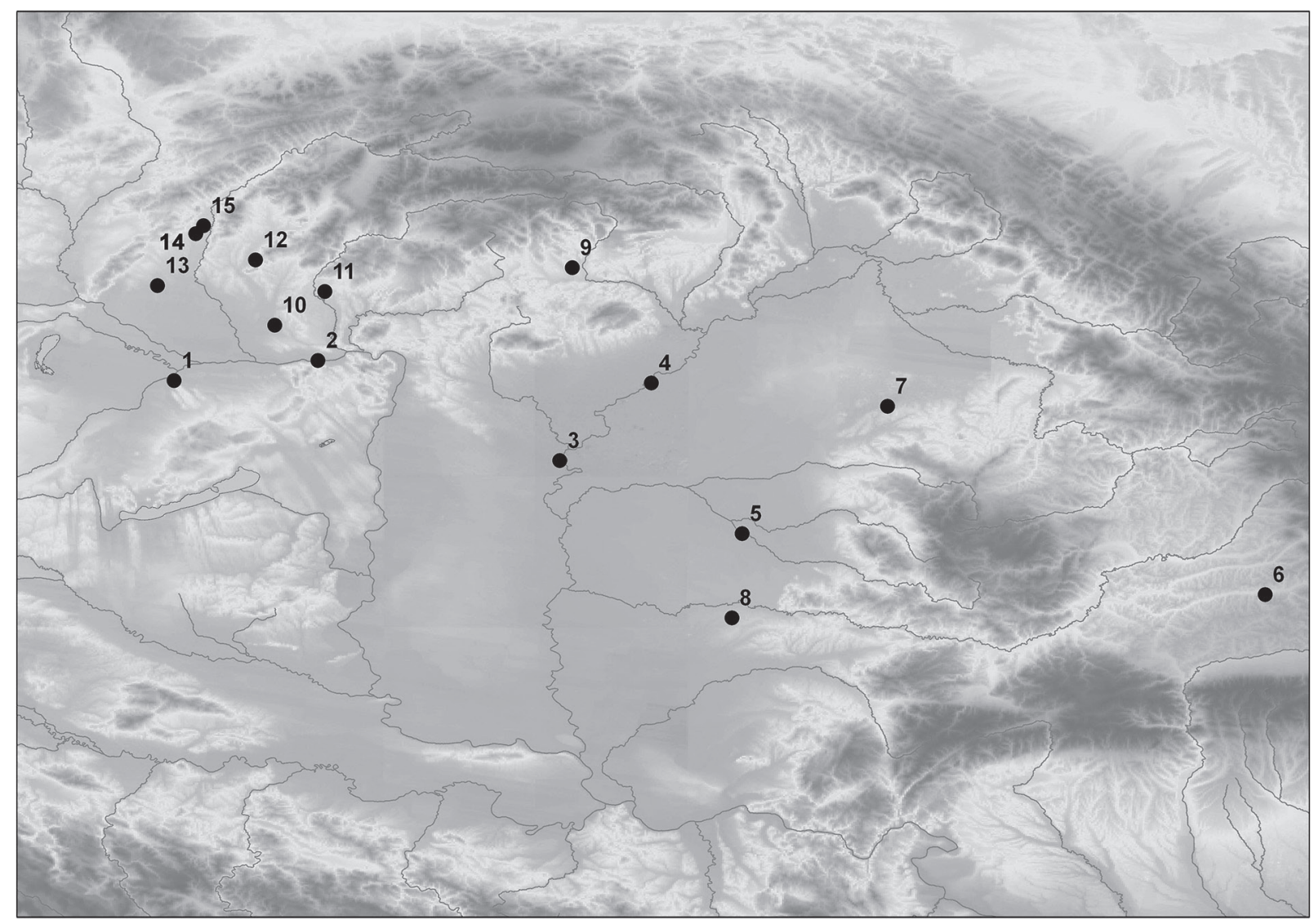

Abb. 6. Das Vorkommen von dekorierten Wandverputzstücken an Gebäuden/Altären im Karpatenbecken. Diese unvollständige Liste (angefertigt von I. Eke) wird mit den Arbeiten von PAULíK 1962, KMETOVÁ-HLADÍKOVÁ-GrEGOR 2010 ergänzt.

1. Ménföcsanak (Ungarn): Lehmverputz mit Spiralornament - nachklassische Věteřov-, frühe mitteldanubische Hügelgräberkultur

2. Nyergesúffalu-Donauufer (Ungarn): Lehmverputzstücke, unter ihnen auch mit Spiralmotiv dekorierte Exemplare - Urnenfelderkultur, Bz D (PATEK 1968, 35-36, 133, Taf. 111.7, Taf. 113-115)

3. Tószeg (Ungarn): Spiralornament, Altar/Herdverputz - mittleres Niveau, Kultur der Spiralbuckelgefäße / frühe Füzesabony-Gruppe (BANNER-BÓNA-MÁRTON 1957, 126-127)

4. Tiszafüred-Ásotthalom (Ungarn): Fassade/Wandverputz - Altar/Herdverputz, in einem geschwungenen Dreieck sitzt ein konzentrischer Kreis - Kultur der Spiralbuckelgefäße / Füzesabony-Gruppe (BóNA 1975, 155, Taf. 197.2)

5. Vărşand (Gyulavarsánd, Rumänien): Spiralornament, Altar/Herdverputz - Kultur der Spiralbuckelgefäße / Gyulavarsánd-Gruppe (BÓNA 1975, 133, Taf. 146.1-7)

6. Sighişoara-Wietenberg (Segesvár, Siebenbürgen, Rumänien): Altar-Feuerherd - Wietenberg-Kultur

7. Sălacea-Vida-Hügel (Szalacs, Rumänien): Gebäudefries mit Spiralornament - Otomani-Kultur

8. Şagu (Németság, Rumänien): Herdverputzstücke, unter ihnen mit Spiralornament verzierte Exemplare - mittlere und/oder Spätbronzezeit (SAVA-HuREZAN-MăRgineAn 2011, 31-41, Fig. 48-49)

9. Barca (Bárca, Slowakei): Altar-Feuerherd - Otomani-Kultur

10. Dvory nad Žitavou (Udvard, Slowakei): Altartisch - karpatenländische Hügelgräberkultur (PAulík 1962, Obr. 1-3)

11. Levice-Géne (Léva, Slowakei): Fassade- und Wandverputz mit gewölbtem Dekor - mittlere oder Spätbronzezeit

(KMETOVÁ-HladíKovÁ-Gregor 2010, Anm. 127, 159, Obr. 6-7)

12. Horné Lefantovce (Felsőelefánt, Slowakei): Lehmverputzstück mit Spiralornament - Vorčaka-Kultur (PAULí 1962, 27, 32)

13. Vel'ký Grob (Magyargurab, Slowakei): gewölbt gedellter Wandverputz/Herd (?) - Čaka-Kultur (PAULíK 1962, Obr. 15-16)

14. Trebatice (Vágterbete, Slowakei): Fassade/Wandverputz, Gebäudefries mit Spiralornament (?) - Velatice-Baierdorf-Phase der Urnenfelderkultur (PAULiK 1962, Obr. 7-10)

15. Pobedim (Pobedény, Slowakei): Lehmverputz eines Pfostens - jüngere Lausitz-Kultur (PAulík 1962, Obr. 5, Obr. 18) 


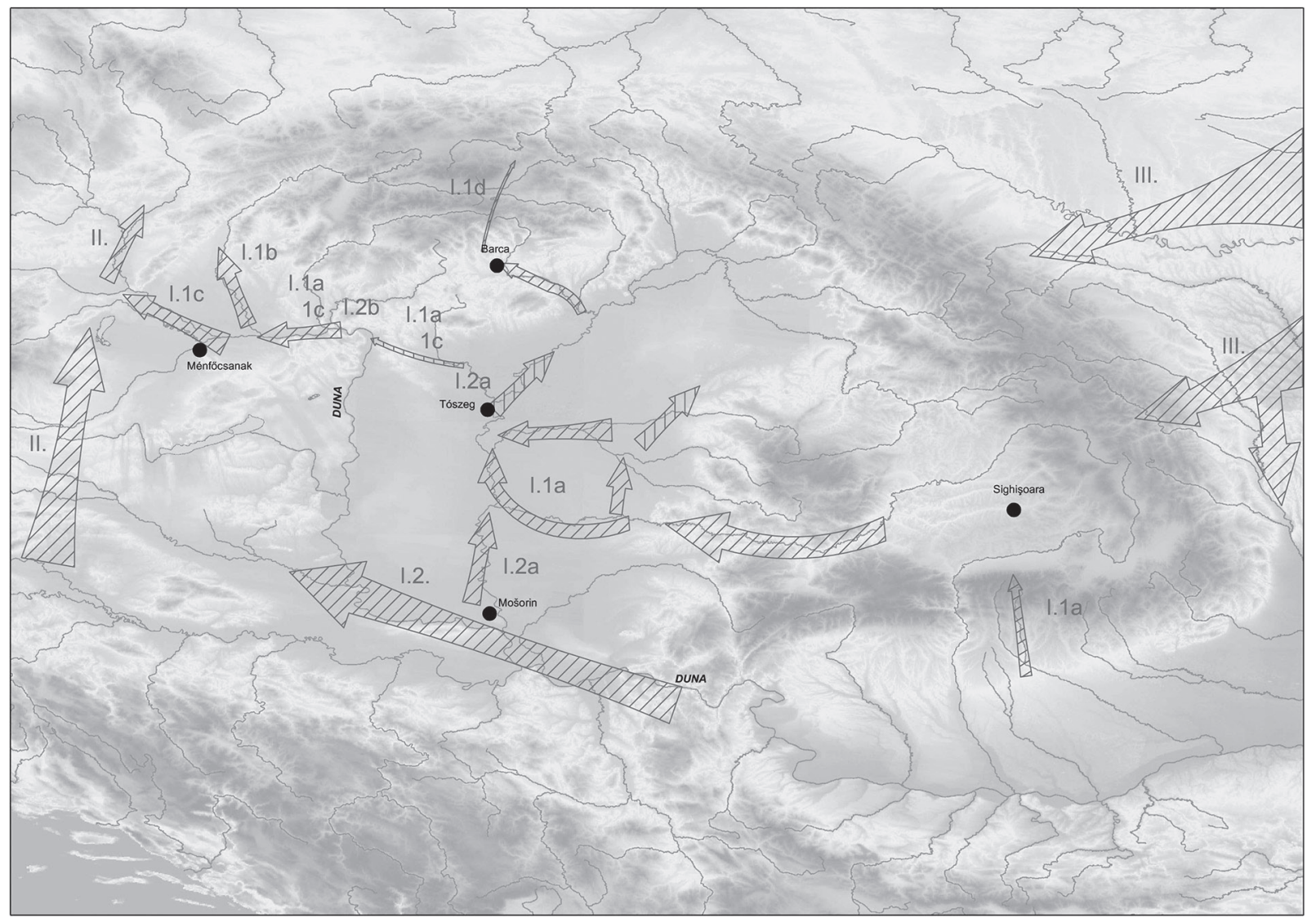

Abb. 7. Die das Karpatenbecken berührenden europäischen Innovations- und Hauptverkehrsrouten in der Koszider-Periode (angefertigt von I. Eke)

Randbruchstück eines Kegelhalsgefäßes. Außen gelbbraun, innen hellbraun, mit Sand und feinkörnigem Kies gemagert, außen wie innen poliert. Dm. des Randes: 24 cm; Wanddicke: 0,8 cm. R.-Nr. 1.34305.7765.23. (Abb. 9.6).

Randbruchstück eines Kegelhalsgefäßes. Außen grau, innen rotbraun, mit Keramikgrus gemagert, die Oberfläche ist außen blasig (eventuell sekundär gebrannt). Dm. des Randes: $18 \mathrm{~cm}$; Wanddicke: $1 \mathrm{~cm}$. R.-Nr. 1.34305.7765.24. (Abb. 9.7).

Randbruchstück eines großen Gefäßes. Außen und innen hellgrau-braun und poliert, mit Sand und Kies gemagert. Dm. des Randes: 19 cm; Wanddicke: 0,8 cm. R.-Nr. 1.34305.7765.26. (Abb. 9.8).

Randbruchstücke (2 St.) eines großen Gefäßes von grober Ausführung, mit ausladendem Rand. Außen hellbraun und dunkelgrau gefleckt, innen dunkelgrau, außen und innen poliert, mit Kies und Keramikgrus gemagert. Maßangaben: 3,6×3,2 cm; Wanddicke: 0,9 cm. R.-Nr. 1.34305.7765.25. (Abb. 9.9).

Wandbruchstücke eines großen Gefäßes. Die äußere Oberfläche ist stark mulmig, innen grau und poliert, mit Sand und Keramik gemagert. An der Freilegung erhielt es die Bezeichnung Beigabe Nr. 11. Maßangaben: $14,5 \times 7 \mathrm{~cm}$; Wanddicke: $1,1 \mathrm{~cm}$. R.-Nr. 1.34305.7765.28.

Halsbruchstück eines großen Gefäßes. Außen und innen grau gefleckt, außen poliert, mit Sand und Kies gemagert. Maßangaben: 7,7×4,8 cm; Wanddicke: 0,9 cm. R.-Nr. 1.34305.7765.32.

Bruchstück des Bandhenkels eines großen Gefäßes. Hellgrau, mit Sand und Keramikgrus gemagert. Maßangaben: 2,6×4,2 cm; Dicke des Henkels: 1,3 cm. R.-Nr. 1.34305.7765.35.

Boden- und Wandbruchstücke eines großen Gefäßes mit grober Oberfläche. Außen und innen hellbraun, mit Sand und Kies gemagert, der Boden leicht profiliert. Dm. des Bodens: ca. $14 \mathrm{~cm}$; Dicke des Bodens: 2,2 cm; Wanddicke: $1 \mathrm{~cm}$. R.-Nr. 1.34305.7765.36. 

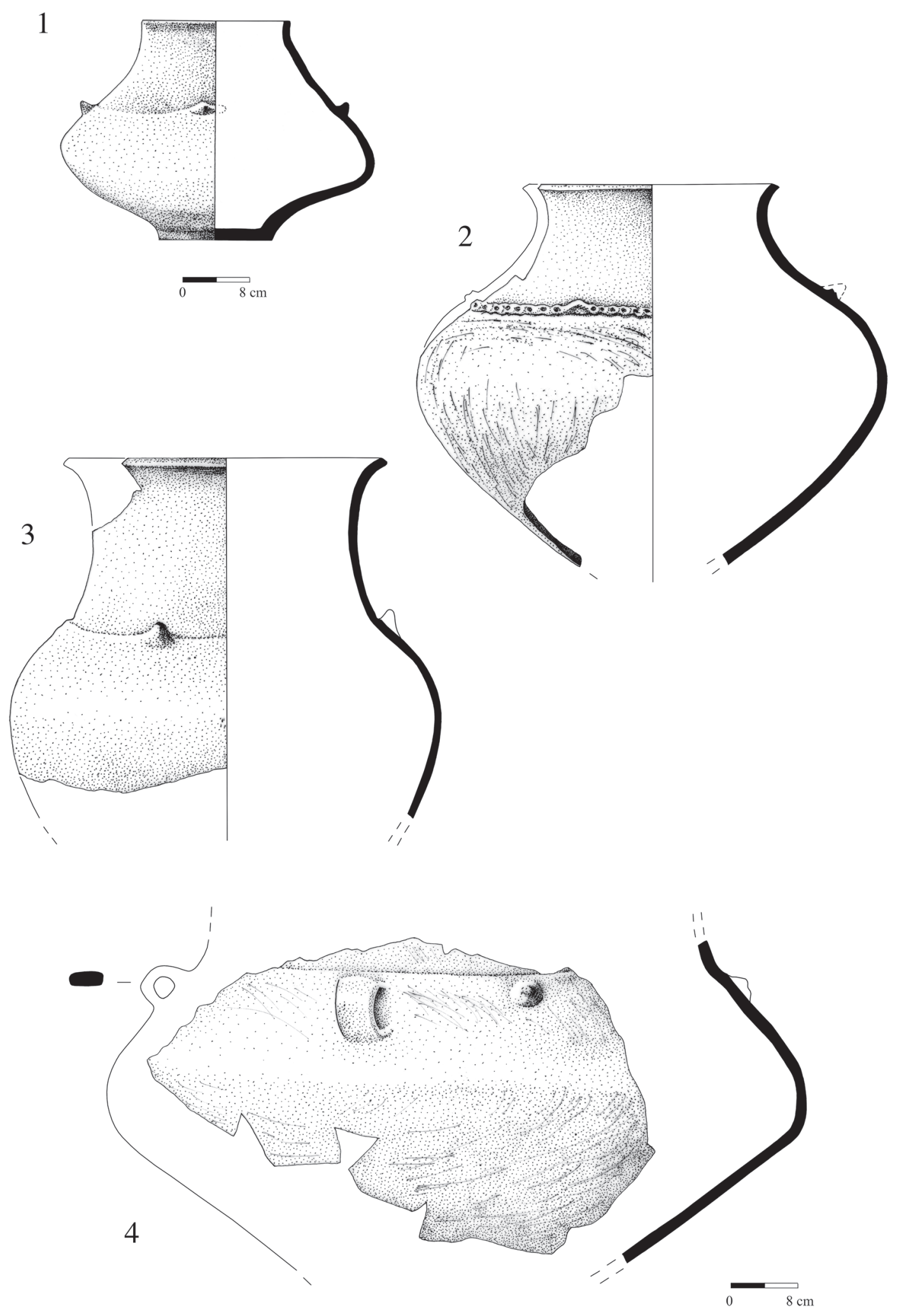

Abb. 8. Vorratsgefäße (gezeichnet von M. Mátyus) 

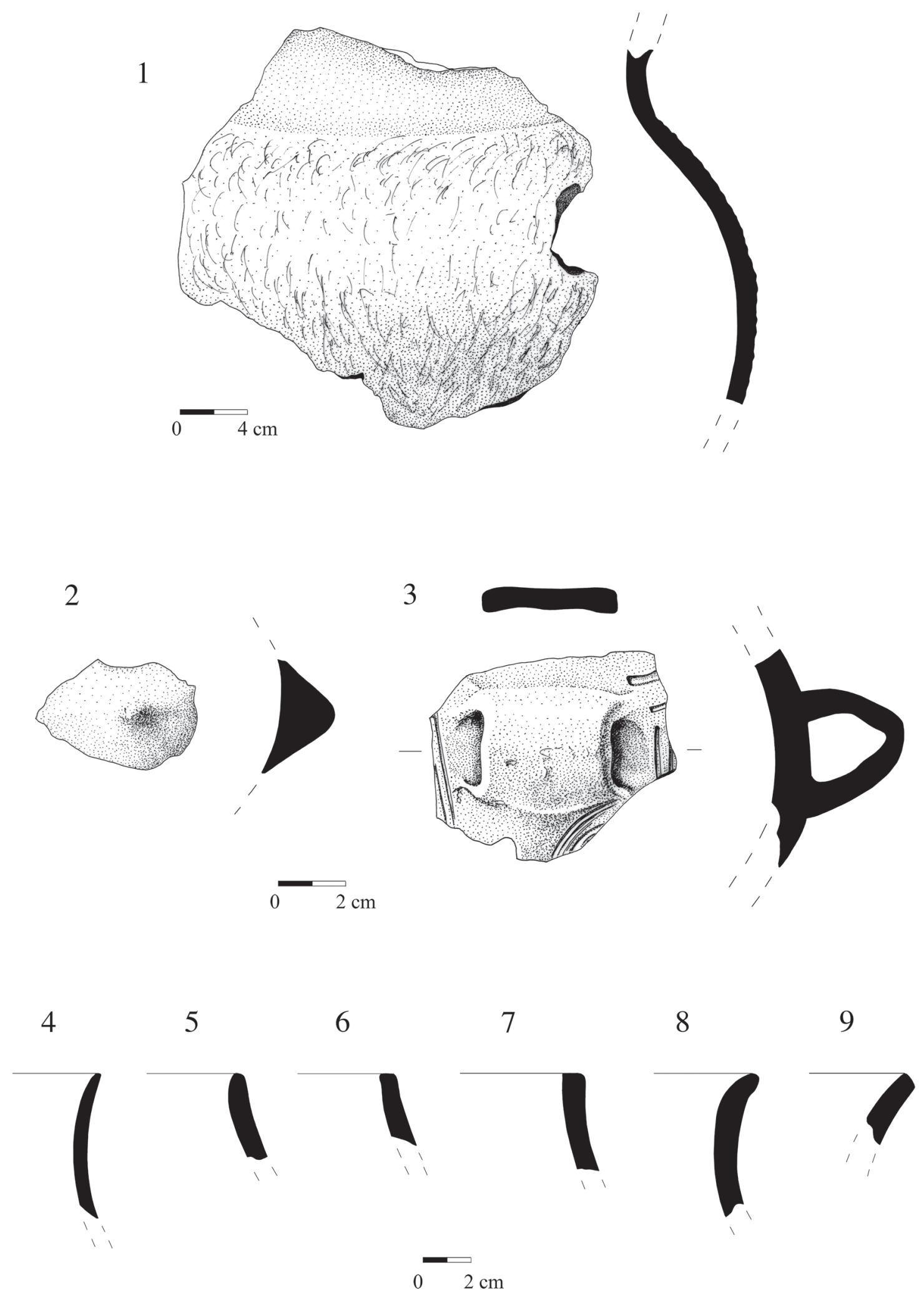

Abb. 9. Vorratsgefäße (gezeichnet von M. Mátyus) 
Bodenbruchstück eines großen Gefäßes. Außen und innen dunkelgrau, mit viel Kies gemagert, auf dem Boden deutliche Nutzungsspuren. Dm. des Bodens: ca. 8 cm; Wanddicke: 1,2 cm. R.-Nr. 1.34305.7765.38.

Bruchstücke eines Zylinderhalsgefäßes. Etwa ein Drittel des Profils ist erhalten geblieben (zeichnerisch ergänzt). Außen und innen gelb und dunkelgrau gefleckt, mit Sand und Keramikgrus gemagert, außen auch poliert. Der Hals ist zylindrisch, der Bauch kugelförmig, der Boden gerade abgeschnitten. An der Freilegung erhielt es die Bezeichnung Beigabe Nr. 5. Höhe: 36 cm; Dm. des Bodens: ca. 12 cm; Wanddicke: 1 cm. R.-Nr. 1.34305.7765.8. (Abb. 10.1). Eine in Größe und Form ähnliche Parallele wurde aus dem Kulturkreis der Věteřov-Kultur (nachklassische Phase) veröffentlicht, und zwar aus dem Grab 1 des Hügels I in Borotice. Dieser Gefäßtyp ist für die Kultur charakteristisch und ist auf mehreren Fundplätzen bekannt (z. B. Blučina, Věteřov). ${ }^{11}$

Zylinderhalsgefäß. Außen und innen braun und grau gefleckt bzw. poliert, mit Sand und Kies gemagert. Die Schulter ist eingeglättet und mit kleinen spitzen Buckeln versehen. An der Freilegung erhielt es die Bezeichnung Beigabe Nr. 2. Höhe: 16,5 cm; Dm. des Randes: 24 cm; Wanddicke: 0,8 cm. R.-Nr. 1.34305.7765.9. (Abb. 10.3). Eine gute Parallele wurde aus der Siedlungsgrube Nr. 601 von Hulín-Pravčice der Věteřov-Kultur veröffentlicht. ${ }^{12}$ Es ist im Fundgut der nahe liegenden, jedoch spärlich dokumentierten Siedlung von Veselé-Hradisko der Magyarád/ Madarovce-Kultur vorhanden. ${ }^{13}$ Die Form ist - anstatt von Buckel mit Henkel ausgestattet und inkrustiert - auch unter den Streufunden des Gräberfeldes von Veszprém-Kossuth-L.-Str. 6 vorzufinden. ${ }^{14}$ Die Formen mit oder ohne Buckel bzw. mit oder ohne Henkel leben in der jüngeren Hügelgräberzeit Bz B2-C (z. B. Smolenice/Szomolány, ${ }^{15}$ Veselé/Vígvár ${ }^{16}$ ) weiter.

Topf. Er besitzt zwei Henkel, der Rand ist eingedrückt, unter dem Rand befindet sich ein mit Fingerabdrücken versehener Leistendekor. Außen und innen hellbraun-grau gefleckt und poliert, mit Kies gemagert. Der Hals ist kurz und verengt sich stark, der Boden ist leicht profiliert. Er wurde aus den Beigaben Nr. 1 und 12 zusammengestellt. Höhe: 27 cm; Dm. des Randes: 25 cm; Dm. des Bodens: 11 cm; Wanddicke: 1,1 cm. R.-Nr. 1.34305.7765.2. (Abb. 10.2; Abb. 17.3).

Randbruchstück eines Topfes. Außen und innen hellbraun-grau gefleckt und poliert, mit Sand und Keramikgrus gemagert. Der Rand ist eingezogen, darunter sitzt ein kleiner Buckel. An der Freilegung erhielt er die Beigabennummer 18. Dm. des ausgemessenen Randes: $12 \mathrm{~cm}$; Wanddicke: 0,9 cm. R.-Nr. 1.34305.7765.10. (Abb. 10.4). Ein fassförmiges Gefäß mit Buckel kam in der Füllungserde des Hügels 27 von Borotice der Věteřov-Kultur zum Vorschein. ${ }^{17}$

Rand- und Wandbruchstücke eines Topfes. Außen grau und braun gefleckt, innen grau, auf beiden Seiten poliert, mit grobem (kalkhaltigem?) Material gemagert. Die Schuler ist mit Leistendekor verziert. Maßangaben: $5,5 \times 2,4 \mathrm{~cm}$; Wanddicke: 0,7 cm. R.-Nr. 1.34305.7765.17. (Abb. 10.5). Ein ähnliches Gefäß mit Leistendekor wurde aus der Siedlung von Mannersdorf publiziert, und zwar aus der Mistelbach-Regelsbrunn-Phase (Bz B1) der Hügelgräberkultur. ${ }^{18}$

Wandbruchstück eines Topfes (?). Außen hellbraun, innen rotbraun und poliert, mit Sand gemagert. Die äußere Oberfläche ist gekämmt. Maßangaben: 2,3×3,3 cm; Wanddicke: 0,8 cm. R.-Nr. 1.34305.7765.14. (Abb. 10.6).

Schale mit „Barockrand“. Außen und innen gelb und grau gefleckt, poliert, mit Kies und Keramikgrus gemagert. Der Körper ist kegelförmig, der Boden profiliert. Der Rand ist mit ausgezogenen Zipfeln dekoriert, die bei der Freilegung beschädigt wurden. Das Fragment erhielt die Beigabennummer 4. Höhe: $23 \mathrm{~cm}$; Dm. des Randes: 42 cm; Dm. des Bodens: $14 \mathrm{~cm}$; Wanddicke: $1 \mathrm{~cm}$. R.-Nr. 1.34305.7765.5. (Abb. 11.1; Abb. 17.5). Weitere Parallelen des Barockrandes sind wie folgt: Im Depotfund von Franzhausen sind sie mit 4-7 Zipfeln zu finden (Datierung: Althügelgräberzeit), ${ }^{19} \mathrm{im}$ Depotfund I von Großmugl (wird als Magyarád/Mađarovce behandelt und auf das Ende der Bz $\mathrm{C}$ datiert) ${ }^{20} \mathrm{im}$ Depotfund von Lednice sind zwei verschiedene Varianten zu finden (Datierung: Bz C). ${ }^{21}$ Die Randaus-

${ }^{11}$ STUCHLík 2006, 35, 255, Obr. 18.2.

${ }^{12}$ PEŠKa 2012, Abb. 4.2

${ }^{13}$ Tос̌IK 1964, 105, Tab. 48.19; 142, Tab. 59.7.

${ }^{14}$ KISs 2012, 306, Pl. 47.2.

${ }^{15}$ M. DUŠEK: Pohrebisko Ludu stredodunajskej mohylovej kultúry v Smoleniciach. Gräberfeld der Träger der mitteldonauländischen Hügelgräberkultur in Smolenice. S1A 28 (1980) 382, Obr. 3.1, Obr. 7.

${ }^{16}$ BARTík 1996, 251-252, Tab. 13.10.

${ }^{17}$ STUCHLÍK 2006, 255, Abb. 100.6.

${ }^{18}$ Neugebauer 1994, 160, Abb. 80.22.
${ }^{19}$ J.-W. Neugebauer et al.: Zu Metall- und Keramikdepots der Bronzezeit aus dem Zentralraum Niederösterreichs. Archäologie Österreichs, Sonderausgabe 9/10 (1998/1999) 30, 32, Abb. 26.

${ }^{20}$ E. LAUERMANN-B. Hahnel: Die mittelbronzezeitlichen Gefäßdepots von Großmugl in Niederösterreich. Archäologie Österreichs, Sonderausgabe 9/10 (1998/1999) 97-99, Taf. 2/9.

${ }^{21}$ H. PALÁtová-M. SAlaš: Bronzezeitliche Gefäßdepotfunde in Mähren und benachbarten Gebieten. Pravěk Supplementum 9. Brno 2002, 17, Tab. 3/1, Tab. 5/4. 


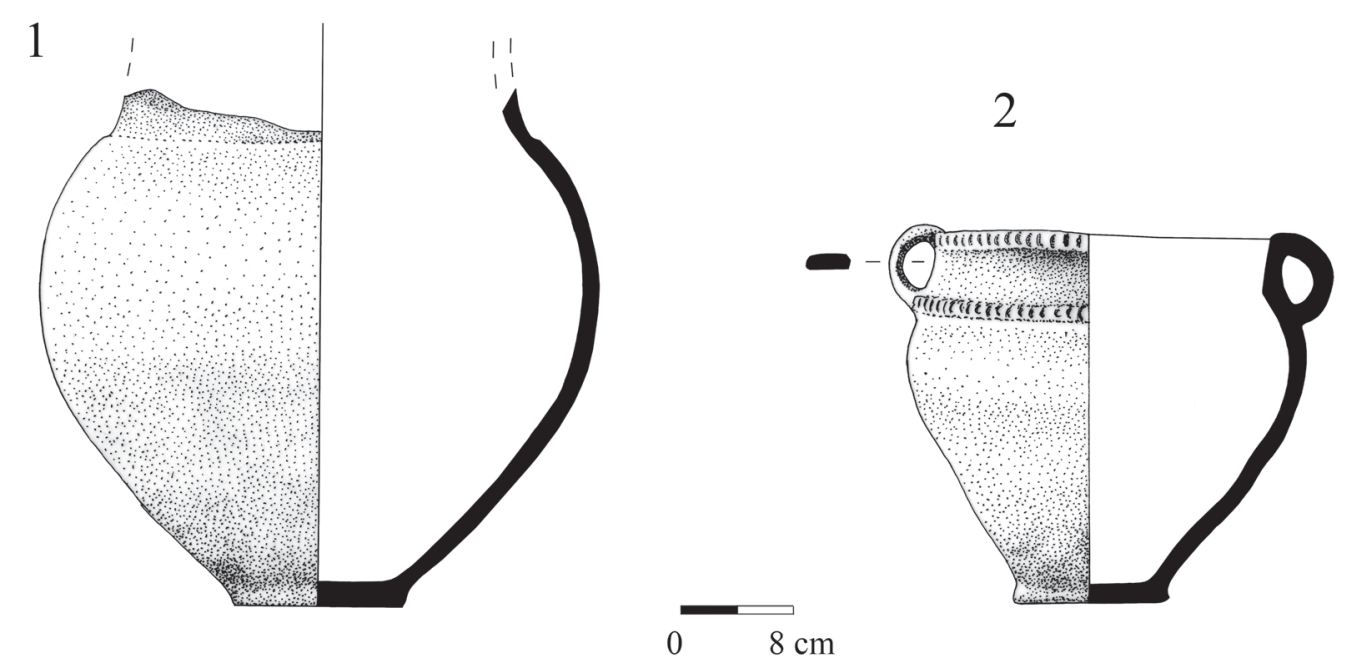

4

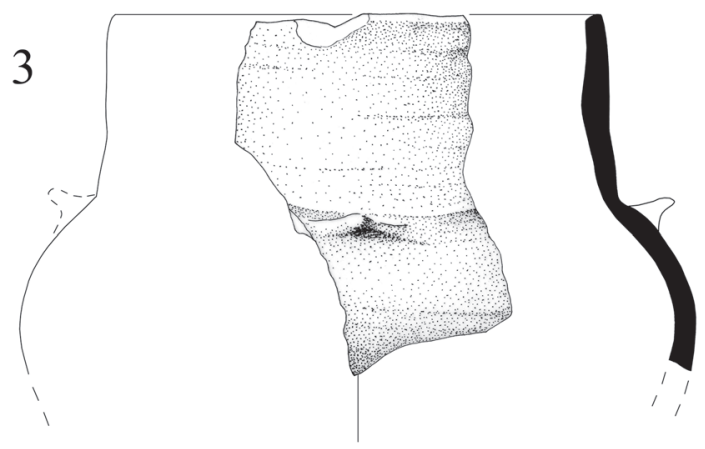

$\widetilde{0} 4 \mathrm{~cm}$
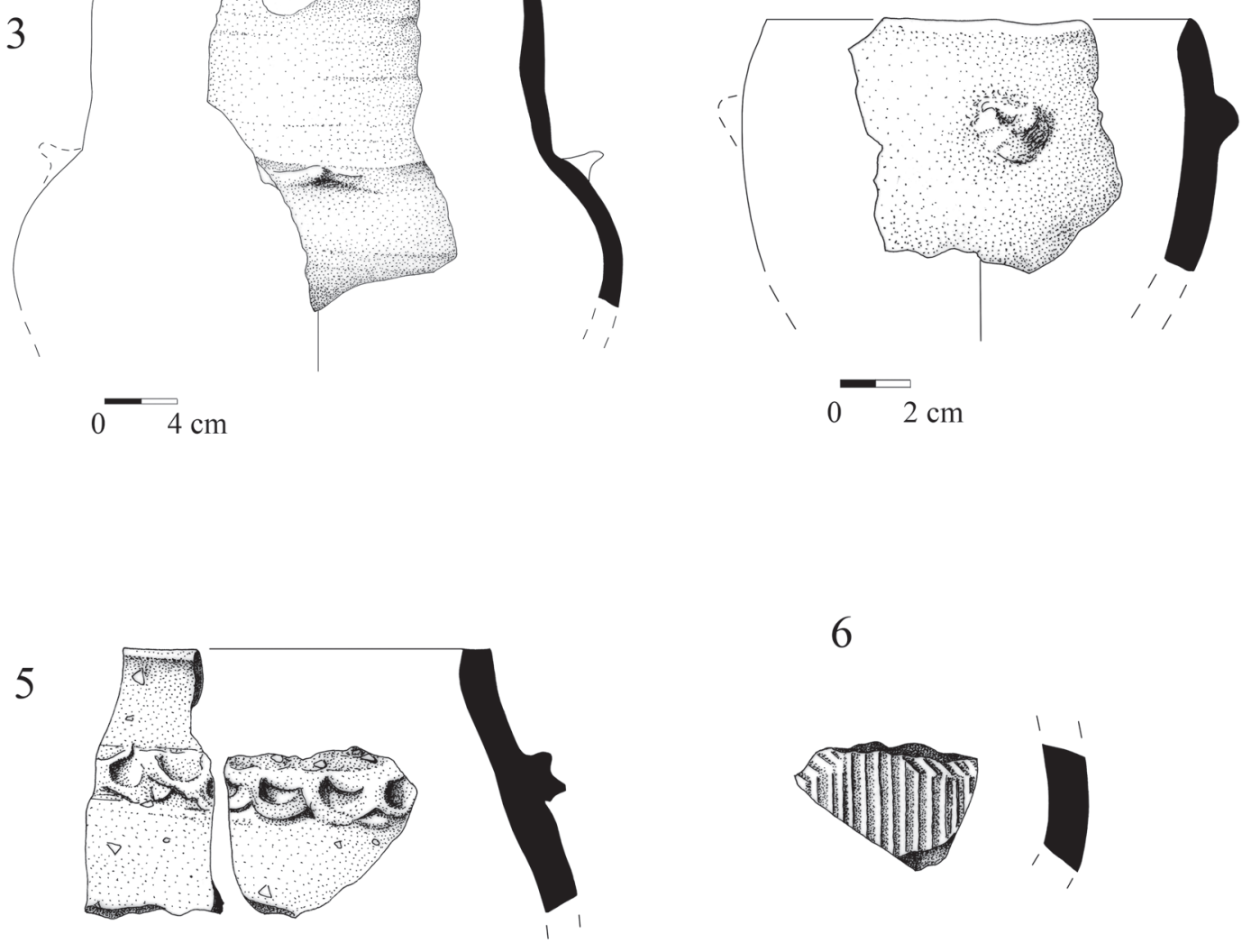

6

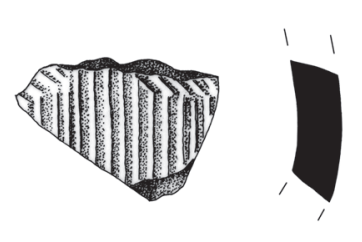

$$
2 \mathrm{~cm}
$$

Abb. 10. Vorratsgefäße (gezeichnet von M. Mátyus) 
bildung war also lange Zeit hindurch in Gebrauch, die Wand der frühen Typen ist jedoch steifer, die Zipfel wurden als Erweiterung der Gefäßwände ausgebildet, wobei die benachbarten Zipfel miteinander fast in Berührung stehen.

Bruchstück einer Schale. Außen hellbraun und grau gefleckt, innen dunkelgrau, mit Sand und Keramikgrus gemagert, beide Seiten der Wände sind poliert. Die Schale besitzt einen ausladenden, leicht profilierten Rand, der Körper ist konisch. Am Rand sitzt ein dreieckiger waagerechter kleiner Zipfel, von dessen Mitte eine kleine Rippenverzierung abhängt. Daneben ist ein flacher, beschädigter Buckel auf der Schulter zu sehen. An der Freilegung erhielt sie die Beigabennummer 9. Höhe des Bruchstücks: $17 \mathrm{~cm}$; Dm. des Randes: $47 \mathrm{~cm}$; Wanddicke: 1,1 cm. R.-Nr. 1.34305.7765.6. (Abb. 11.2). Diese Randform existiert parallel mit der Barockmündung. Eine der besten Analogien ist im Depotfund von Veszprém-Kádárta-Gelemér ${ }^{22}$ bekannt. Die waagerechte Rille auf dem Zipfel ist im Kulturkreis der mitteldonauländischen Hügelgräber üblich, so kommt er z. B. in der Füllerde des Hügelgrabes Nr. 38 in Borotice vor. ${ }^{23}$

Bruchstück einer Schale. Außen und innen hellbraun und poliert, mit Sand und feinem Kies gemagert. Der Rand ist waagerecht abgeschnitten, die Form ist die eines Kugelabschnittes. Am Rand ist ein länglicher, waagerecht stehender Zipfel appliziert. An der Freilegung erhielt sie die Beigabennummer 14. Dm. des Randes: $25 \mathrm{~cm}$; Wanddicke: 0,6 cm. R.-Nr. 1.34305.7765.11. (Abb. 11.3). Eine schöne Parallele wurde in der befestigten Siedlung von Nitra-Ponitrianska galéria, im Befund 4 der Magyarád/Mađarovce-Kultur freigelegt. ${ }^{24}$ Eine Schale mit ähnlicher Form, doch mit kleinerem Zipfel wurde aus der Bestattung 1 des Hügels 6 aus Borotice (Věteřov-Kultur) veröffentlicht. ${ }^{25}$ Anhand des Fundmaterials der Siedlung von Pressburg/Bratislava/Pozsony-Mlynská dolina ${ }^{26}$ wurde diese Schalenform als archaischer Typ innerhalb der mitteldonauländischen Hügelgräberkultur bestimmt. Die jüngeren Exemplare sind stumpfkegelförmig und besitzen einen kleinen Bandhenkel, die Zipfel am Rand sind wesentlich kleiner (siehe Smolenice ${ }^{27}$ und Veselé28).

Bruchstück einer Schale mit eingezogenem Rand. Außen und innen hellbraun und grau gefleckt bzw. poliert, mit Sand und Keramikgrus gemagert. Der Rand ist mit einem nach oben gerichteten spitzen Zipfel ausgestattet, an dem eine senkrechte, kurze Leiste appliziert ist. Dm. des Randes: $18 \mathrm{~cm}$; Wanddicke: 0,8 cm. R.-Nr. 1.34305.7765.12. (Abb. 11.5). Im Befund 44 der frühhügelgräberzeitlichen Siedlung von Domaszék-Börcsök-tanya kommt die mit Leiste versehener Randzipfel auf einer Schale vor. ${ }^{29}$

Bruchstïck einer Schale mit eingezogenem Rand. Außen grau, innen graubraun, beide Oberflächen sind poliert. Mit Kies gemagert. Der Rand ist mit einem stark nach oben ausgezogenen Zipfel ausgestattet. Maßangaben: 4,8 $\times 5,2 \mathrm{~cm}$; Wanddicke: 0,5 cm. R.-Nr. 1.34305.7765.13. (Abb. 11.4).

Kugelabschnittförmige Schale mit eingezogenem Rand. Außen rotbraun-grau gefleckt, innen grau, mit Sand gemagert, beide Oberflächen sind poliert. Dm. des Randes: $20 \mathrm{~cm}$; Wanddicke: 0,6 cm. R.-Nr. 1.34305.7765.15. (Abb. 11.6).

Wandbruchstück eines Kugelgefäßes. Die Außenseite ist mulmig. Innen hellbraun und poliert, mit Sand gemagert. Maßangaben: 5,9×5,4 cm; Wanddicke: $1 \mathrm{~cm}$. R.-Nr. 1.34305.7765.31.

Hals- und Wandbruchstück einer Tasse. Außen und innen hellbraun und poliert, mit Sand und Kies gemagert. Auf dem Hals ist eine waagerechte doppelte Kannelierung zu sehen, die von oben mit einer feinen eingedrückten Punktreihe abgeschlossen ist. Dm. des Randes: $6 \mathrm{~cm}$; Wanddicke: 0,5 cm. R.-Nr. 1.34305.7765.16. (Abb. 12.1).

Bodenbruchstück einer Tasse mit Buckel. Der Buckelfuß weist Gebrauchsspuren auf. Außen wie innen grau, mit Sand und Kies gemagert, außen poliert. Maßangaben: 2,6×3,6 cm; Wanddicke: 0,9 cm. R.-Nr. 1.34305.7765.18. (Abb. 12.3). Dieser Gefäßtyp wird diesmal nicht weiter behandelt, da er bereits im Zusammenhang mit der Bestattung von Nagydém und dem Gefäßdepot von Hegykő erörtert wurde. ${ }^{30}$ Zusammengefasst soll hier nur erwähnt werden, dass die Vorbilder der Buckelfüße in der Aunjetitz-Kultur erscheinen, und zwar auf Schalen und Tassen. ${ }^{31}$ Etwas später werden die an Näpfen/Krügen applizierten Buckelfüße in der Věteřov-, ${ }^{32}$ Magyarád/

${ }^{22}$ ILON 2012, Fig. 8.2.

${ }^{23}$ STUCHLÍK 2006, 122, Obr. 118.3.

${ }^{24}$ Marková-Samuel 2008, 71, 90, Obr. 8.4.

${ }^{25}$ STUCHLÍK 2006, 51, Obr. 41.12.

${ }^{26}$ J. BARTíK-B. EgYHÁZY-JuRovská: Sídlisko stredodunajskej mohylovej kultúry v Bratislave-Mlynskey doline. ZSN 92 Archeológia 8 (1998) 58, Abb. 6.9.

${ }^{27}$ M. DUŠEK op. cit. in Anm. 15, Tab. 7.11, 8.2, 4, 5, 22.
${ }^{28}$ BARTík 1996, Tab. 4.3, 15.4, 6.

${ }^{29}$ SÁNTA 2009, Abb. 4.1.

${ }^{30}$ ILON 1999, Taf. 1.4, Taf. 8.1, 4.

${ }^{31}$ M. BARTELheim: Studien zur böhmischen Aunjetitzer Kultur - Chronologische und chorologische Untersuchungen I-II. UPA 46. Bonn 1998, Taf. 43. L5, M5.2.

${ }^{32}$ Benkovsky-Pivovarová 2008, 31, Taf. V.2; PešKa 2012, Abb. 4.4

Acta Archaeologica Academiae Scientiarum Hungaricae 65, 2014 

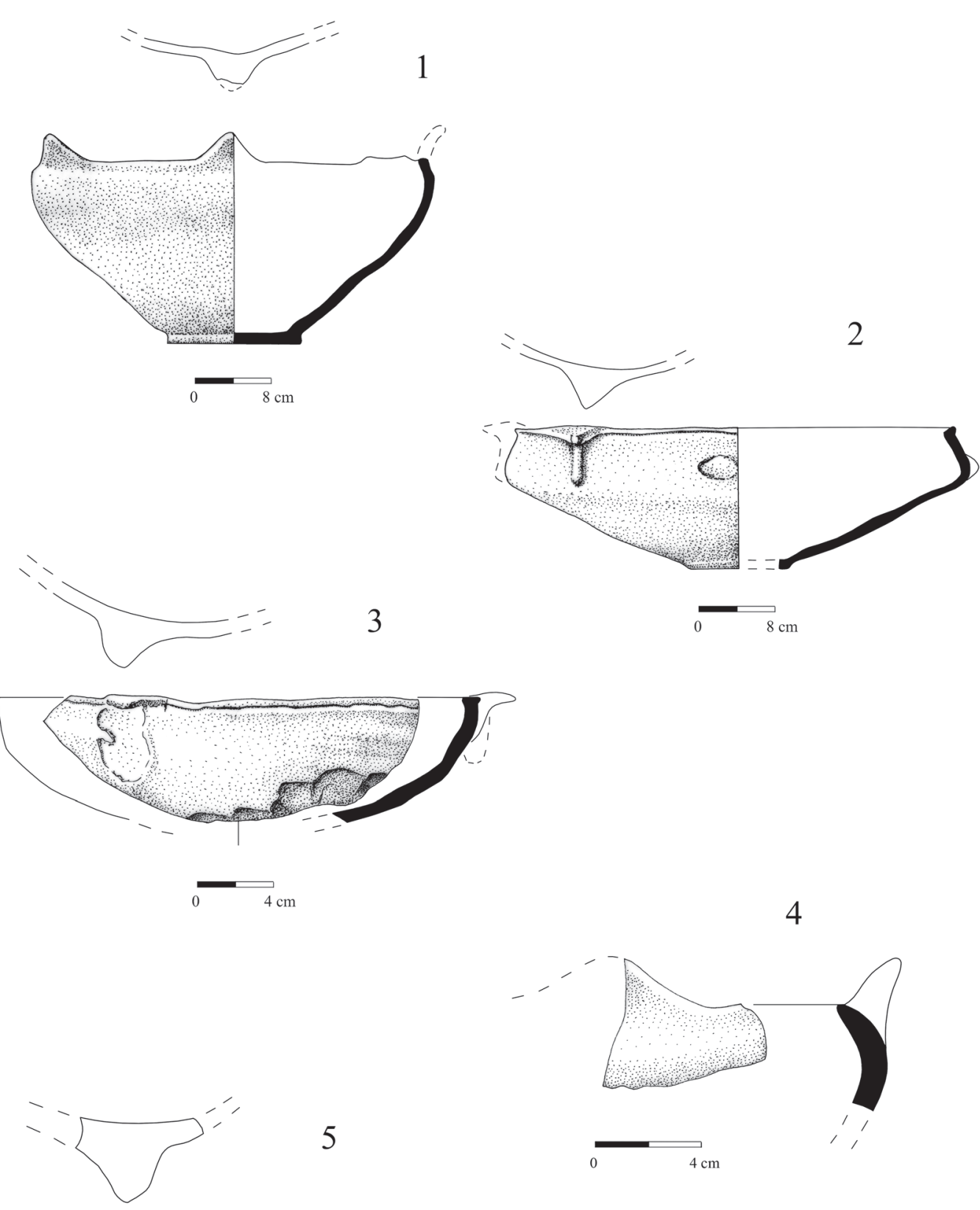

5

4

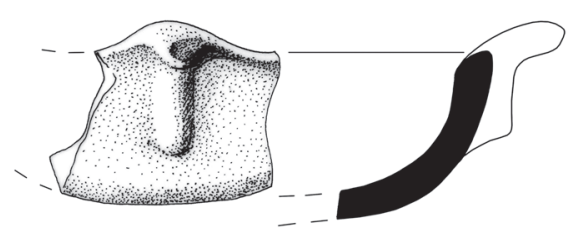

$\stackrel{4}{0} \mathrm{~cm}$

6

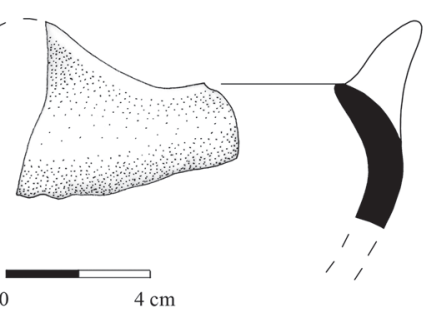

Abb. 11. Schalen (gezeichnet von M. Mátyus) 
1

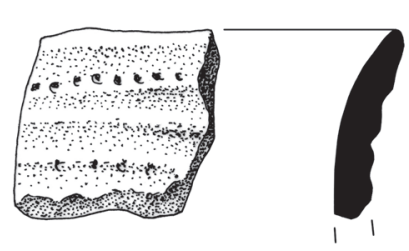

2
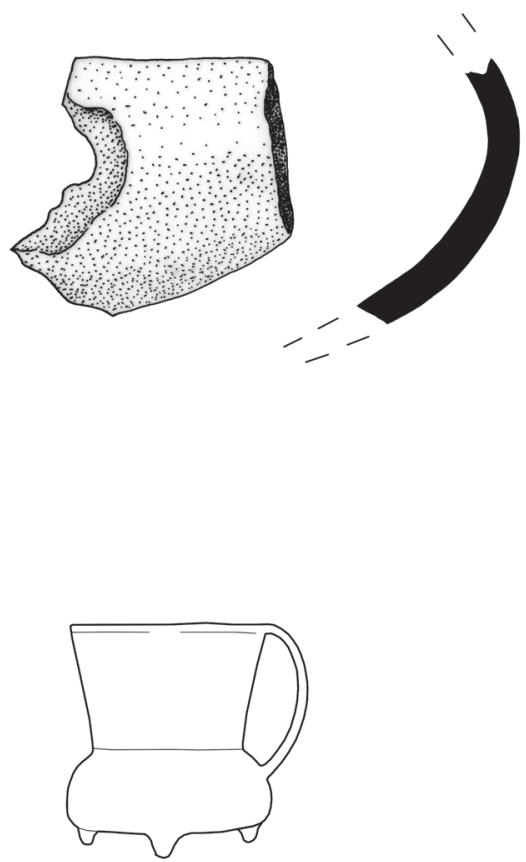

Rekonstruktion

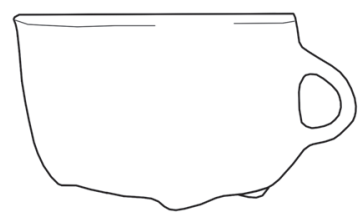

4

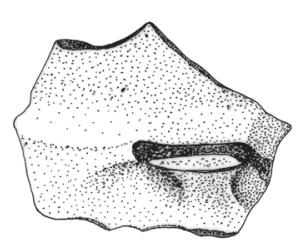

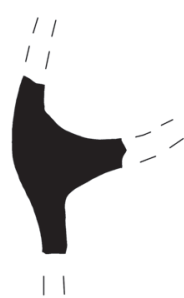

5
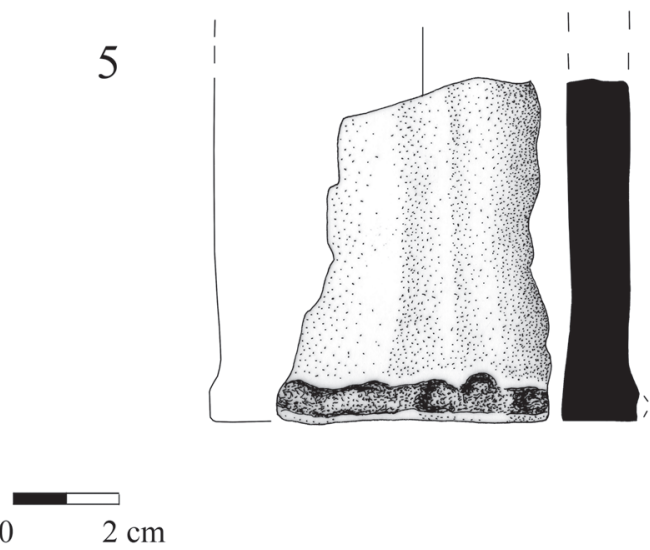

Abb. 12. 1-4: Näpfe; 5: tragbarer Feuerherd (gezeichnet von M. Mátyus) 
Madarovce- ${ }^{33}$ und in der Hügelgräberkultur ${ }^{34}$ allgemein benutzt und lange Zeit hindurch beliebt. Die neuesten Exemplare der Buckelfüße (Datierung: Bz B1) wurden in der Nähe unseres Fundplatzes, in den frühhügelgräberzeitlichen Siedlungen von Kóny-Barbacsi-See ${ }^{35}$ bzw. etwas weiter entfernt, am südlichen und nördlichen Ufer des Plattensees in Ordacsehi-Bugaszeg ${ }^{36}$ und Veszprém-Kádárta-Gelemér ${ }^{37}$ gefunden. (Diese Funde wurden auch veröffentlicht.) Das Fragment aus dem Befund 1 von Domaszék-Börcsök-tanya ${ }^{38}$ wurde in die ausgehende Phase der Koszider-Periode datiert. Der Wandansatz unserer Tasse ähnelt dem mitteldonauländischen hügelgräberzeitlichen Gefäß des Grabes II im Hügelgrab 38 von Borotice. ${ }^{39}$ Gleichzeitig ist es nicht auszuschließen, dass unser Exemplar eher eine Tasse/Schale repräsentiert als einen Napf/Krug.

Wandbruchstück einer Tasse (?). Außen und innen hellbraun, mit Sand gemagert, außen poliert. Maßangaben: 3,5 × 3,6 cm; Wanddicke: 0,4 cm. R.-Nr. 1.34305.7765.30. (Abb. 12.2).

Schulterbruchstück einer Tasse mit Henkelansatz. Außen hellbraun, innen grau, mit Sand gemagert, außen poliert. Maßangaben: 3,9×5,2 cm; Wanddicke: 0,4 cm. R.-Nr. 1.34305.7765.34. (Abb. 12.4).

Fußfragment eines tragbaren Herdes (Pyraunos?). Außen und innen rotbraun, raue Oberfläche, mit wenig Kies gemagert. Höhe: 6,5 cm; Wanddicke: 1,2 cm. R.-Nr. 1.34305.7765.33. (Abb. 12.5). Das Fragment kann nach P. Romsauer ${ }^{40}$ zum Typ A1 oder A3 gezählt werden: Die Wand dieser Exemplare ist fast senkrecht und der Fußteil verdickt sich nach außen. Die besten Formparallelen kamen in der Magyarád/Mad̉arovce-Siedlung von Nitra-Ponitrianska galéria, ${ }^{41}$ in der Otomani-Siedlung von Košice-Barca,${ }^{42}$ unter den Magyarád/Mađarovce- und inkrustierten keramischen Siedlungsfunden von Rybník-Kusa hora, ${ }^{43}$ in der Siedlung von Ciceu-Corabia, ${ }^{44}$ im Urnengrab 216/69 des Pilinyer Gräberfeldes von Radzovce in Miniaturform (Bz B2, erwachsene Frau + ein 4-jähriges und ein neugeborenes Kind) ${ }^{45}$ bzw. in der Bestattung 1159 von Zagyvapálfalva (erwachsene Frau + ein 15-jähriges, ein 1-10-jähriges und ein 2-4-jähriges Kind $)^{46}$ vor.

$\mathrm{Zu}$ einem Gebäude gehörende Lehmplastik: Bruchstück eines Frieses. Es ist hellgelb und gut durchgebrannt, die Oberfläche ist mit einer grauen, $1 \mathrm{~mm}$ dicken Wassersteinschicht bedeckt. (Diese Schicht musste zum Zweck der Beobachtung und Zeichnung des Motivs mit Skalpell entfernt werden.) Der Durchschnitt ist dreieckig, eine Seite ist jedoch gebogen, was auf eine Befestigung an einem hölzernen Gebäudeelement (Holzblock) hinweist. Eine Seite ist glatt, auf der anderen Seite sind drei, mit Fingerstrich gemachte, ineinander knüpfende Spiralmotive unter zwei, miteinander parallel laufenden, mit Finger eingestrichenen Linien zu sehen, einmal mit einer feinen Lehmschicht wahrscheinlich erneuert. Der Diameter der mittleren Spirale ist größer, als der der beiden anderen. Auf beiden Seiten der mit „laufendem Hund“ Motiv (anders: mit „fließendem Hakenmotiv“) verzierten Platte befinden sich zwei bogenförmige Ausschnitte, die auf die Verzierung einer Krönung hindeuten. Am Profil ist es gut zu beobachten, dass die Plastik in drei Phasen aufgebaut wurde. An der Freilegung erhielt sie die Beigabennummer 20. H: $38 \mathrm{~cm}$; die größte Breite der verzierten Platte: $15 \mathrm{~cm}$; die größte Breite der unverzierten Platte: $13 \mathrm{~cm}$; Breite der gewölbten Seite: 24 cm. R.-Nr. 1.34305.7765.39. (Abb. 13; Abb. 14.1-2).

Ein fast identisches Friesbruchstück ${ }^{47}(A b b .14 .3)$ wurde aus Sălacea-Vida-Hügel (früher Szalacs, heute Rumänien), in dem in die Phase II der Otomani-Kultur II datierten Heiligtum ${ }^{48}$ des Tells gefunden, zusammen mit Altären und verzierten Lehmbewurfstücken. Es ist wichtig zu erwähnen, dass auch Muschel (Glycimerys glycime-

${ }^{33}$ Točík 1964, Obr. 11.A/2-4.

${ }^{34}$ ToČíK 1964, Obr. 36.

${ }^{35}$ I. EGRY: Korahalomsíros nép települése a Kóny-Barbacsi tóparton (The settlement of a people characterised with early mound graves at the lake of Kóny-Barbacs). Arrabona 40 (2002) 10, 13, Fig. 5.2.

${ }^{36}$ V. KISS: Settlement of the Tumulus Culture at Ordacsehi (Hungary). In: Ch. Gutjahr-G. Tiefengraber (Hrsg.): Beiträge zur Mittel- und Spätbronzezeit sowie zur Urnenfelderzeit am Rande der Südostalpen. Internationale Archäologie, Arbeitsgemeinschaft, Symposium, Tagung, Kongress, 15. Rahden/Westf. 2011, Fig. 4.

${ }^{37}$ ILON 2012, Fig. 11-12.

${ }^{38}$ SÁnta 2009, 262, Abb. 3.4.

${ }^{39}$ STUCHLíK 2006, 125, Obr. 118.14.

${ }^{40}$ RomSAUER 2003, 172-173, 175, Obr. 3.

${ }^{41}$ Marková-SAmuel 2008, 71, 90, Obr. 8.10.

${ }^{42}$ Romsauer 2003, 106-107, Tab. VII/3, VIII/1.
${ }^{43}$ Romsauer 2003, 110, Tab. XIII/1-2.

${ }^{44}$ Romsauer 2003, 125, Tab. XXII/1-2.

${ }^{45}$ Romsauer 2003, 109-110, Tab. XXV/3.

${ }^{46}$ Sz. GubA: Pyraunoi in Miniaturform der Pilinyer Kultur. In: R. Kujovský-V. Mitáš (red.): Václav Furmánek a doba bronzová Zborník k sedemdesiatym narodeninám. ASM Communicationes 13. Nitra 2012, 99-101, Abb. 3.1, Abb. 4.

${ }^{47}$ Über das Motiv siehe: DAVID 2002, Abb. 3.10.23, Version 4; DieTrich-Dietrich 2011, Abb. 2.10a, 11a. Die Diameter der Spiralen sind auf dem Foto von sehr schlechter Qualität zwar gleich, aber leider wurden weder die Maßangaben noch eine Zeichnung über die Struktur des Fragments veröffentlicht.

${ }^{48}$ N. ChidioşAN-I. ORdentlich: Un templu-megaron din epoca bronzului descoperit la Sălacea. Ein in Sălacea entdeckter Megaron-Tempel der Bronzezeit. Crisia (1975) 19, 22, Abb. 2; BADER 1990, 182-183, Abb. 2; Lichardus-VladÁR 1996, 29. 

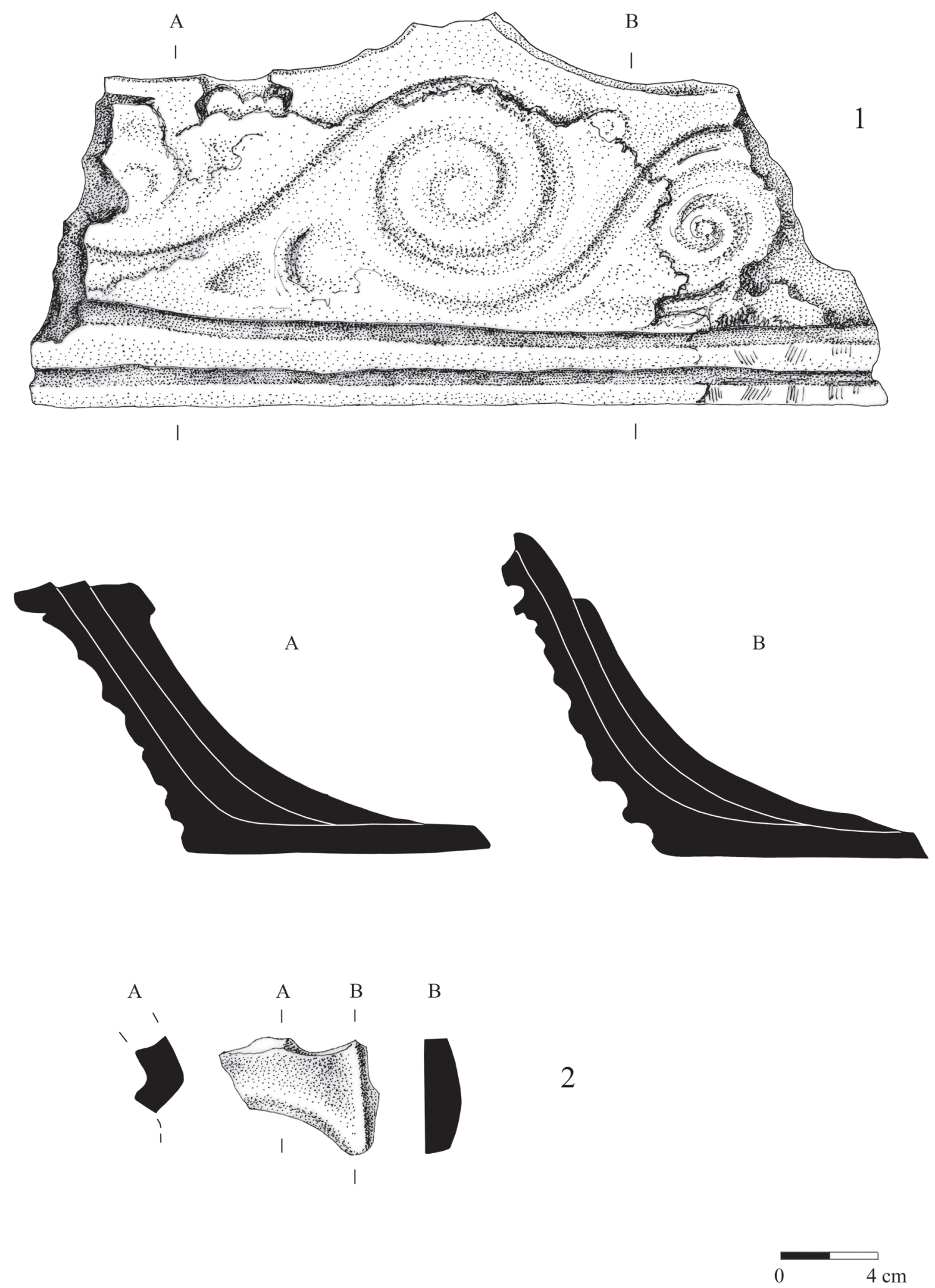

Abb. 13. Friesbruchstücke des Hauses (gezeichnet von M. Mátyus) 
1

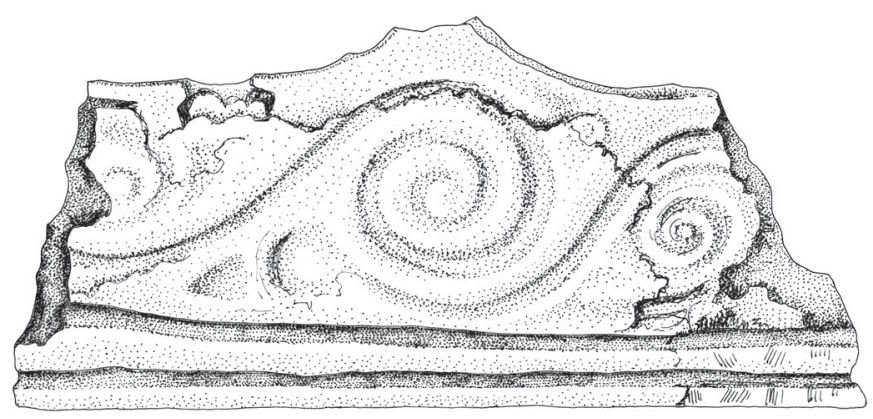

2

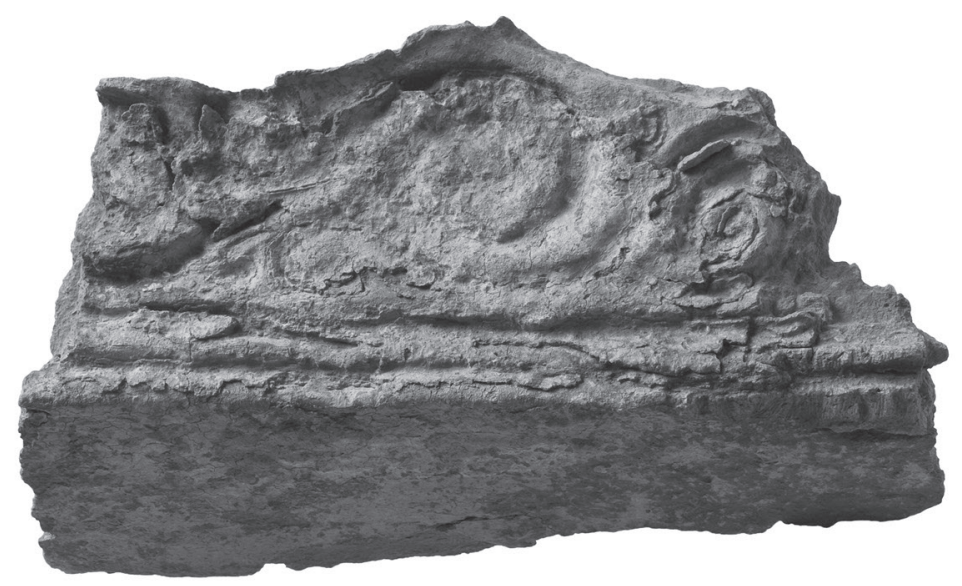

3

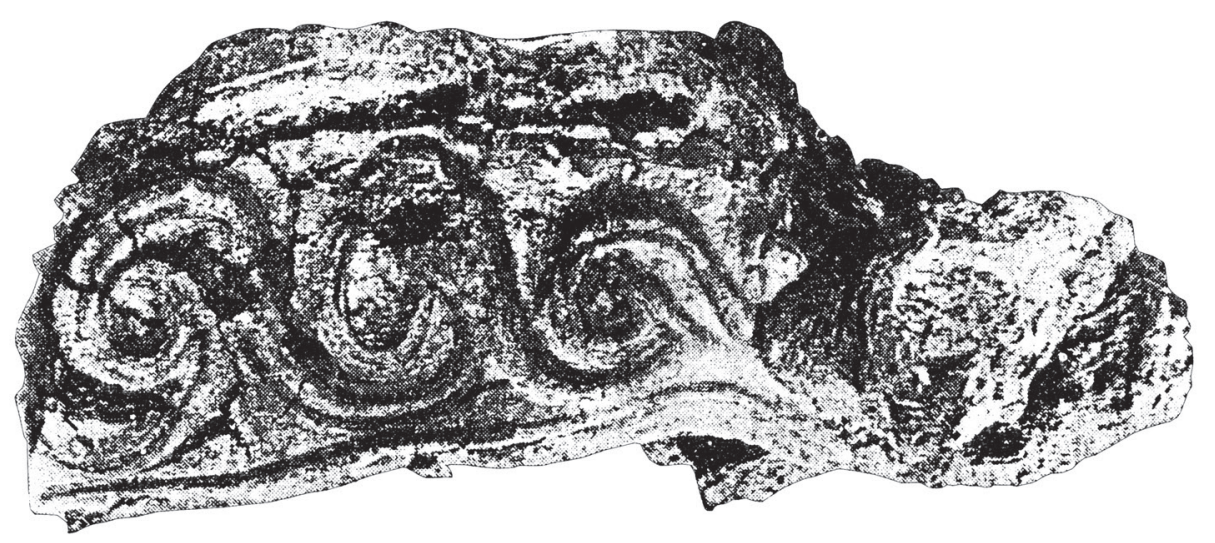

Abb. 14. Das Friesbruchstück mit Spiralornament von Ménföcsanak

(1-2) und Sălacea (3) (gezeichnet von M. Mátyus, Photo von T. Takács bzw. nach ChidioşAN-OrdentLich 1975, Abb. 2) Acta Archaeologica Academiae Scientiarum Hungaricae 65, 2014 
ris) zum Vorschein kamen, die im Schwarzen Meer nicht, nur im östlichen Mittelmeerraum heimisch sind. ${ }^{49}$ Dies kann auf einen direkten Kontakt zwischen Sălacea und dem Ostmittelmeerraum hindeuten.

Verzierte Lehmverputzfragmente sind bereits in der frühen Bronzezeit bekannt, und zwar in der Siedlung der Nagyrév-Kultur von Tiszaug-Kéménytetö ${ }^{50}$ (Bz A1). Die Verzierung dieser Fragmente besteht aus eingeritzten geraden, parallelen Linien und aus Zickzackmuster bzw. aus deren Kombination. Am Haus der mittleren und späten Phase der Vattina-Kultur in Mošorin-Feudvar (früher Mozsor-Földvár, heute: Serbien) ${ }^{51}$ wurden eingeglättete gerade Zickzack-, Wellen- und Rhombusmuster zwischen den Türen oder Fenstern beobachtet. An den Hausdarstellungen der aus farbigen Mosaiksteinen hergestellten Stadtdarstellung von Knossos (MM II-III, 18.-17. Jahrhundert v. Chr.) sind mehrere waagerechte Verzierungen sowie dekorierte Tür- und Fensterrahmen zu beobachten. ${ }^{52}$ Einige von ihnen waren sicherlich zweidimensional und bemalt, andere konnten dreidimensional sein.

Der von J. Paulík als konzentrischer Kreis rekonstruierte Krönungsdekor aus der in die frühe Urnenfelderzeit (Velatice-Baierdorf-Phase) datierten Siedlung von Trebatice (Vágterbete, Slowakei) ${ }^{53}$ könnte auch als Friesbruchstück funktioniert haben. Unsere Rekonstruktion als Krönungsornament kann auch durch die spätbronzezeitlichen und früheisenzeitlichen Hausurnen aus Norddeutschland (Schwanbeck F), ${ }^{54}$ Skandinavien (z. B. Bramminge $)^{55}$ bzw. aus Italien (z. B. Vulci) ${ }^{56}$ bestätigt werden, bei denen die Friese als Dekorfeld unter der Verschalung erscheinen.

Unterer Mahlstein. Halbkugelförmig, mit einer Arbeitsfläche, in vier Stücken. Das Rohmaterial ist rotbrauner Sandstein mit schlecht sortiertem Kies. Sehr hart und verschleißfest. Wahrscheinlich stammt er aus dem Treibgut der Donau. ${ }^{57}$ I.1. Maßangaben der Arbeitsfläche: $22 \times 17 \mathrm{~cm}$; Höhe: $18,5 \mathrm{~cm}$; I.2. Maßangaben: $16,5 \times 7,8 \times 13,4$ cm; I.3. Maßangaben: $12,9 \times 9 \times 15,6 \mathrm{~cm}$; I.4. Maßangaben: $12,9 \times 9,3 \times 16,5 \mathrm{~cm}$. R.-Nr. 1.34305.7765.40. (Abb. 16.I.1-4; Abb. 4.2a).

Unterer Mahlstein. Halbkugelförmig, mit einer Arbeitsfläche und rezenter Bruchfläche, in zwei Stücken. Das Rohmaterial ist gelbgrauer Sandstein mit gut sortiertem Kies. Sehr hart und verschleißfest. Wahrscheinlich stammt er aus dem Treibgut der Donau. ${ }^{58}$ Maßangaben der Arbeitsfläche: $26 \times 20 \mathrm{~cm}$; Höhe: 16,2 cm. R.-Nr. 1.34305.7765.41. (Abb. 16.II; Abb. 4.2b).

Die Mahlsteine, über die bisweilen nur eine einzige nennenswerte Zusammenfassung erschien, ${ }^{59}$ bilden einen recht vernachlässigten Fundkreis der heimischen archäologischen Fachliteratur. Diese Arbeit wurde durch Teilbearbeitungen ergänzt, ${ }^{60}$ gleichzeitig haben die archäometrischen Analysen ${ }^{61}$ vor allem zur Bestimmung des Abstammungsortes einen beträchtlichen Schwung genommen. Ähnliche Mahlsteine mit der gleichen chronologischen Stellung wurden von den Fundplätzen von Bölcske, Jászdózsa, Kajászó, Pákozd und Százhalombatta veröffentlicht. ${ }^{62}$

${ }^{49}$ BADER 1990, 189; MAKKAY 1999, 47.

${ }^{50}$ M. CsÁnYI-I. STANCZIK: Tiszaug-Kéménytető. In: P. Raczky (Dir. techn.): Le bel Âge du Bronze en Hongrie. Mont Bauvray-Budapest 1994, 118, Fig. 76, Cat. 120.

${ }^{51}$ HänSEL-Medović 1991, 74-75, Abb. 9-10.

${ }^{52}$ K. Demakopoulou: Les palais égéens. In: L'Europe au temps d'Ulysse. Copenhague-Bonn-Paris-Athènes 1999, 66-67, 224: Cat. 49-50

${ }^{53}$ PAUlík 1962, 37, 56, Obr. 9.

${ }^{54}$ S. Sabatini: House Urns. A European Late Bronze Age Trans-Cultural Phenomenon. Göteborg 2007, 211, Pl. 20.

${ }^{55}$ S. SABATini op. cit., 182, Pl. 1.

${ }^{56}$ S. SABATINI op. cit., 154, Fig. 86.

${ }^{57}$ I. OLÁH: Ergebnisse der makro- und mikroskopischen mineralogischen Untersuchungen der Mahlsteine aus der archäologischen Freilegung von Győr-Ménfőcsanak-Széles-földek. Bericht im Archiv des UNM - Nationalzentrum für Kulturerbe, Budapest 2012.

${ }^{58}$ I. OLÁH op. cit.

${ }^{59}$ T. HoRvÁTH: Az örlés folyamata és szerszámai az őskor időszakában Magyarországon (The process and the tools of grinding in the praehistorical times in Hungary). In: G. Ilon (ed.): Válogatás a Berzsenyi Dániel Főiskola régésztechnikusainak és a József Attila Tudományegyetem régész hallgatóinak tanulmányaiból 2. Pannicvlvs Ser. B. 5. Szombathely 2000, 101-143.

${ }^{60}$ T. Horváth-M. KozÁK-A. Petõ: Újabb adatok a középső bronzkor kőiparához: Bölcske-Vörösgyír bronzkori tell-település kőanyagának komplex (petrográfiai, régészeti) feldolgozása (Neue Angaben über die Steinverarbeitung in der mittleren Bronzezeit. Die Aufarbeitung des Komplexes des Steinmaterials der bronzezeitlichen Hügelsiedlung von Bölcske-Vörösgyír, petrographisch-archäologisch). Komárom-Esztergom Megyei Múzeumok Közleményei 7 (2000) $187-235$.

${ }^{61}$ Gy. Szakmány-B. NAGy: Die Ergebnisse der petrographischen Untersuchungen der spätkupferzeitlichen Mahlsteine aus rotem Sandstein von Balatonlelle-Felső Gamász. Archeometriai Műhely 2005 (3),13-21, http://www.ace.hu/am; T. HoRvÁTH-B. PÉTERDI: Geschliffene Steinwerkzeuge, Mahlsteine und weitere bearbeitete und unbearbeitete Artefakte aus Gestein. In: T. Horváth (ed.): Prähistorische Siedlungsteile von Balatonőszöd-Temetői Flur. Budapest 2012, 403-526.

${ }^{62}$ T. HoRváth op. cit. in Anm. 59, 118-119. 
1

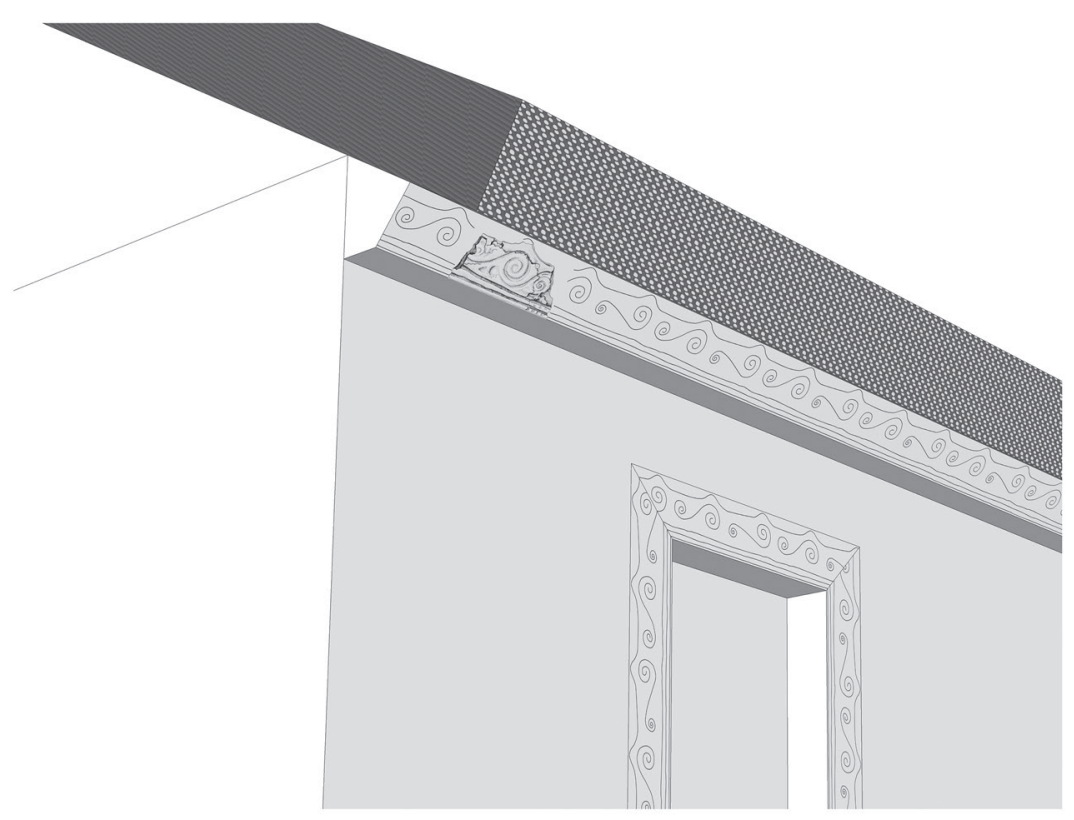

2

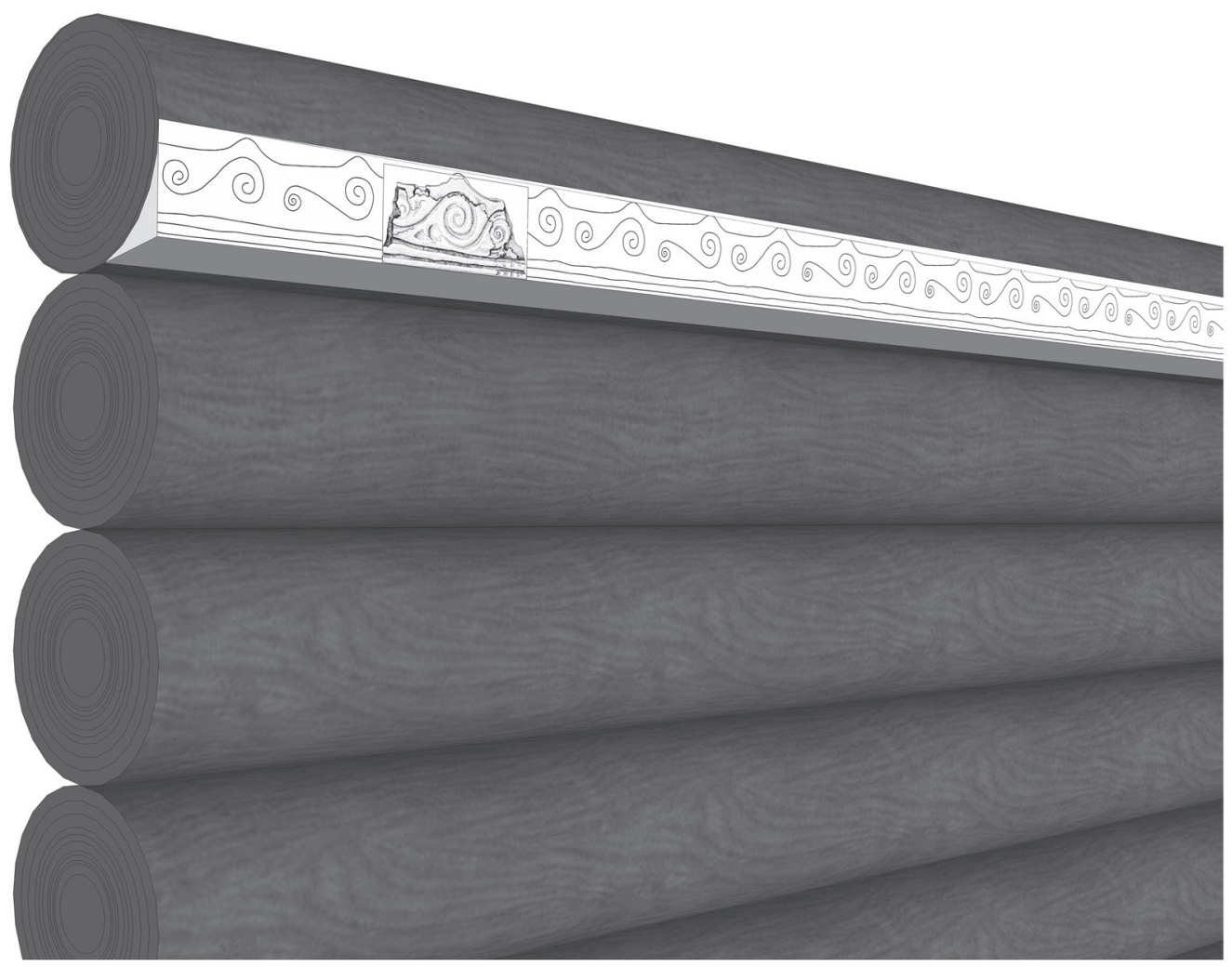

Abb. 15. Rekonstruktion des Frieses aus Ménföcsanak (gezeichnet von A. Radics und T. Takács) 

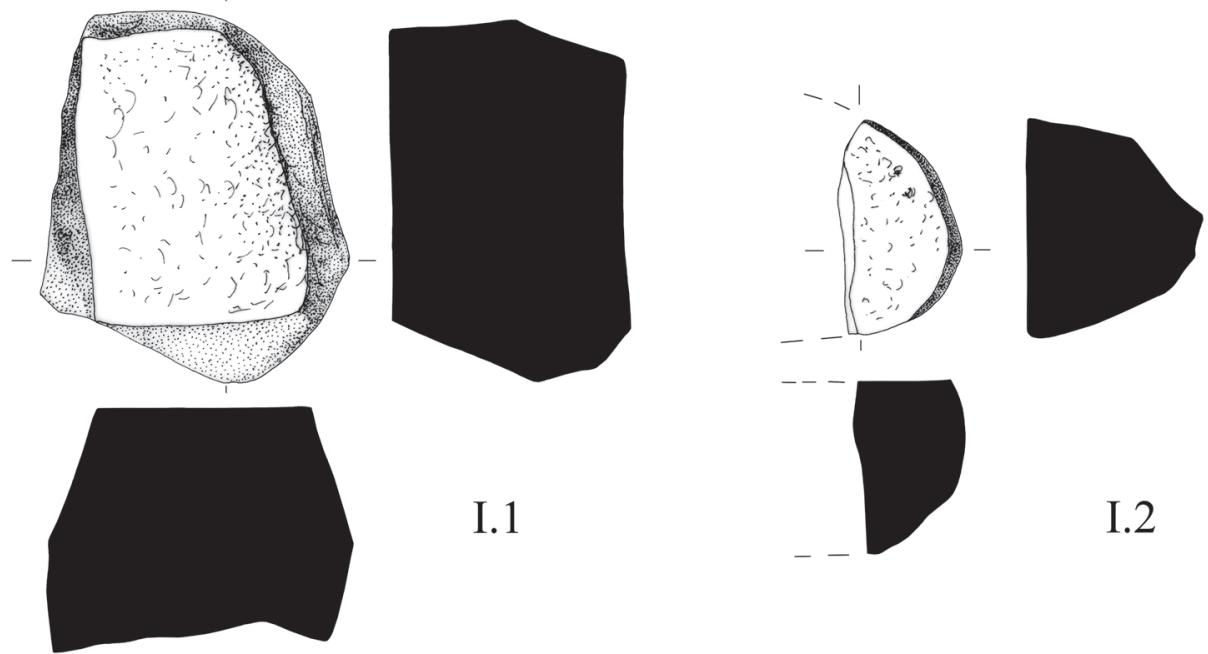

I. 1

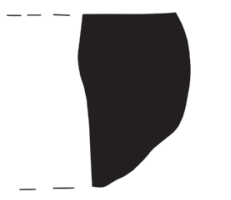

I. 2
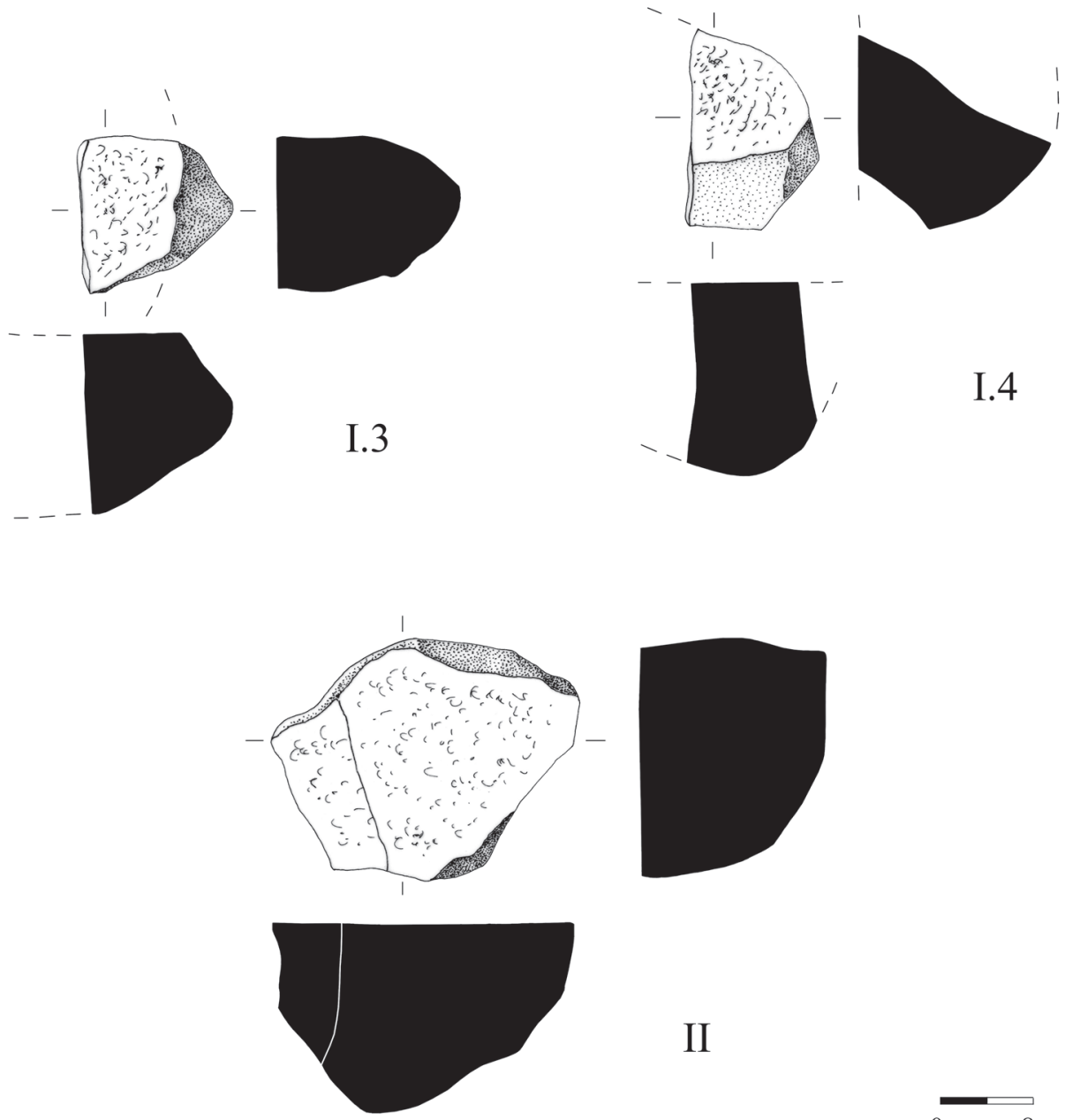

\section{I.4}

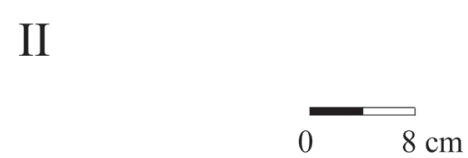

Abb. 16. Bruchstücke von Mahlsteinen (gezeichnet von M. Mátyus) 
In der oberen Füllungsschicht des Befundes wurden Knochenreste von Rind, Schaf/Ziege, Schwein, Hecht und Karpfen bzw. Muschelschalen gefunden. Im unteren Drittel der sich leicht verschmälernden Grube wurde eine stark gemischte Schicht beobachtet, die große und kleine Gefäßfragmente, zwei Bruchstücke von unteren Mahlsteinen, gebrannte Knochen von Kleinkäuern, Muschelschalen, ferner Holzkohlereste eines Feuers bzw. Getreide-, Pflanzen- und Speisereste beinhaltete. In der Nähe der südwestlichen Seite der Grube wurde das Skelett eines 5-8-jährigen Kindes freigelegt. Das Skelett lag in einer starken Hockerlage und war mit dem Kopf nach Norden gerichtet. Es wurde in die Fragmente eines großen Vorratsgefäßes (an der Freilegung erhielten sie die Beigabennummer 3 und 10; $A b b .2-3$ ) hineingedrängt und mit weiteren Gefäßbruchstücken bedeckt (der Reihenfolge nach: Bruchstücke eines Vorratsgefäßes [Beigabennummer 7-8 und weitere Fragmente], die Beigabennummer 9 und schließlich die Schale mit Barockmündung [Beigabennummer 4]). Die fragmentarischen Mahlsteine und das Friesfragment wurden nord-nordöstlich vom Skelett, in Bogenform angeordnet. Die Lage des Skelettes und des Gefäßes (Beigabenummer 10) gleicht einer Pithos-Bestattung, die Gefäßfragmente umgaben jedoch nicht den ganzen Körper, während Scherben auch unterhalb des Skelettes lagen. Das Phänomen weicht von den übrigen Siedlungsbestattungen ab; es handelt sich hier nicht um Bestattungsgruben mit mehreren, in anatomischer Ordnung liegenden Skeletten. In diesen Fällen wurden meistens Erwachsene beigesetzt (Varianten „B“ und „ „F“ von P. Jelínek), ${ }^{63}$ während in unserem Fall ein Kind begraben wurde (Variante „A“ von P. Jelínek; die Beispiele reichen vom Neolithikum bis zur Bronzezeit). ${ }^{64}$ In der Umgebung, sowohl im Kulturkreis der inkrustierten Keramik (Patince/Patpuszta IV ${ }^{65}$ als auch in der Magyarád/Madarovce-Kultur (Nitriansky Hrádok/Kisvárad 242, Unín/Nagyúny) ${ }^{66}$ finden wir vergrabene Kinderskelette in Siedlungsobjekten. Nichtsdestoweniger wurden Kinder in dieser Periode normalerweise in Pithos-Bestattungen beigesetzt.

Im Weiteren sollen einige Fragen erörtert werden - jedoch wegen Platzmangel nicht mit dem Anspruch auf Vollständigkeit. Als Erstes soll das Phänomen der in Siedlungsgruben begrabenen Skelette von Kindern und Erwachsenen besprochen werden, und zwar vom Gebiet des bronze- und eisenzeitlichen Karpatenbeckens bzw. aus der unmittelbaren Nachbarschaft.

In einer Grube der zur Glockenbecherkultur gehörenden Siedlung von Skalica (SW-Slowakei) wurden die Skelette von zwei Kindern freigelegt, die jünger als 10 Jahre waren. Gleicherweise wurden zwei Kinder unter 10 Jahren in Nitra-Ponitrianska galéria ${ }^{67}$ in einer zur Magyarád/Madarovce-Kultur gehörenden Grube (in Begleitung von Pferdeknochen) und in der Bz B1-zeitlichen, zur karpatenländischen Hügelgräberkultur gehörenden Grube 10/84 von Štúrovo-Obid zwei Kinder unter 10 Jahren und ein Kind im Inf. III-Alter freigelegt. ${ }^{68}$ Die Sitte der Beisetzung von zwei Kindern in einer Siedlungsgrube entstand im Äneolithikum und in der Frühbronzezeit in dieser Region (Variante „D“ von P. Jelínek). ${ }^{69}$

Im mittelmährischen Prostějov-Ošlan-Zlatniska wurde eine Pithos-Bestattung mit den Skelettresten eines ein paar Monate alten Kindes in einem großen, in die klassische Periode (Bz B2-C1) datierten Grubenkomplex der zur mitteldonauländischen Hügelgräberkultur gehörenden Siedlung freigelegt. ${ }^{70}$

An den Skelettresten der Siedlungsgrube Nr. 64 des zur Hügelgräberkultur (Bz C1-C2/D1) gehörenden Fundplatzes Velim-Skalka wurden Gewaltspuren identifiziert (Variante „E, F, H“ von P. Jelínek). ${ }^{71}$ Daneben wurden Bruchstücke von Gefäßen, Mahlsteinen, Tongewichten und einer Gussform sowie Tierknochen (Rind, Schwein, Schaf/Ziege) und Pflanzenreste (Mohrenhirse und Hirse) ${ }^{72}$ freigelegt. Die Gussform dieser Grube deutet auf Metallhandwerk hin, während die „goldene Frau“ des Befundes $27^{73}$ derselben Siedlung die rituelle Handlung einer wohlständigen Schicht erahnen lässt.

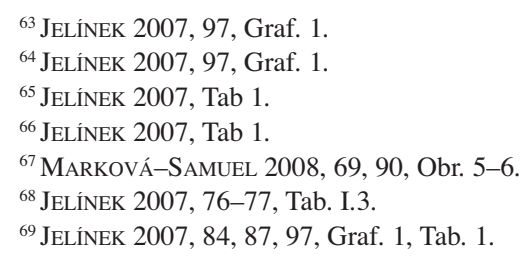

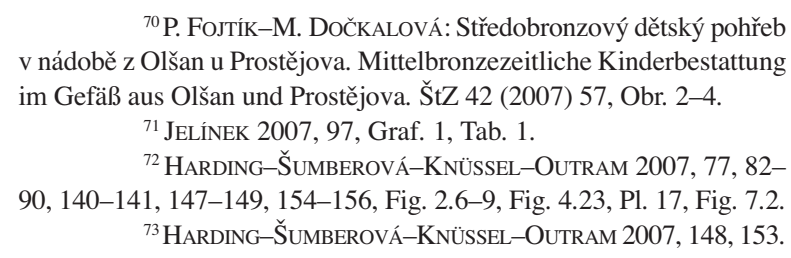

${ }^{70}$ P. FoJTíK-M. DočKALOVÁ: Středobronzový dětský pohřeb v nádobě z Olšan u Prostějova. Mittelbronzezeitliche Kinderbestattung im Gefäß aus Olšan und Prostějova. ŠtZ 42 (2007) 57, Obr. 2-4.

${ }^{71}$ JeLÍNEK 2007, 97, Graf. 1, Tab. 1.

${ }^{72}$ Harding-Šumberová-KNǗSSEL-OUtRAM 2007, 77, 82 90, 140-141, 147-149, 154-156, Fig. 2.6-9, Fig. 4.23, Pl. 17, Fig. 7.2. ${ }^{73}$ HARDING-ŠUMBEROVÁ-KNÜSSEL-OUTRAM 2007, 148, 153. 
Auf dem Fundplatz Gór-Kápolnadomb (Kom. Vas) ${ }^{74}$ kamen menschliche Skelette in den zur späten Phase der Urnenfelderkultur gehörenden Siedlungsteilen in mehreren Gruben ans Tageslicht (Quadrant K-6, Grube „a“: zwei Erwachsene und ein jüngerer Mann + Schaft einer Axt aus Rotwildgeweih, Feldhase; Quadrant L-8, Grube „a“: ein Kind im Alter von 3-5 Jahren + Rotwild, Schwein, Feldhase). Eines der Skelette trug auch Gewaltspuren. Das gleiche Phänomen, also die Beisetzung von Kindern und Erwachsenen in Siedlungsgruben wurde auch in Ostungarn, in mehreren Siedlungen der Gáva-Kultur beobachtet (z. B. Nyíregyháza-Rozsrétszőlő, Grube 368: erwachsene Frau und älterer Mann; Nyíregyháza-Oros, Grube 3031: erwachsene Frau; Grube 3116/01: 7-8-jähriges Kind). ${ }^{75}$

An Bauarbeiten der neuen Befestigung von Stillfried vom Ende der Urnenfelderzeit (Ha B2; C14-Daten 870 BC) wurde eine komplette Familie mit sieben Mitgliedern, unter ihnen auch Kinder (Varianten „F, H“ von P. Jelínek ${ }^{76}$ ), aufgeopfert. ${ }^{77}$

In einer Siedlungsgrube (Nr. 390) des keltischen Fundplatzes Szombathely-Reiszig-erdő alatti dűlő (Kom. Vas) wurde das Skelett eines Mädchens mit 15-18 Jahren freigelegt (Variante „A“ von P. Jelínek ${ }^{78}$ ). Unter dem Skelett wurden Mahlsteine dokumentiert. Mindestens nach geschlechtsspezifischer Arbeitsteilung können die Mahlsteine meiner Meinung nach auf eine Person weiblichen Geschlechts hindeuten. ${ }^{79}$ Diese Vorstellung könnte auch ein Ausschnitt des Gesanges XX der Odyssee unterstützen:

„Plötzlich hört' er ein mahlendes Weib, das glückliche Worte

Redete, nahe bei ihm, wo die Mühlen des Königes standen.

Täglich waren allhier zwölf Müllerinnen beschäftigt,

Weizen- und Gerstenmehl, das Mark der Männer, zu mahlen."80

Als Zweites soll hier auf die Pithos-Bestattungen des Karpatenbeckens hingewiesen werden.

Im Gräberfeld von Ostojićevo/Tiszaszentmiklós in Serbien wurden fast 300, vom Ende der Frühbronzezeit bis zur Koszider-Phase der Vatya-Kultur datierte Gräber freigelegt. Aus der Schlussphase des Gräberfeldes wurden 103 Pithos-Bestattungen, also in Töpfen oder Amphoren beigesetzten Kindergräber, dokumentiert. ${ }^{81}$

Im Verbreitungsgebiet der Maros/Perjámos-Kultur kamen im Gräberfeld von Deszk „A“ vier, im Gräberfeld von Szőreg (Periode 3: mittlere Bronzezeit 1/2; Bz A2a-b) ${ }^{82}$ zwei oder drei Pithos-Bestattungen zum Vorschein. ${ }^{83}$ Die Pithoi aus Deszk sind mit denen von Dunaalmás-Foktorok gleichzeitig oder etwas jünger. ${ }^{84}$

${ }^{74}$ G. ILON: Keftiubarren ingot from Urn-Grave culture settlement at Gór-Kápolnadomb (C. Vas). ActaArchHung 44 (1992) 239-259; G. ILON: Siedlungswesen und Bestattungssitten in Gór. Zum Übergang von der Urnenfelder- zur Hallstattzeit. In: A. Lippert (Hrsg.): Die Drau-, Mur- und Raab-Region im 1. vorchristlichen Jahrtausend. Akten des internationalen und interdisziplinären Symposiums vom 26. bis 29. April 2000 in Bad Radkersburg. UPA 78. Bonn 2001, 243-267; Zs. K. ZoFFMANN: Embertani leletek az Urnamezőskultúra Gór-Kápolnadomb lelőhelyéről (Anthropological finds from the site Gór-Kápolnadomb dating from the Urnfield-period). Savaria 30 (2007) 145-158.

${ }^{75}$ M. URÁK-L. MARTA: Human remains of the Late Bronze Age settlements in the Upper Tisza area. In: S. Berecki-R. NémethB. Rezi (eds): Bronze Age Rites and Rituals in the Carpathian Basin. Proceedings of the International Coll. from Târgu Mureş, 8-10 October 2010. Bibliotheca Mvsei Marisiensis. Ser. archaeologica 4. Târgu Mureş 2011, 156, 159, 161, Fig. 2, Fig. 8-9.

${ }^{76}$ JELÍNEK 2007, 97, Graf. 1, Tab. 1.

${ }^{77}$ C. EIBNER: Die Mehrfachbestattung aus einer Grube unter dem urnenfelderzeitlichen Wall in Stillfried an der March, NÖ. Forschungen in Stillfried 4 (1980) 135, Taf. 51, Taf. 53-54.

${ }^{78}$ JELÍNEK 2007, 97, Graf. 1, Tab. 1.

${ }^{79}$ G. ILON: Őskori temetkezések az utóbbi évtized Vas megyei ásatásain. Adatok a mellékletek és az eltemetett nemének kérdéséhez (Vorzeitliche Bestattungen auf den archäologischen Ausgrabungen vom letzten Jahrzehnt im Komitat Vas. Angaben zu den
Beigaben und zur Frage des Geschlechtes der Beerdigten). In: G. Ilon (ed.): M'QMO $\Sigma$ III. Őskoros Kutatók III. Országos Összejövetelének konferenciakötete. Halottkultusz és temetkezés. Bozsok-Szombathely, 2002. október 7-9. Szombathely 2004, 217-218, Taf. XXI.

${ }^{80}$ Übersetzung von W. Schadewaldt; Hervorhebungen des Autors.

${ }^{81}$ M. GIRIĆ: Die Maros (Moriš, Mures) -Kultur. In: N. Tasić (Hrsg.): Kulturen der Frühbronzezeit des Karpatenbeckens und Nordbalkans. Beograd 1984, 44; K. P. FisCHL-V. KISS: A Vattina-Kultur kutatása és északi kapcsolatainak kérdése (Die Forschung der VattinaKultur und die Frage ihrer nördlichen Verbindungen). MFMÉ - Studia Archaeologica 8 (2002) 131.

${ }^{82}$ BÓNA 1975, 105: Zeittabelle; Kiss 2012, 324-325, Fig 3.

${ }^{83}$ BónA 1975, 87; G. SzABó: Wosinsky Mór és Móra Ferenc ásatása a két névadó lelőhelyen: Gerjen és Szőreg - elméletek és valóság (Die Ausgrabungen von Mór Wosinsky und Ferenc Móra auf den beiden namengebenden Fundorten: Gerjen und Szőreg - Theorien und die Wirklichkeit). In: G. Ilon (ed.): $\mathrm{M}^{\prime} \Omega M O \Sigma$ III. Ốskoros Kutatók III. Országos Összejövetelének konferenciakötete. Halottkultusz és temetkezés. Bozsok-Szombathely, 2002. október 7-9. Szombathely 2004, 430

${ }^{84}$ É. VÉKONYNÉ VADÁSZ: Az észak-dunántúli mészbetétes kerámia esztergomi alcsoportjának települése Dunaújváros-Foktorokban (Die Siedlung der Esztergomer Untergruppe der inkrustierten Keramik von Nordtransdanubien in Dunaújváros-Foktorok). Komárom-Esztergom Megyei Múzeumok Közleményei 8 (2000), Anm. 18. 
Im Gräberfeld der Otomani-Kultur von Pir/Szilágypér (Siebenbürgen, Rumänien) ist ein Kinderskelett in einer Pithos-Bestattung bekannt. ${ }^{85}$

Auf dem Fundplatz Dunaalmás-Foktorok legte É. V. Vadász zwei Pithos-Gräber in der Siedlung der Kultur der Transdanubischen Inkrustierten Keramik (nach der ungarischen Terminologie mittlere Bronzezeit 2= Bz A2b) in einem freien Bereich (Gräberfeldteil für Kinder?) frei. ${ }^{86}$ In der Publikation kommt sie zur Schlussfolgerung, dass diese Bestattungssitte nicht vom südlichen Ursprung sei.

Auch das Gräberfeld von Tiszafüred-Majoroshalom enthielt Pithos-Bestattungen mit Kindern (die Gräber 35, 84 und 218). Der Ritus erschien hier in der Hügelgräberphase des Gräberfeldes. ${ }^{87}$

In der Siedlung der inkrustierten Keramik von Patince/Patpuszta befand sich eine Pithos-Bestattung mit einem Kind im Befund IV/56. ${ }^{88}$ Anderen Siedlungsbestattungen (Nitriansky Hrádok, Šarovce) ähnlich wurde die Erscheinung als Schutzopfer gedeutet. ${ }^{89}$

Im südmährischen Vedrovice wurde ein mit Schüssel bedecktes Vorratsgefäß in einer engen Grube (Befund Nr. 1) entdeckt. Im Gefäß befanden sich Skelettreste eines 8-jährigen Kindes mit Knochenperlen und Knochenanhänger. In unmittelbarer Nähe wurde eine weitere, etwas seichtere Grube mit einem Rippenknochen von Schaf/ Ziege freigelegt. Die Schüssel ist ein typisches Gefäß des Věteřov-Magyarád/Madarovce-Böheimkirchen-Komplexes, das auch in der (nach mitteleuropäischer Terminologie) mittelbronzezeitlichen Hügelgräberkultur beliebt war. Der Pithos des Grabes ist ein typischer Gefäßtyp der Aunjetitzer Kultur, der gleichzeitig auch im Fundgut der Věteřov-Kultur vorhanden ist. Der Befund wurde auf die jüngere, postklassische Phase der Aunjetitzer Kultur datiert. Der kreisförmige Anhänger ist ein Sonnensymbol. In der Nähe von Vedrovice, in einem Grab der VěteřovKultur von Olbramovice wurde gleichfalls eine Pithos-Bestattung dokumentiert. ${ }^{90}$

Das Pithos-Grab der Věteřov-Kultur aus Mikulov-Kowalského beinhaltete Skelettreste eines 2- und eines 6-jährigen Kindes. ${ }^{91}$

Im Verbreitungsgebiet der Aunjetitz- und Věteřov-Kultur wurden meistens topfförmige Gefäße zu PithosBestattungen benutzt. ${ }^{92}$

\section{DIE INTERPRETATION UND AUSWERTUNG DES BEFUNDES}

Die Erscheinung der Grubenbestattung in Ménfőcsanak kann als eine Sonderform der Pithos-Bestattungen angesehen werden. Seit dem Ende der Frühbronzezeit (nach mitteleuropäischer Chronologie) wurden keine Erwachsenen, nur Säuglinge und Kleinkinder in echten Pithos-Bestattungen beigesetzt. In der Regel wurde in einem Grab jeweils nur ein Kind bestattet, es kamen aber auch zwei- oder dreifache Bestattungen vor. Die anthropologischen Untersuchungen wiesen darauf hin, dass Frau und Kind auf solche Weise nicht beigesetzt wurden, die Beisetzung eines Mannes mit Kind kam jedoch manchmal vor. Die Art und Form solcher Beerdigungen können innerhalb einer Siedlung nicht als normale Alternativen angesehen werden..$^{93}$

T. Kovács kam zur Einsicht, dass dieser - seiner Meinung nach vom Süden her stammende - Brauch in der Großen Ungarischen Tiefebene am frühesten und ausschließlich im Gebiet der Perjámos-Kultur erschien. ${ }^{94}$ Den Ursprung des Brauchs glaubte I. Bóna ${ }^{95}$ in Griechenland, vor allem im Gebiet Anatoliens, im 2.-3. Jahrtausend v. Chr. gefunden zu haben, jedoch schloss er den lokalen Ursprung nicht vollständig aus. Der Brauch war ab der klassischen Phase der Otomani-, Magyarád/Madarovce- und Věteřov-Kultur beliebt. ${ }^{96}$ Laut den Forschungen von M. Salaš kommt der Pithos in Tschechien, in der unteren Theißregion, in der Zuflussstelle des Marosch und der 1, Taf. 5.1-2.

${ }^{85}$ BADER 1990, 183.

${ }^{86}$ É. VÉKONYNÉ VADÁSZ op. cit. in Anm. 84, 14-17, Abb.

${ }^{87}$ T. KovÁcs: Tumulus culture cemeteries of Tiszafüred. RégFüz Ser. II.17. Budapest 1975, 12, 15, 27, 48-49, Fig. 18, Pl. 21.218 .

\footnotetext{
${ }^{88}$ VLADÁR 1973, 295-296, Abb. 37-38.

${ }^{89}$ FURMÁNEK-VELIAČIK-VLADÁR 1999, 167.

${ }^{90}$ SALAŠ 2007, 153-161, Obr. 6, 8-9.
}

${ }^{91}$ S. STUChLíK: Pohřby v nádobách v době bronzové na Moravě. Bronzezeitliche Bestattungen in Gefäßen in Mähren. ŠtZ 42 (2007) 201, 204, 207, Obr. 6.

${ }^{92}$ SALAŠ 2007, 160.

${ }^{93}$ Primas 2008, 81-82; B. HOREJS-F. KANZ: Eine spätbronzezeitliche Bestattung in Halkapınar bei Ephesos. Jahreshefte des ÖAIW 77 (2008) 107-129.

${ }^{94}$ KovÁcs 1975, 48-49, Anm. 107.

${ }^{95}$ KovÁCS 1975, 87.

${ }^{96}$ VLADÁR 1973, 295-297. 
Theiß meist in Gräberfeldern, während in der SW-Slowakei und in Transdanubien in Siedlungen vor. Seine Ergebnisse können mit den Daten von Pir ergänzt werden. Es kann hinzugefügt werden, dass ein Gefäß mit Kindesbestattung im Heiligtum von Sălacea, beim Eingang in einer Grube freigelegt wurde. ${ }^{97}$ Anhand der chronologischen Lage der oben aufgezählten Pithos-Bestattungen kann tatsächlich vorgestellt werden ${ }^{98}$ dass diese Bestattungsform im mitteleuropäischen Kulturkreis (z. B. Aunjetitz [Peigarten, Bz A2 ${ }^{99}$, Věteřov, Magyarád/Mađ̉arovce ${ }^{100}$ und Transdanubische Inkrustierte Keramik) bzw. in den westlich der Donau liegenden Gebieten des Karpatenbeckens entstand.

Die Vorstellung des südlichen Ursprungs hat jedoch auch in der neuesten Forschung Anhänger. ${ }^{101}$ Neben den befestigten „Akropolen“ werden der Steinbau, der plastische Wandverputz, die tragbaren Feuerherde (Pyraunos), die Kultwagen, die Brotlaibidole sowie die kultischen Brunnen, für Opferdarbietung vorbehaltene Plätze und auch die Gefäßbestattungen (Pithos) vom Südosten, aus dem Mittelmeerraum hergeleitet. Im Gegensatz dazu kann anhand der vorher bereits erwähnten neuen Studie von B. Horejs ${ }^{102}$ nur so viel behauptet werden, dass die Begrabungssitte in Anatolien von der Früh- bis zur Spätbronzezeit bekannt, jedoch auf dem nördlichen und mittleren Teil des Balkans in der zweiten Hälfte des 2. Jahrtausends unbekannt war. Zwar kommt diese Bestattungsform in der gegebenen Periode in weiten Gebieten Europas vor, kann zusammenfassend festgestellt werden, dass ihr Ursprungsort sowohl südlich als auch lokal bestimmt werden kann. Die voneinander unabhängigen (sic!) Vorbilder sind im Äneolithikum und in der Frühbronzezeit sowohl in Kleinasien und auf dem Balkan als auch im Karpatenbecken bewiesen worden. ${ }^{103}$ Der symbolische Inhalt des Brauchs ist die Rückkehr des Kindes in den Körper der Mutter, darüber hinaus weist er auf die Zyklizität und Kontinuität der menschlichen Existenz hin. ${ }^{104}$ Die Frage, wieso Kinder im gleichen Alter - in Mähren meistens 6-8-jährige Kinder - auch auf traditionelle Weise in Gräbern beigesetzt wurden, bleibt unbeantwortet. Jedenfalls deuten solche Erscheinungen in einer Siedlung auf eine rituelle Erklärung hin. ${ }^{105}$

In den freigelegten Gruben der Siedlungen findet man menschliche Skelette oder Teile von Skeletten, Tierknochen und vollständige oder bruchstückhafte Gefäße. Diese können als rituelle Phänomene erklärt werden, die sakralen, d. h. heiligen Orte im Freien markieren, und die sakralen Handlungen wurden mit Trank- oder Speiseopfer begleitet. ${ }^{106}$ Gleichzeitig dürfen diese Erscheinungen nicht mit den - wahrscheinlich ebenfalls auf Riten hinweisenden - Gefäße bzw. Gefäße und Tierknochen beinhaltenden Deponierungen verglichen werden. (Mit diesem Thema beschäftigte ich mich in der Studie über die Koszider-zeitliche, zur frühen Hügelgräberkultur gehörende Grube von Veszprém. Die Grube enthielt außer Gefäßen und Tierknochen auch „obere Mahlsteine“, d. h. Läufer, aber keine menschlichen Reste. ${ }^{107}$ Gleichzeitig fand man untere Mahlsteine in der Grube von Ménföcsanak und dem bereits erwähnten Velim.)

Die Funktion der mit menschlichen Resten verborgenen Mahlsteine wurde von J. Makkay ${ }^{108} 1978$ detailliert behandelt. Anhand neolithischer, kupfer- und bronzezeitlicher kleinasiatischer, ost- und südosteuropäischer Beispiele stellt er fest, dass sie bei Fruchtbarkeitsriten - z. B. beim rituellen Mahl - eine wesentliche Rolle spielten. Nach Beendigung des Ritus wurden die unbrauchbar gewordenen Gegenstände, mitunter die zerbrochenen (!) Mahlsteine mit den Speiseresten (z. B. Fleischreste mit Knochen, Getreidereste) mit menschlichen Resten begraben. Anders gesagt: Sie wurden in einem symbolischen Grab beigesetzt. Die Bestattung einer oder mehrerer Mitglieder einer Gemeinschaft - in der Bronzezeit vor allem Kinder - in einem Depot dürfte als Opfer höheren Grades interpretiert werden.

${ }^{97}$ BADER 1990, 183, Abb. 1; G. ZIPF: Formalisierung, Reduzierung, Inszenierung - Zur wissenschaftlichen Konzeption von Ritualen und ihrer Umsetzung in der Interpretation archäologischer (Be-)Funde. In: C. Metzner-Nebelsick (Hrsg.): Rituale in der Vorgeschichte, Antike und Gegenwart. Int. Arch. Arbeitsgemeinschaft, Symposium, Tagung, Kongress 4. Rahden/Westf. 2003, 13.

${ }^{98}$ BOUZEK 1966, 257; BÓNA 1975, 87.

${ }^{99}$ F. BERG: Ein Kindergrab aus der Aunjetitz-Siedlung in Peigarten, G. B. Haugsdorf, Niederösterreich. ArchA 65 (1981) 69.

${ }^{100}$ M. NovotnÁ-B. NovotnÝ: Die Mad'arovce-Kultur. In: N. Tasić (Hrsg.): Kulturen der Frühbronzezeit des Karpatenbeckens und Nordbalkans. Beograd 1984, 327.

${ }^{101}$ PEŠKA 2012, 303.

${ }^{102}$ HoRejs-Kanz 2008, besonders 117, Abb. 7. und 8.
${ }^{103}$ K. Bacvarov: A long way to the West: Earliest jar burials in southeast Europe and the Near East. In: K. Bacvarov (ed.): Babies Reborn: Infant/Child Burials in Pre- and Protohistory. BAR IntSer 1832. Oxford 2008, 61-70; HoREJS-KANZ 2008, Abb. 7.

${ }^{104}$ H. SchwARZBERG: Durch menschliche Kunst und Gedanken gemacht. Studien zur anthropomorphen Gefäßkeramik des 7. bis 5. vorchristlichen Jahrtausends. Münchner Archäologische Forschungen 1. Rahden/Westf. 2011, 191.

${ }^{105}$ FURMÁNEK-VELIAČIK-VLADÁR 1999, 167; SALAŠ 2007, 153-161, Obr. 6, 8-9; Primas 2008, 81-82.

${ }^{106}$ HARDING-ŠUMBEROVÁ-KNÜSSEL-OUTRAM 2007, 151.

${ }^{107}$ ILON 2012.

${ }^{108}$ J. MAKKAY: Mahlstein und das rituale Mahlen in den prähistorischen Opferzeremonien. ActaArchHung 30 (1978) 13-36.

Acta Archaeologica Academiae Scientiarum Hungaricae 65, 2014 
Kann auf Grund der Gebäudeplastik (Abb. 15) im Falle von Ménfócsanak - wahrscheinlich mit Recht - auf ein mit Fruchtbarkeitsopfer verstärktes Bauopfer gefolgert werden? Kann das vielleicht auf eine Zeremonie hindeuten, die vor oder während des Errichtens des Gebäudes oder beim Einzug durchgeführt wurde? Dürfte das Spiralmotiv des Frieses auf die führende Rolle der Bauherren ${ }^{109}$ und/oder auf die herausragende Bedeutung des Gebäudes im Leben der Gemeinschaft hindeuten? Es ist jedenfalls fraglich und kann nicht bewiesen werden, dass das in Pithos beigesetzte Kind - vielleicht ein Mädchen, worauf das Pyraunos-Fragment hinweisen könnte - aus der Familie der Bauherren stammte.

Unter den Tierknochen befinden sich keine Reste, aus denen man auf die Jahreszeit des Schlachtens, d. h. der Zeremonie, folgern könnte. Die kleineren Knochenreste von der Grubensohle trugen Brandspuren, während die aus der Füllung der Grube stammenden Knochenreste unversehrt waren. Die Brandspuren können vielleicht Folgen einer allgemeinen Verbrennung, eines Brandopfers oder der Zubereitung einer Speise sein. Die Verwendung von Feuer wird auch durch die durch Flotation gesammelten Holzkohlereste nachgewiesen. Aus der Füllung stammende, nicht gebrannte Knochen können nicht verwendete, deponierte Fleischknochen gewesen sein, die als Lebensmittel ins Jenseits mitgegeben wurden.

Jedenfalls ist es bemerkenswert, dass Tierknochen (linke Beinknochen eines jungen Schaf/Ziege) nach dem Einfluss der Věteřov-Kultur im Gräberfeld von Gemeinlebarn F unter den 258 Gräbern nur in einem Fall registriert wurden. Im Gegensatz zur vorangehenden Periode ging also der Brauch der Speisebeigaben in der Region stark zurück. ${ }^{110}$ Gleichzeitig wurde das in der Nähe befindliche hügelgräberzeitliche Grab 1A von Nagydém reichlich mit Tierbeigaben abwechslungsreicher Qualität ausgestattet (15-18-monatiges Kalb, ausgewachsenes Rind und Schwein, 6-8-monatiges Lamm, 1,5-2-jähriger Schafsbock und Fisch). ${ }^{111}$ In der ebenfalls hügelgräberzeitlichen Grube des Gefäßdepots des etwas ferner liegenden Fundplatzes Veszprém-Kádárta-Gelemér wurden außer Knochenreste von Feldhase, Schaf, Schwein (das Letztere in größter Menge) auch Rinderknochen ${ }^{112}$ dokumentiert. Es wird hier auf die entscheidende Rolle des Stierkultes ${ }^{113}$ in der Ägäis nicht näher eingegangen. Die Rinderknochen der Grube können die Beliebtheit des Tieres in der Region ${ }^{114}$ und das Maß des Wohlstandes bezeichnen.

Die wenigen Muschelschalen könnten eher auf Verzehr als Leckerbissen hindeuten, weniger auf eine bedeutende Proteinzufuhr.

Die nach der Flotation entnommenen Emmer- und Gerstenreste bzw. die Phytolithen der Mahlsteine (Abb. 4.1) können mit großer Wahrscheinlichkeit mit rituellen Handlungen verbunden werden, die bei der Opferung und Beisetzung des Kindes durchgeführt wurden.

Im Zusammenhang mit der Interpretation der Grube ist es interessant, einen Ausschnitt des Gesanges XI aus der Odyssee zu zitieren:

„Aber nun eilt ich und zog das geschliffene Schwert von der Hüfte,

Eine Grube zu graben, von einer Ell ins Gevierte.

Hierum gossen wir rings Sühnopfer für alle Toten:

Erst von Honig und Milch, von süßem Weine das zweite,

Und das dritte von Wasser, mit weißem Mehle bestreuet.

[...]

Bringe stattliche Opfer dem Meerbeherrscher Poseidon,

Einen Widder und Stier und einen mutigen Eber.

Und nun kehre zurück und opfere heilige Gaben

Allen unsterblichen Göttern, des weiten Himmels Bewohnern,

Nach der Reihe herum." $" 115$

${ }^{109}$ DAVID 2002, 404; METZNER-NEBELSICK 2009, 18-20, 22.

${ }^{110}$ C. Neugebauer-Maresch-J.-W. Neugebauer: Speiseund Getränkebeigabensitten in der süddanubischen Frühbronzezeit Niederösterreichs. BudRég 36 (2002) 259.

${ }^{111}$ I. VöRös: Étel- és állatáldozat leletek Nagydém-Középrépáspuszta középső bronzkori temetőjében (Funde von Speisebeigaben und Opfertieren in dem mittelbronzezeitlichen Gräberfeld Nagydém-Középrépáspuszta). Acta Musei Papensis 5 (1995) 149-155.

${ }^{112}$ ILON 2012, 20; B. TuGYA: Appendix. Veszprém-Kádárta, Geleméri-dűlő lelőhely 50. objektuma állatcsontleleteinek rövid elemzése - A short analysis of the faunal remains of feature no. 50 at the Acta Archaeologica Academiae Scientiarum Hungaricae 65, 2014
Veszprém-Kádárta, Geleméri-dűlő site. In: J. Kisfaludi (ed.): Régészeti kutatások Magyarországon 2010 - Archaeological Investigations in Hungary 2010. Budapest, 54. 2003, 148, Abb. 4.

${ }^{113}$ BOUZEK 1966, 262-263, Fig. 15.4-5; MÜLLER-KARPE

${ }^{114}$ L. BARTOSIEWICZ: Bronze Age animal keeping in Nortwestern Transdanubia, Hungary. Acta Musei Papensis 6 (1996) 35, Tab. 1, Fig. 3.

${ }^{115}$ Übersetzung von W. Schadewaldt; Hervorhebungen des Autors. 
Diese Erscheinung, dass nämlich die mit einem Bauopfer in Zusammenhang stehende Pithos-Bestattung aus Ménföcsanak in einer Siedlung freigelegt wurde, kann in das bereits erwähnte, von M. Salaš skizzierte geographische Verbreitungsgebiet topographisch gut hineingefügt werden. Gleichzeitig ist die Frage der Kontinuität ${ }^{116}$ des heiligen Ortes der rituellen Opfer zu überlegen und berechtigt; demnach soll der Bronzefund I der Koszider-zeitlichen Grabungsfläche mit dieser Pithos-Bestattung ergänzt werden.

Anhand der Grube (Abb. 2-3) dürfte ein vorgestelltes duales Weltbild, ${ }^{117}$ das für die Gemeinde kennzeichnend war, vermutet werden. Das Kinderskelett befand sich in dem Pithos auf einer Berme der Grube, während die „Beigaben“ (Mahlsteine, Gefäße usw.) tiefer lagen. Im Gegensatz zu der tiefer liegenden Einheit befanden sich die Reste der verzehrten Tieropfer etwas höher. ${ }^{118}$ Es ist sicherlich auch kein Zufall, dass das Kind in anatomischer Ordnung, die Tierreste jedoch ohne Anordnung in die Grube gelangten.

\section{ÜBER DIE SPIRALMOTIVE}

Die erste Erscheinung der Spiralmotive (Abb. 13-15) im Karpatenbecken kann im Zeitraum ${ }^{119}$ Bz A2-B1 / LH/LM II / 1700-1500 BC bestätigt werden. Es wird hier auf die Schilderung der unterschiedlichen und gut zusammengefassten Theorien ${ }^{120}$ sowie auf die bis heute nicht abgeschlossenen Diskussionen verzichtet. Diese beziehen sich auf einen eventuellen eurasiatischen (Abaševo-Kultur) oder anatolischen Ursprung des Motivs und dessen Verbreitungsrichtung - Karpatenbecken (Anfänge der Spiralkeramik: B III / Langquaid), ${ }^{121}$ Mykene und Süddeutschland - bzw. betreffen die Beziehungssysteme dieser Gebiete, ihre Einwirkungen und chronologischen Verhältnisse. ${ }^{122}$

Es ist allgemein bekannt, dass dieses Motiv (Spirale/Welle/Schlange) sowohl in der Ägäis auf Kreta (z. B. im Thronsaal des Palastes von Knossos; Datierung: MM III/LM IA-IB ${ }^{123}$ ) als auch - infolge der Ausstrahlung - auf Thera zu finden ist ${ }^{124}$ (das Trennungselement der Wandmalerei im Raum 4 des sog. westlichen Hauses sowie die Abbildung eines Altarornaments/Altarrahmens im Raum 3 von Xeste 3). Das Motiv wurde auch von der mykenischen Elite angewandt (auf dem rituellen Feuerherd des Palastes von Pylos; ${ }^{125}$ auf der unteren Seite der Grabstele des Schachtgrabes V im mykenischen Grabbezirk A findet man Spirallinien mit unterschiedlichem Spiraldurchmesser, ${ }^{126}$ wie auf der Grabstele von Razlog in SW-Bulgarien ${ }^{127}$ ). Das Motiv erscheint in Westrumänien (Siebenbürgen) in der Wietenberg-Kultur (Altar-Herd ${ }^{128}$ ), zur selben Zeit in der Woiwodina in der Siedlung von Mošorin-Feudvar, ${ }^{129}$ in dem Pančevo-Omoljica-Keramikstil (MD I, d. h. Bz A/B), der die Anfangsphase der Vattina-Kultur ist, sowie in der Marosch-Kultur. ${ }^{130}$ In der Tellsiedlung von Jászdózsa finden wir die Verzierung auf einer doppelten Tonaxt eingestochen, ${ }^{131}$ in Tószeg ist sie auf einem Altar-Feuerherd zu finden (Bz A2). ${ }^{132}$

${ }^{116}$ G. ZIPF op. cit. in Anm. 97; S. HANSEN: Bronzezeitliche Horte als Indikatoren für ,,andere Orte“. Das Altertum 53 (2008) 291314.

${ }^{117}$ KRISTIANSEN-LARSSON 2005, Fig. 124.

${ }^{118}$ T. SorocEAnU: Zweiteilige Einheit oder geeinte Zweiheit? Zur Frage der Dualität in den bronzezeitlichen Deponierungen. In: S. Berecki-R. Németh-B. Rezi (eds): Bronze Age Rites and Rituals in the Carpathian Basin. Proceedings of the International Coll. from Târgu Mureş, 8-10 October 2010. Bibliotheca Mvsei Marisiensis. Ser. archaeologica 4. Târgu Mureş 2011, Taf. 2.1-2.

${ }^{119}$ BouzeK 1996, 178, Fig. 10.

${ }^{120}$ Kristiansen-Larsson 2005, 185, Fig. 78-79; S. KaDRow: Examples of Migration in the Early Phases of the Metal Ages from a Contemporary Sociological Perspective. In: K. Dzięgielewski-M. S. Przybyła-A. Gawlik (eds): Migration in Bronze and Early Iron Age Europe. Kraków 2010, 47-61.

${ }^{121}$ Mozsolics 1967, 119, 121-123.

${ }^{122}$ BAder 1990; Lichardus-Vladár 1996, 26-27; S. PenNER: Schliemanns Schachtgräberfund und der europäische Nordosten. Studien zur Herkunft der frühmykenischen Streitwagenausstattung. Saarbrücker Beiträge zur Altertumskunde 60. Bonn 1998, 160-162, 179-180, 211-215; DAVID 2001.
${ }^{123}$ VladÁR 1973, 304, Abb. 41; V. KLONTZA-JAKLOVÁ: Aegean parallels to Carpathian Bronze Age pendants. In: R. Kujovský-V. Mitáš (Hrsg.): Václáv Furmánek a doba bronzová. Zborník k 70. narodeninám. Nitra 2012, 196; BouZEK 1966, Fig. 10.6.

${ }^{124}$ N. MARINATOS: Kunst und Religion im alten Thera. Zur Rekonstruktion einer bronzezeitlichen Gesellschaft. Athen 1987, Abb. $28,53$.

${ }^{125}$ KristiansEN-LARSSON 2005, Fig. 66.

${ }^{126}$ BouZEK 1966, Fig. 10.1; V. KLONTZA-JAKLOVÁ op. cit. in Anm. 123, 195, Tab. 3.15.

${ }^{127}$ LiCHARDUS-VladÁR 1996, Taf. 4.6.

${ }^{128}$ BOUZEK 1966, 261, 267, Fig. 17.2; KRISTIANSEN-LARSson 2005, Fig. 66.

${ }^{129}$ B. HÄNSEL-P. Medović: Zur Stellung des bronzezeitlichen Pančevo-Omoljica-Stils innerhalb der Keramikentwicklung der Vattina-Kultur. Starinar 40-41 (1991) 117-118, Abb. 6.

${ }^{130}$ HänSEL-Medović 1991, 78-79, Taf. 6.9.

${ }^{131}$ MAKKAY 1999, 47-48, Fig. 2.1.

132 BANNER-BónA-MÁRTON 1957, 117, 126, Abb. 24.5, Abb. 25.8; BouZeK 1966, 261, 268, Fig. 17.5. 
Die „mykenischen Elemente“ erscheinen in den östlichen, nordöstlichen und nördlichen Gebieten des Karpatenbeckens auf Gebäudeplastik (Abb. 6), und zwar in den befestigten Siedlungen der klassischen und postklassischen Phase der Otomani- und Magyarád/Mađaarovce-Kultur (z. B. Barca, Spišský Štvrtok ${ }^{133}$ ), später auch in der Urnenfelderzeit (Şagu, Nyergesújfalu, Levice, Pobedim, Trebatice ${ }^{134}$ ). Die verzierten Lehmverputze kommen noch nördlicher, in Tschechien, in Velké Žernoseky und in der Sammlung des Museums von Teplice vor. ${ }^{135}$ Daneben wurde das Spiralmotiv im Karpatenbecken und somit in den westlichen Gebieten ${ }^{136}$ zu einem beliebten Dekorelement im Formenschatz der Keramik-, Knochen- und Metallindustrie. ${ }^{137}$ In der nördlichen Region des Kontinents erscheint das Motiv in der Periode I und II der Bronzezeit als Verzierungselement, z. B. auf Halsschmuck. Die frühesten Stücke sind die von Mecklenburg und Zapkow. ${ }^{138}$ Die Richtung und die Verknüpfungsweise unseres Spiralmotivs zeigen Ähnlichkeiten mit Gegenständen, die aus voneinander entfernten Gebieten unseres Kontinents stammen: z. B. auf einer Lanze des Depotfundes von Borodino, ${ }^{139}$ auf dem Altar-Feuerherd von Wietenberg, ${ }^{140}$ auf der Grabstele des Schachtgrabes V im Grabbezirk A von Mykene, ${ }^{141}$ auf einem Gefäßbehälter von Temes-Kubin ${ }^{142}$ und auf dem Blech des französischen Marnay. ${ }^{143}$

Nach der Meinung mehrerer Forscher konnte das Motiv auf unterschiedliche Weise ins Karpatenbecken gelangen (Abb. 7). ${ }^{144}$ Die Route I.1a könnte im östlichen Teil des Karpatenbeckens, in Siebenbürgen (z. B. Schwerte ${ }^{145}$ ) in NW-Richtung verlaufen haben, zuerst ins Hochland, d. h. in die Ost- und NW-Slowakei (z. B. die Schwerte von Sävtý Jur/Pozsonyszentgyörgy und Galanta/Galánta ${ }^{146}$ ), und von da aus als Route $1 b$ in Richtung Norden nach Mähren ${ }^{147}$ und Böhmen, dann weiter nach Norddeutschland und Skandinavien. Die Route 1c führte nach Westen, in der Treffzone der Großen Ungarischen Tiefebene und des nordungarischen Mittelgebirges (was in letzter Zeit auch durch die Brotlaibidole bestätigt wird ${ }^{148}$ ), durch die Hainburger Pforte, die Uferseiten der Donau nutzend (hier, auf der Kleinen Ungarischen Tiefebene befindet sich Ménföcsanak, unser Fundplatz), und schließlich verlief die Route 1d in Richtung Polen (z. B. die Trensenknebel von Belz in der heutigen Ukraine ${ }^{149}$ ) und weiter zum Nordsee. ${ }^{150}$ Die Route I.2. führte in die Richtung des Schwarzen Meeres - da die frühen mykenischen Funde im nördlichen Griechenland fehlen ${ }^{151}$-, dann mit der Berührung der Unteren Donau und entlang der Donau oder in den Tälern des Vardar und der Morava (Razlog ${ }^{152}$ ) führte sie zur mit etwas längerem Hiatus von Bz A2/B1 an bis $\mathrm{C} 2 / \mathrm{D}^{153}$ lebenden Siedlung Mošorin-Feudvar im Zusammenflussgebiet der Theiß und der Donau (verzierter Knochengegenstand ${ }^{154}$ ). Von da aus ging die Route (2a) mit der Berührung des entlang der Theiß liegenden Tószeg in die Richtung Ostslowakei oder (2b) entlang der Donau führte sie zur Hainburger Pforte.

Der mögliche Weg II (Abb. 7) führte in der Nähe des westlichen Küstengebietes auf der Balkanhalbinsel ${ }^{155}$ (Albanien, Kroatien), durch Westungarn (bronzener Kultgegenstand von Hashendorf/Hasfalva ${ }^{156}$ ), im östlichen Alpenvorland (Grab 164 von Pitten mit einer in mykenischem Stil verzierten Knochentrense; ${ }^{157}$ die Brotlaibidole und spiralverzierte Knochengegenstände von Waidendorf-Buhuberg ${ }^{158}$ ). Dieser Verkehrskorridor existierte sowohl

${ }^{133}$ VLADÁR 1973, Karte 1.

${ }^{134}$ V. Sava-G. P. HuREZAN-F. MĂRginean: Şagu Sit A1_1: A Late Bronze Age settlement on the Lower Mureş. Cluj-Napoca 2011, 31-41; E. PATEK: Die Urnenfelderkultur in Transdanubien. ArchHung 44. Budapest 1968, 35-36, 133; P. KMEŤOvÁ-K. HLADíKovÁ-M. Gregor: Plasticky zdobená mazanica z Levíc-Géne (Der plastisch verzierte Hüttenlehm aus Levice-Géna). In: Popolnicové polia a doba halštatská. Nitra 2010, 139-160; BouZEK 1966, Fig. 19.1, 5-7, Fig. 20.1; VLADÁR 1973, 298.

${ }^{135}$ BouZEK 1966, 264, Fig. 17.4, Fig. 19.2-4.

${ }^{136} \mathrm{O}$. H. URBAN: Der lange Weg zur Geschichte. Die Urgeschichte Österreichs. Wien 2000, 182-184.

${ }^{137}$ VLADÁR 1973.

${ }^{138}$ H. WROBEL: Die Halskragen der nordischen Bronzezeit. Mitteilungen der Berliner Gesellschaft für Anthropologie, Ethnologie und Urgeschichte 30 (2009) 4, 7, 9, Abb. 4, Taf. 2.

${ }^{139}$ V. KOLOČKO: Zur bronzezeitlichen Bewaffnung in der Ukraine. Die Metallwaffen des 17.-10. Jhs. v. Chr. Eurasia Antiqua 1 (1995) 89, Abb. 2.2; LiCHARdUS-Vladár 1996, Taf. 22.2.

${ }^{140}$ BOUZEK 1966, Fig. 17.2.

${ }^{141}$ VLADÁR 1973, Abb. 40.

${ }^{142}$ VladÁR 1973, Abb. 73.3.
${ }^{143}$ VLADÁR 1973, Abb. 75.

${ }^{144}$ Kristiansen-Larsson 2005, Fig. 46.

${ }^{145}$ BADER 1990, Abb. 24.

${ }^{146}$ Mozsolics 1967, 59-60, 155, Taf. 45.2; BouZEK 1985,

33.

${ }^{147}$ VLADÁR 1973, 308, Abb. 62.

148 J. Koós: Bronzkori „kenyéridolok” a nagyrozvágyi telepről (Bronzezeitliche „Brotlaibidole“ aus der Siedlung von Nagyrozvágy). CommArchHung 2008, 55-63.

${ }^{149}$ VladÁr 1973, Abb. 52.

${ }^{150}$ KRISTIANSEN-LARSSON 2005, Fig. 91.

${ }^{151}$ LiCHARDUS-VLADÁR 1996, 36.

${ }^{152}$ Lichardus-VladÁR 1996, 38, Taf. 4

${ }^{153}$ B. HÄNSEL: Stationen der Bronzezeit zwischen Griechenland und Mitteleuropa. BRGK 83 (2002) 87, Abb. 2.

${ }^{154}$ HÄNSEL-MEDOVIĆ 1991, 66, Abb. 6.3.

${ }^{155}$ HARDING 2000, Fig. 5.12.

${ }^{156}$ Demakopoulou op. cit. in Anm. 52, 267, Cat. 197.

${ }^{157}$ F. HAMPL-H. KERCHLER-Z. BENKOVSKY-Pivovarova: Das mittelbronzezeitliche Gräberfeld von Pitten in Niederösterreich. 1. MPK 19-20 (1981) 100, Taf. 229.164/3.

${ }^{158}$ Neugebauer 1994, 123, Abb. 63.3, Abb. 64.1, 4-5. 
früher in der Bronzezeit ${ }^{159}$ als auch später in der Urnenfelderzeit. ${ }^{160}$ So konnte man mit der Berührung der Kleinen Ungarischen Tiefebene die Donau erreichen. Die von hier ausgehenden Möglichkeiten sind mit den Routen I.1b und I.1c identisch. Der Grund für die Benutzung dieser Straßen ist offensichtlich der Handel von Gold, Kupfer, Silber, Bernstein und Salz ${ }^{161}$ zwischen den Anführern der Kulturen des Karpatenbeckens und Nordeuropas bzw. der mykenischen Elite. Wichtige Beweise dieses Beziehungssystems sind der etwas jüngere Schiffsfund von Uluburun $^{162}$ sowie die Nachahmung der Linearschrift $\mathrm{B}$ aus dem Tell von Túrkeve ${ }^{163}$ in unserer näheren Umgebung, die Eberhauerplatten als Helmschmuck von Törökszentmiklós ${ }^{164}$ und aus dem Grab 280 von Nižná Myšlla ${ }^{165}$ (Slowakei, früher Alsómislye).

Es gibt eine weitere, mit Recht Gedanken weckende Verkehrsroute (Route III; Abb. 7), die von der östlichen Seite des Urals ihren Anlauf nimmt und die kaukasisch-anatolischen Innovationen (z. B. Pyraunoi, Pithos) durch den Abaševo-Potapovo-Sintašta-Kulturkomplex ${ }^{166}$ in die Steppe hinüberträgt. Die Beweise dafür sind die Funde der befestigten Siedlung sowie des Gräberfeldes von Sintašta (Pferdegeschirr aus Knochen, Gefäß mit Mäanderverzierung ${ }^{167}$ ) und der Schatzfund von Borodino. ${ }^{168}$ Die Auswirkungen sind im unteren Donaugebiet sowie im östlichen Teil des Karpatenbeckens nachweisbar (im Keramikmaterial mit Spiralverzierung ${ }^{169}$ ), weil die eurasiatische Steppe ungefähr hier endet und eine andere natürliche Umwelt beginnt, die eine andere Lebensweise voraussetzt.

Nach der heute bereits allgemein anerkannten Meinung der Forschung kann das Spiralmotiv mit großer Wahrscheinlichkeit mit den Schichten höheren Standes einer Gesellschaft, mit der Elite, in Zusammenhang gebracht werden. ${ }^{170}$ Die Hypothese von L. und O. Dietrich, ${ }^{171}$ wonach dieses Motiv ein Pferd symbolisierte, könnte das beweisen. Das Kinderopfer ${ }^{172}$ sowie die mit ihm verbundenen vielfältigen Riten weisen auf einen herausragenden gesellschaftlichen Status hin. Die einzelnen Komponenten dieses Rituals sind die Knochen von zahlreichen, während der Zeremonie verspeisten Tieren und die Knochenreste der Speisebeigaben (oder sie wurden wegen der Seltenheit oder des Wertes symbolisch durch dekorierten Fries ersetzt), Mahlsteine, Getreide- und Speisereste sowie große Mengen von zerbrochenen und nicht vollständigen Gefäßen. Die gesellschaftliche Prestige ${ }^{173}$ wird also durch das Vorhandensein des Frieses und durch die Komplexität des Ritus widerspiegelt.

\section{DIE RELATIV- UND ABSOLUTCHRONOLOGISCHE STELLUNG DER GRUBE}

Der mitteldonauländische Hügelgräberkomplex entstand in Südmähren und in Niederösterreich auf Věteřov- ${ }^{174}$ bzw. Věteřov-Magyarád/Madarovce-Basis ${ }^{175}$ und entfaltete sich in den westlichen Regionen der SWSlowakei bis zum Fluss Waag ${ }^{176}$ bzw. in Westtransdanubien, ${ }^{177}$ im Burgenland und weiter bis Mittel- und NWTschechien, in NO-Ungarn und im südlichen Teil der Großen Ungarischen Tiefebene. Es ist jedenfalls sicher, dass

${ }^{159}$ M. PRIMAS: Innovationstransfer vor 5000 Jahren. Knotenpunkte an Land- und Wasserwegen zwischen Vorderasien und Europa. Eurasia Antiqua 13 (2007) 13-15, Abb. 11, Abb. 24.

${ }^{160}$ Lichardus-VladÁr 1996, 39; R. Jung: Aspekte des mykenischen Handels und Produktenaustauschs. In: B. HorejsR. Jung-E. Kaiser-B. Teržan (Hrsg.): Interpretationsraum Bronzezeit. Bernhard Hänsel von seinen Schülern gewidmet. UPA 121. Bonn 2005, 57-58.

${ }^{161}$ VladÁr 1973, 321; BouZEK 1985, 80-83, Fig. 1, Fig. 24; Makkay 1999, 48; Kristiansen-Larsson 2005, 125; L. DieTRICH: Eliten der frühen und mittleren Bronzezeit im südöstlichen Karpatenbecken. PZ 85 (2010) 200-202.

162 Ü. Yalçin-C. PulaK-R. Slotta (Hrsg.): Das Schiff von Uluburun. Welthandel vor 3000 Jahren. Bochum 2005.

${ }^{163}$ MAKKAY 1999, 49.

${ }^{164}$ J. TÁRNOKI: Törökszentmiklós-Terehalom. In: P. Raczky (Dir. techn.): Le bel Âge du Bronze en Hongrie. Mont Bauvray-Budapest 1994, Fig. 88, Cat. 274.

${ }^{165}$ MakKay 1999, 49, Abb. 3.4; L. Olexa: Nižná Myšl'a. Osada a pohrebisko z doby bronzovej (Siedlung und Gräberfeld aus der Bronzezeit). Košice 2003, Obr. 28, F45.
${ }^{166}$ LiCHARDUS-VladÁR 1996, 55, Taf. 20.

${ }^{167}$ Lichardus-VladÁR 1996, 39-41, Taf. 8.13-14, Taf.

14.25 .

${ }^{168}$ Mozsolics 1967, 121.

${ }^{169}$ BÓNA 1975, 121-178; DieTRICH-DIETRICH 2011.

${ }^{170}$ David 2002, 404; MetZNER-NEBELSICK 2009, 18-20, 22.

${ }^{171}$ DieTrich-DieTrich 2011, 77, Abb. 2.10a.

${ }^{172}$ BOUZEK 1985, 79.

${ }^{173}$ KRISTIANSEN-LARSSON 2005, 35-36, Fig. 8.

${ }^{174}$ S. STUChLíK: Die Entstehung der Hügelgräberkultur in Mähren und ihre Entwicklung. In: V. Furmánek-F. Horst (Hrsg.): Beiträge zur Geschichte und Kultur der mitteleuropäischen Bronzezeit II. Berlin-Nitra 1990, 470.

${ }^{175}$ Urban op. cit. in Anm. 136, 179.

${ }^{176}$ Z. BenKovsKy-Pivovarová: Zur Existenz von Lokalgruppen innerhalb des Mad̉arovce-Věteřov-Kulturkreises. ArchAu 76 (1992) 41-45.

${ }^{177}$ G. VÉKONY: A koszideri időszak a Dunántúlon (Die Koszider-Periode in Transdanubien). Komárom-Esztergom Megyei Múzeumok Közleményei 7 (2000) 174, 177, 180. 
die Hügelgräberkulturen im westlichen Teil des Karpatenbeckens älter sind als die in den bayerischen Gebieten ${ }^{178}$ bzw. die in der frühen Mistelbach-Regelsbrunn-Phase auch südlich der Donau, in Ostösterreich, vorzufinden sind. ${ }^{179}$ Dieser Entwicklungsprozess ging im Zeitraum zwischen Bz B1 und dem Übergang Bz C/D vor und der Abschluss wird durch die Blučina-Kopčany-Stufe der Hügelgräber-Velatice-Phase gekennzeichnet. ${ }^{180}$ Meiner Meinung nach ist für NW-Transdanubien (die Gebiete der Komitate Komárom-Esztergom, Győr-Moson-Sopron, Vas und Zala bis zum Moorgebiet des Plattensees und zum Transdanubischen Mittelgebirge) eine stark vermischte, kulturell (!) mosaikhafte Vielfältigkeit charakteristisch (Věteřov, Magyarád/Mađ̉arovce, Litzenkeramik und Hügelgräber). ${ }^{181}$ Diese Vorstellung wird durch die in den letzten zwei Jahrzehnten publizierten authentischen ${ }^{182}$ Daten aus der Umgebung (innerhalb von $1 \mathrm{~km}$ ) der hier erörterten Grube bestätigt.

In den letzten zwei Jahrzehnten veröffentlichten die ungarischen Forscher nur wenige, NW-Transdanubien betreffende neue Informationen aus dieser Periode. ${ }^{183}$ Gleichzeitig wurden Radiokarbonmessungen bedauerlicherweise nur in geringer Zahl durchgeführt, ${ }^{184}$ demnach konnten diesbezügliche Angaben auch nicht publiziert werden. In dieser Hinsicht unterliegt die ungarische Forschung den benachbarten Ländern.

Nach den Radiokarbondaten kann die Věteřov-Kultur in Mähren zwischen 1950/1900 und 1750/1680/1500 BC, die mitteldonauländische Hügelgräberkultur zwischen 1650/1600 und 1300/1255 BC, beide können also auf die Wende der mittleren und jüngeren Bronzezeit ${ }^{185}$ (nach mitteleuropäischer Terminologie) datiert werden.

Im Gräberfeld von Jelšovce (Slowakei) werden die zur Magyarád/Mađarovce-Kultur gehörenden Gräber zwischen 1700 und 1530 BC datiert. ${ }^{186}$

Die Věteřov-Kultur kann in Ostösterreich - auf Grund der in Berlin gemessenen Daten - zwischen 1900 und 1300 BC datiert werden. ${ }^{187}$ Der Anfang der Mittelbronzezeit (nach mitteleuropäischen Terminologie), die Hügelgräberperiode also, kann um 1600 BC gesetzt werden. ${ }^{188}$ Die letztgenannte Periode wird in der Steiermark mit dem Retznei-Hasreith-Horizont gleichgesetzt, dessen in Miami und in Wien gemessene Daten zwischen $2 \sigma 1760$ und $1300 \mathrm{BC}$ zu finden sind, ihr Gewichtpunkt liegt bei 1520 BC. ${ }^{189}$ Die aus der Nordgruppenregion des Hallstätter Salzbergwerks stammenden fünf Daten liegen im Durchschnitt bei 2 o 1650-900 BC. ${ }^{190}$

Die Ergebnisse der Messungen eines Holztroges aus dem siebenbürgischen Băile Figa (Füge, Rumänien) zeigen, dass der Abbau in der Salzgrube zwischen 2 o 1620 und 1500 BC vorging. ${ }^{191}$

In Süddeutschland wurden Knochen aus zwölf Gräbern aus der gesamten Hügelgräberzeit untersucht. Unter ihnen waren nur drei Männer über 30 Jahren (Tiengen, Untermeitingen, Hundersingen), die in die Bz B Periode, also in die Zeit zwischen 1550 und $1450 \mathrm{BC}$, datiert werden konnten. ${ }^{192}$

In der Akropolis von Monkodonja ergaben die Messungen des bei dem Südtor 2 freigelegten Tierknochens die folgenden Werte: $1 \sigma$ 1604-1524 BC, 2 o 1680-1514 BC und die Daten eines Menschenknochens lagen bei $1 \sigma$ 1600-1461 BC bzw. 2 o 1616-1447 BC. ${ }^{193}$

${ }^{178}$ LiCHARDUS-VLADÁR 1996, 33.

${ }^{179}$ NeUGebauer 1994, 22.

${ }^{180}$ V. FuRMÁNEK-O. OŽDÁNI: Kontakte der Hügelgräberkulturen und des Kulturkomplexes der südöstlichen Urnenfelder. In: V. Furmánek-F. Horst (Hrsg.): Beiträge zur Geschichte und Kultur der mitteleuropäischen Bronzezeit I. Berlin-Nitra 1990, 129-130.

${ }^{181}$ KovÁcs 1994, 162; J. KvASSAY-V. KISS-M. BondÁR: Őskori és középkori település emlékei Zalaegerszeg-Ságod-Bekeháza lelőhelyen (Prähistorische und mittelalterliche Siedlungsreste von Zalaegerszeg-Ságod-Bekeháza). ZalaiMúz 13 (2004) 136-139; G. ILON-M. NAGY: Vép, Vasút Straße, Wohnanlage (Komitat Vas, Westtransdanubien, Ungarn). In: W. David (Hrsg.): Enigma - Der mysteriöse Code der Bronzezeit. Ausstellungskatalog, Manching. Im Druck.

182 Kovács 1997; I. EgRY: Halomsíros temető GyőrMénfőcsanak-Bevásárlóközpont területén (Cemetery of Tumulus culture in the territory of the Sopping-center of Györ-Ménföcsanak). In: G. Ilon (ed.): $\mathrm{M}^{\prime} \Omega M O \Sigma$ III. Őskoros Kutatók III. Országos Összejövetelének konferenciakötete. Halottkultusz és temetkezés. BozsokSzombathely, 2002. október 7-9. Szombathely 2004, 121-137.

${ }^{183}$ Kovács 1994; Kovács 1997; ILON 1999; ILON 2012; KIss 2007; KIss op. cit. in Anm. 36.
${ }^{184}$ ILON 1999

${ }^{185}$ PEŠKA 2012, 305, 309, 311, Abb. 7, 10, 11, 12.

${ }^{186}$ J. GÖRSDORF: Interpretation der Datierungsergebnisse von Menschenknochen aus dem Gräberfeld Jelšovce. In: J. Bátora: Das Gräberfeld von Jelšovce/Slowakei. Kiel 2000, 569, Abb. 2.

${ }^{187}$ Benkovsky-Pivovarová 2008, 32, Abb. 5, Abb. 6

${ }^{188}$ NeUGebauer 1994, 20.

${ }^{189}$ TIEFENGRABER 2007, 97, Abb. 14.

${ }^{190}$ P. STADLER: Aktueller Stand der Absolutdatierung der verschiedenen Gruppen des urgeschichtlichen Bergbaus und eines Blockbaus in Hallstatt auf Grund von 14C-Daten. ANhM 101 A (1999) 79, Abb. 2, Tab. 2.

${ }^{191}$ A. F. HARDING-V. KaVRUK: Prehistoric salt production site at Băile Figa, Romania. Eurasia Antiqua 16 (2010) 148, 150, Tab 1, Fig. 31.

192 J. MÜLLER-B. LOHRKE: Neue absolutchronologische Daten für die süddeutsche Hügelgräberzeit. Germania 87 (2009) 2627, 30-32, Abb. 2, 4-6.

${ }^{193}$ B. HÄNSEL-B. TERŽAN-K. Minovilić: Radiokarbondaten zur älteren und mittleren Bronzezeit Istriens. PZ 82 (2007) 32, 41, Abb. 2.7, Abb. 6 . 

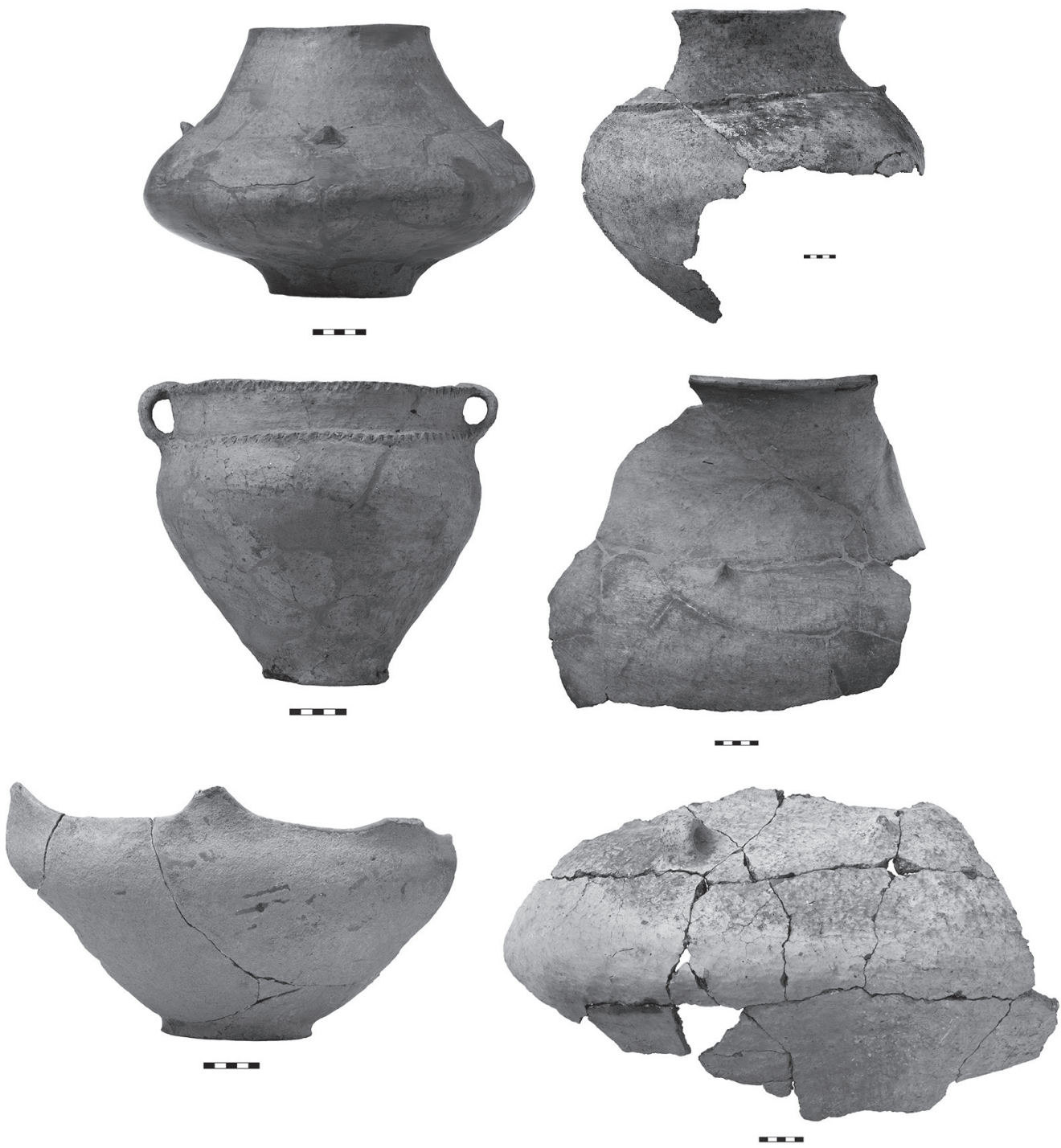

Abb. 17. Keramische Funde aus der Grube (Foto: T. Takács)

Der Ausbruch von Thera/Santorini ist für die Chronologie dieser Periode wesentlich: Mit einer Wahrscheinlichkeit von 95 \% geschah das um 1663-1599 BC. ${ }^{194}$ Die Daten wurden mit Hilfe der im arktischen Eis identifizierten Tefra auf 1622-1618 BC präzisiert. Neulich ergaben die Messungen an Olivenbäumen die Werte von 1613 \pm 13 BC. ${ }^{195}$ Die Periode der neuen Paläste von Kreta (MM III-LHIA) und die der Schachtgräber auf dem griechischen Festland (späte MH-LHI) begann auf Grund der neuesten C14-Datierung vor 1600 BC. Die LMIA-II Periode darf in die Zeit zwischen $1 \sigma 1710$ und 1410 BC datiert werden. Laut der traditionellen archäologischhistorisch-kunstgeschichtlichen Chronologie ist der Übergang von LMIB-LMII um 1450 BC, der Anfang des ägyptischen Neuen Reiches auf 550/1540/1530 BC zu datieren. Das Alter der in einem Pithos im anatolischen

${ }^{194}$ Ch. Bronk Ramsey-W. S. Manning-M. Galimberti: Dating the volcanic eruption at Thera. Radiocarbon 46/1 (2004) 336337, Fig. 6.
${ }^{195}$ L. W. FRIEDRICH: Der Vulkanausbruch von Santorini um 1613 v. Chr. und seine Auswirkungen. In: Abstracts zum 4. Mitteldeutschen Archäologentag. 1600 - Kultureller Umbruch im Schatten des Thera-Ausbruchs? Internationale Tagung in Halle (Saale), 14.-16. Oktober 2011. 8.

Acta Archaeologica Academiae Scientiarum Hungaricae 65, 2014 
Halkapinar ${ }^{196}$ gefundenen menschlichen Knochen beträgt 2 o 1520-1400, 1 o 1495-1425 BC. Demnach weichen die letzterwähnten geschichtlichen Daten ca. um 100-120 Jahre von den AMS-Ergebnissen ab. ${ }^{197}$

In die zitierte Datenreihe können die AMS-Messungen der in dieser Studie erörterten Grube genau eingepasst werden. Die Ergebnisse sind wie folgt:

Aus Tierknochen, DeA-1753: Radiocarbon Age 3269 \pm 27

Calibration data set: intcal09.14c \# Reimer et al. 2009

10 year moving average

One Sigma Ranges: [start:end] relative area

[cal BC 1606: cal BC 1573] 0.406246

[cal BC 1558: cal BC 1550] 0.080543

[cal BC 1538: cal BC 1502] 0.513211

Two Sigma Ranges: [start:end] relative area

[cal BC 1618: cal BC 1493] 0.975629

[cal BC 1475: cal BC 1462] 0.024371

Aus Kinderknochen, DeA-1854: Radiocarbon Age 3293 26

Calibration data set: intcal09.14c \# Reimer et al. 2009

10 year moving average

One Sigma Ranges: [start:end] relative area

[cal BC 1608: cal BC 1569] 0.547404

[cal BC 1562: cal BC 1529] 0.452596

Two Sigma Ranges: [start:end] relative area

[cal BC 1629: cal BC 1503] 1

Falls wir diese AMS-Daten (Abb. 5) mit den an menschlichen Knochen durchgeführten traditionellen Messungen des Grabes 1A von Nagydém aus der frühen Hügelgräberzeit (Bz B1) vergleichen, ${ }^{198}$ bekommt man das Gefühl, dass die Letztgenannte älter sei als man das erwarten würde. Meine Vermutung lässt den lehrreichen Vergleich von J. Peška ${ }^{199}$ bestätigen, in dem er die in verschiedenen Labors gemessenen, einander nur teilweise überdeckenden Daten der Věteřov-Kultur darstellte. Auf die allgemeinen Probleme der C14-Datierung und der Dendrochronologie des Kontinents machte J. Bouzek ${ }^{200}$ die Forschung ebenfalls nachdrücklich aufmerksam.

Die im Gefäßdepotfund von Hegykő befindlichen Schüsseln ${ }^{201}$ mit nach oben gerichtetem Henkel und Leistendekor haben gute Analogien in der Grube Nr. 19 von Waidendorf-Buhuberg, ${ }^{202}$ in der das keramische Material der Aunjetitz- und Věteřov-Kultur gemeinsam vorkommt. Diese sowie die Töpfererzeugnisse der Hügelgräbersiedlung von Bratislava/Pozsony-Mlynská dolina ${ }^{203}$ fehlen in unserer Grube. Das Fundensemble der Grube von Csanak ist jünger als das erstgenannte, jedoch älter als das letztgenannte Fundmaterial. Das Keramikensemble des Retznei-Hasreith-Horizontes in der Steiermark ${ }^{204}$ und die Töpfererzeugnisse des etwas jüngeren Fundplatzes des slowenischen Gornje njive bei Dolga vas ${ }^{205}$ zeigen keine näheren Parallelen, abgesehen von der Halsausbildung mancher Vorratsgefäße. Sie bilden also unterschiedliche keramische Provinzen. Die gedellten Buckel fehlen im Fundgut der Grube von Csanak, sie sind aber sowohl im Gräberfeld von Nagydém als auch im Gefäßdepot von

${ }^{196}$ HoreJs-KanZ 2008, 117.

${ }^{197}$ W. S. Manning-CH. Bronk Ramsey-W. KutscheraTh. Higham-B. Kromer-P. Steier-M. E. Wild: Chronology for the Aegean Late Bronze Age 1700-1400 B.C. Science 312 (28 April 2006) 568-569, Fig. 2-3; W. KuTSCHERA-M. BiATEK-M. E. WiLD-CH. Bronk Ramsey-M. Dee-R. Golser-K. Kopetzky-P. StadlerP. STEIER-U. ThanheISER-F. Weninger: The chronology of Tell elDaba: A crucial meeting point of 14C dating, archaeology, and Egyiptology in the $2^{\text {nd }}$ millennium BC. In: E. Boaretto-R. N. Rebollo Franco (eds): Proceedings of the $6^{\text {th }}$ International Radiocarbon and Archaeology Symposium. Radiocarbon 54 (3-4) (2012) 418-420, Fig. 7. ${ }^{198}$ ILON 1999.
${ }^{199}$ PeŠKA 2012, 305, Abb. 8

${ }^{200}$ J. BouzEK: Die Rapiere des Karpatenbeckens und die Gussform von Spišský Štvrtok. In: J. Bátora-V. Furmánek-L. Veliačik (Hrsg.): Einflüsse und Kontakte alteuropäischer Kulturen. Festschrift für Jozef Vladár zum 70. Geburtstag. Nitra 2004, 280.

${ }^{201}$ ILON 1999, Taf. 6.2-3.

${ }^{202}$ Benkovsky-Pivovarová 2008, 31, Taf. IVB, Taf. VI.1, 3.

${ }^{203}$ BArtík-Egyházy-Jurovská op. cit. in Anm. 26, 58.

${ }^{204}$ TIEFENGRABER 2007, Abb. 15.

${ }^{205}$ J. DULAR: Zur Datierung der bronzezeitlichen Siedlung Oloris bei Dolnji Lakoš. AV 62 (2011) 116, Abb. 3-8. 
Hegykő vorhanden. ${ }^{206}$ Ausschließlich die Parallele des Vorratsgefäßes mit Kegelhals ( $A b b$. 8.1) finden wir in Nagydém und in Hegykő. ${ }^{207}$ Das Gefäß mit zylindrischem Hals ( $A b b$. 10.3) und der Topf ( $A b b$. 10.4) können im keramischen Material der jüngeren Phase der nördlichen Gruppe der Transdanubischen Inkrustierten Keramik wieder gefunden werden. ${ }^{208}$ Die charakteristische eingedrückte Věteřov-Verzierung fehlt gleicherweise, doch ist sie im Grab 12 von Nagydém präsent. ${ }^{209}$ Auch der einfache Leistendekor ist hier nicht vorhanden, er ist aber im Grab $1 \mathrm{~A}^{210}$ von Nagydém belegt. Der nach oben gerichtete spitze Buckel ist sowohl im Grab 1A von Nagydém als auch im Gefäßdepot von Hegykő vorhanden. ${ }^{211}$ Anhand des keramischen Inventars der Grube kann festgestellt werden, dass die in der Region gut bekannte Litzenkeramik ${ }^{212}$ nicht repräsentiert ist, daher ist die Grube jünger als die Hügelgräber-Litzenkeramik-Periode. Der Einfluss der Magyarád/Mađarovce-Kultur ist nicht bedeutend, gleichzeitig ist die starke Wirkung der Věteřov- (nachklassische Phase) und der Hügelgräberkultur nachvollziehbar. Diese Feststellung steht mit den Radiokarbondaten der oben angeführten Kulturen der benachbarten und nahen Gebiete im Einklang.

Auf Grund des Bestattungsritus von Ménföcsanak kann man zusammenfassend das Folgende sagen: 1. Normalerweise wurden Kinder, den Bräuchen der Periode gemäß, in Pithos-Bestattungen beigesetzt. Der Brauch ist entweder von heimischem oder von südlichem Ursprung. 2. Die „Beisetzung“ von Kindern in Siedlungsgruben kommt auf den Fundplätzen der inkrustierten Keramik, der Magyarád/Mad̉arovce-Kultur, der Věteřov-Kultur und der Hügelgräberkultur vor. 3. Die Menge und die Vielfalt der „Beigaben“ deuten in unserem Fall auf Fruchtbarkeitsund Bauopfer hin.

Der Lehmfries mit dem Spiralornament (Abb. 15) aus der Opfergrube (das „Spiralmotiv“, die Innovation der „Wellenbandornamentik“, ${ }^{213}$ die in der Koszider-Periode beliebt wird ${ }^{214}$ ) könnte teilweise die nordwestliche Einwirkung/Vermittlerrolle/Expansion (?) der Otomani-Kultur ${ }^{215}$ bestätigen, jedoch ist auch die Vorstellung eines neben dem Adriatischen Meer existierenden Wirkungsmechanismus realistisch, sogar ist das gleichzeitige Vorhandensein beider nicht ausgeschlossen. Das gemeinsame Auftreten des Gefäßensembles, des Bestattungsritus und des Spiralornaments weist auf die gleichzeitige Einwirkung mehrerer Kulturen, $d$. h. auf das Zusammentreffen eines nordischen Kulturkomplexes mit einem von süd-südwestlichem Ursprung, hin, das auf Grund der Grube aus Ménfö́csanak in die zweite Hälfte der $B z B{ }^{216}$ Periode datiert werden kann. Gleichzeitig dürfte Ménföcsanak auf Grund der topographischen Lage des Fundplatzes - in der Kreuzung von nord-südlichen und ost-westlichen Wege - in der oben angeführten Handelsausübung eine Rolle gespielt haben. Die greifbaren Beweise (z. B. Gold, Kupfer, Bernstein, Salz ${ }^{217}$ ), abgesehen von dem Friesfragment, sind in dieser Periode bisher unbekannt. (Die Entdeckung eines fragmentarischen Brotlaibidols ${ }^{218}$ ist jedoch sehr wichtig.) Gleichzeitig lenken die bereits erwähnten „mykenisierenden“ Knochen- und Geweihgegenstände aus Pitten und Věteřov die Aufmerksamkeit - von den früher angenommenen und aufgezeichneten Routen ${ }^{219}$ - auf den zweiten Innovationskorridor hin, eine Vermittler- und Handelsstraße, die sich - mit der Region um Ménfócsanak - in der Treffzone ${ }^{220}$ der Alpen und Transdanubien befindet.

${ }^{206}$ ILON 1999, Taf. 1.3, Taf. 8.3, Taf. 1.1, Taf. 6.1.

${ }^{207}$ ILON 1999, Taf. 1.1, Taf. 6.1.

${ }^{208}$ V. KISS: Middle Bronze Age Encrusted Pottery in Western Hungary. VAH 27. Budapest 2012, 68, 73, Fig. 15. Ub6, Bs2.

${ }^{209}$ ILON 1999, Taf. 5.1.

${ }^{210}$ ILON 1999, Taf. 2.2, 9

${ }^{211}$ ILON 1999, Taf. 2.10, Taf. 8.4.

${ }^{212}$ KovÁcs 1994, 161-162; G. ILON: Szombathely őskori településtörténetének vázlata. Avagy a római kor előtt is volt élet (Outline of the Pre-historic Settlement of Szombathely, or life before the Roman Age). Szombathely 2004, Taf. 83; Kiss 2007, 17-18; KISS 2012, 324.

${ }^{213}$ DAVID 2001, 51-80.

${ }^{214}$ URBAN op. cit. in Anm. 136, 179.

${ }^{215}$ N. TAsić: Einleitung. In: N. Tasić (Hrsg.): Kulturen der Frühbronzezeit des Karpatenbeckens und Nordbalkans. Beograd 1984, 12-13; FURMÁNEK-OŽDÁNI op. cit. in Anm. 180, 138-139; KRISTIANSEN-LARSSON 2005, 125.

${ }^{216}$ B. HÄNSEL: Beiträge zur Chronologie der mittleren Bronzezeit im Karpatenbecken. Bonn 1968, 161; DAVID 2002, Abb. 3.17.
${ }^{217}$ Aus einer in einer Entfernung von $22 \mathrm{~km}$ liegenden frühurnenfelderzeitlichen (Bz D-Ha A1) Siedlungsgrube in LébényKaszás-Hügel wurde ein Bergsalzbrocken geborgen. Anhand dieses Fundes ist der auch Ménföcsanak betreffende Handel dieses Produktes in früheren Zeiten vorstellbar. T. G. NÉMETH: Adalék a késő bronzkori sóforgalomhoz (Contribution to the salt trade in the Bronze Age). Arrabona 49/1 (2011) 251, 253, 262, Taf. 3.

${ }^{218}$ W. DAVID: Enigma - Der rätselhafte Code der Bronzezeit. „Brotlaibidole“ als Medium europäischer Kommunikation von mehr als 3500 Jahren. Mitteilungen der Freunde der Bayerischen Vorund Frühgeschichte 130 (2011) 2-15; G. ILON: Kenyéridol Ménfőcsanakról. Bread idol from Ménfócsanak. In: J. Kvassay (ed.): Évkönyv és jelentés a Kulturális Örökségvédelmi Szakszolgálat / Magyar Nemzeti Múzeum Nemzeti Örökségvédelmi Központ 2010. évi feltárásairól - Field Service for Cultural Heritage / The National Heritage Protection Centre of the Hungarian National Museum 2010 Yearbook and Review of Archaeological Investigations. Budapest 2013. Im Druck.

${ }^{219}$ VladÁR 1973, Karte 2; LiChARDUS-VladÁR 1996.

${ }^{220}$ HARDING 2000, Fig. 5.12; Urban op. cit. in Anm. 136,

180. 
Dieser früher für den ,,ersten“ (mittlerweile eher für den zweiten ${ }^{221}$ ) gehaltene intensive mykenisch-karpatenländische und mitteleuropäische Wirkungsmechanismus wurde von J. Bouzek ${ }^{222}$ und J. Vladár ${ }^{223}$ an die Wende der LH I = Bz A2/B1, in den Vorhügelgräberhorizont, datiert. Im Verhältnis dazu skizzierten A. Harding, ${ }^{224}$ W. David, ${ }^{225}$ J. Maran ${ }^{226}$ bzw. K. Kristiansen und Th. B. Larsson ${ }^{227}$ eine andere Möglichkeit im Verbindungssystem der Gebiete von Mykene, Mitteleuropa, England und Skandinavien. Demnach begannen die Interaktionen früher (mittelminoische/MM-Zeit), und die erwähnten Forscher hielten diese im Intervall Bz A(1-)2-B1 etwa für kontinuierlich, aber von wechselnder Intensität. Die Radiokarbondaten unserer Grube decken die jüngere Phase der angegebenen Zeitperiode, da die Daten ins Intervall von 1600 bis $1500 \mathrm{BC}$ ( $A b b .5)$ für diese Periode gegeben sind. Wenn wir annehmen, dass die AMS-Daten - auf Grund der Ergebnisse des Niveaus 18/17-6 von Kastanas 228 - im Vergleich zu den archäologisch-historischen Vorstellungen um 80-100 Jahre ältere Daten ergaben, kann die Frage, ${ }^{229}$ wie viele Jahrhunderte die Existenz der Hügelgräberkultur im Gebiet des heutigen Ungarn umfasste bzw. wie die Daten für den Anfang und das Ende in absoluten Zahlen anzugeben sind, immer noch nicht befriedigend beantwortet werden. Zu einer stichhaltigen Beantwortung der Frage sind noch weitere Messungen aus authentischen Grabungen notwendig. Es ist jedoch klar, dass der balkanisch-karpatenländische und mittel- bzw. osteuropäische Wirkungsmechanismus in der folgenden, nichtsdestotrotz mit einer mehr einheitlichen materiellen und geistlichen Kultur gekennzeichneten Urnenfelderzeit weiter bestand. ${ }^{230}$

Zum Schluss soll noch erwähnt werden, dass das Ziel dieser Studie nichts anderes war, als die Ergänzung der bereits durchgeführten Untersuchungen bezüglich des angenommenen Beziehungssystems ${ }^{231}$ der mitteleuropäischen Bronzezeit mit der mykenischen Welt - und zwar anhand der Erscheinung des Spiralmotivs als architektonischen Elements. ${ }^{232}$

\section{DANKSAGUNG}

Die Restaurierung des Fundmaterials wurde von den Mitarbeitern der Archeolor GmbH (Budapest) unter der Leitung von Szilvia Döbröntey-David durchgeführt. Hervorzuheben ist dabei die sorgfältige Behandlung des Lehmfrieses, die Arbeit von Norbert Németh. Ich bin den folgenden Kollegen für ihre Arbeit besonders dankbar: Gábor Nagy für die Wirbeltieruntersuchung, Prof. Dr. Pál Sümegi (Universität Szeged) für die Muschelanalyse, Prof. Dr. László Bartosiewicz (Eötvös-Loránd-Universität, Budapest) für die Untersuchung der Fischknochen und Dr. Alfred Galik (Veterinärmedizinische Universität, Wien) für die Untersuchung der freigelegten Schuppen. Mein Dank gilt den Mitarbeitern des Zentrums für Nationales Kulturerbe der UNM, insbesondere Árpád Kenéz für die archäobotanische Untersuchung, Dr. Ákos Pető für die Phytolithanalyse und dem Geologen István Oláh für die Rohstoffanalyse der Mahlsteine. Die Radiokarbonmessungen wurden in der ATOMKI (Debrecen) durchgeführt, für die AMS C14-Datierungen bin ich Dr. Mihály Molnár und seinen Mitarbeitern dankbar. Natürlich soll hier die Arbeit, die bei der Ausgrabung geleistet wurde, allen Mitarbeitern bedankt werden, namentlich Archäologen, Gra-

${ }^{221}$ KRISTIANSEN-LARSSON 2005, 118-127.

${ }^{222}$ BOUZEK 1966, 261, 268; BouZEK 1996, 178.

${ }^{223}$ VLADÁR 1973, 297, 310-311, 326, 335.

${ }^{224}$ HARDING 2000, 165, 167, 170, 181, Fig. 5.3.

${ }^{225}$ DAVID 2001, 69-73.

${ }^{226}$ Er nimmt eine kurzlebige Beziehung während der frühen Hügelgräberzeit im 16. Jahrhundert an. MARAN 2004, 49-54, besonders 60-61.

${ }^{227}$ LARSSON 2005, 161.

${ }^{228}$ R. JUNG-B. WeNINGER: Appendix: Zur Realität der Diskrepanz zwischen den kalibrierten 14C-Daten und der historischarchäologischen Datierung in Kastanas. In: R. Jung: Kastanas. Ausgrabungen in einem Siedlungshügel der Bronze- und Eisenzeit Makedoniens 1975-1979. Die Drehscheibenkeramik der Schichten 19 bis 11. Prähistorische Archäologie in Südosteuropa 18/1. Kiel 2002, 225, Abb. 1-2.

${ }^{229}$ T. SZALAI: Mit tudunk mondani a Halomsíros-kultúra abszolút dátumairól? (Was können wir über die genaue Datierung der Acta Archaeologica Academiae Scientiarum Hungaricae 65, 2014
Hügelgräberkultur sagen?). Komárom-Esztergom Megyei Múzeumok Közleményei 7 (2000) 149-172; T. KovÁcs: Neue Angaben und Beobachtungen zur Untersuchung der Gesellschaftsstruktur der Hügelgräberkultur im Karpatenbecken. ActaArchHung 51 (1999/2000) 97.

${ }^{230}$ BouZeK 1996, 175-178; B. HÄNSEL: Die Götter Griechenlands und die südost- bis mitteleuropäische Spätbronzezeit. In: B. Gediga-D. Piotrovska (Hrsg.): Die symbolische Kultur des Urnenfelderkreises in der Bronze- und frühen Eisenzeit Mitteleuropas. Warszawa-Wrocław-Biskupin 2000, 332; MÜLLER-KARPE 2003; Kristiansen-LARsson 2005, 317-319, Fig. 146; W. David: Die Zeichen auf der Scheibe von Nebra und das altbronzezeitliche Symbolgut des Mitteldonau-Karpatenraumes. In: H. Meller-F. Bertemes (Hrsg.): Der Griff nach den Sternen. Int. Symposium in Halle (Saale), 16.-21. Februar 2005. Tagungen des Landesmuseums für Vorgeschichte, Halle, 5/1 (2010) 481-482.

${ }^{231}$ BÓNA 1975, 18-20.

${ }^{232}$ Kristiansen-Larsson 2005, 161-167, Fig. 65-66. 
bungstechnikern, Technikern und Geodäten. Die Zeichnungen dieser Studie wurden von Magdolna Mátyus angefertigt, die Rekonstruktion ist die Arbeit von András Radics und Tibor Takács, die Fundfotos wurden von Tibor Takács aufgenommen. Ihre sorgfältige Arbeit sei auch hiermit recht herzlich bedankt. Ich bedanke mich bei Dr. Viktória Kiss ebenfalls recht herzlich für ihre exakte Begutachtung und ihre wertvollen Hinweise.

\section{LITERATUR}

BADER 1990

BANNER-BÓNA-MÁRTON 1957

BARTÍK 1996

BENKOVSKY-PIVOVAROVÁ 2008

BÓNA 1975

BOUZEK 1966

BOUZEK 1975

BOUZEK 1996

CHIDIOSAN-ORDENTLICH 1975

DAVID 2001

DAVID 2002

DIETRICH-DIETRICH 2011

FURMÁNEK-VELIAČIK-VLADÁR 1999

HÄNSEL-MEDOVIĆ 1991

HARDING 2000

HARDING-ŠUMBEROVÁ-KNÜSELOUTRAM 2007

ILON 1999

ILON 2012

JELÍNEK 2007

KISS 2007

KISS 2012
$=$ T. BADER: Bemerkungen über die ägäischen Einflüsse auf die alt- und mittelbronzezeitliche Entwicklung im Donau-Karpatenraum. In: Orientalisch-ägäische Einflüsse in der europäischen Bronzezeit. Monographien RGZM 15. Bonn 1990, 181-205.

= J. BAnner-I. BónA-L. Márton: Die Ausgrabungen von L. Márton in Tószeg. ActaArchHung 10 (1957) 1-140.

= J. BARTíK: Sídlisko stredodunajskej mohylovej kultúry vo Veselom. Siedlung der mitteldanubischen Hügelgräberkultur in Veselom. SlA 44 (1996) 189-252.

$=$ Z. BENKOvSKY-PivovAROvÁ: Zur bronzezeitlichen Siedlung Buhuberg in Waidendorf. ŠtZ 43 (2008) 23-41.

= I. BóNA: Die mittlere Bronzezeit Ungarns und ihre südöstlichen Beziehungen. ArchHung 49. Budapest 1975

$=\mathrm{J}$. BouZEK: The Aegean and Central Europe, an introduction to the study of cultural interrelations 1600-1300 BC. PA 57 (1966) 242-277.

= J. BouzeK: The Aegean, Anatolia and Europe: Cultural Interrelations in the second millennium B.C. Göteborg-Prague 1985.

$=\mathrm{J}$. BOUZEK: Greece and the Aegean area and its relationship with continental Europe. ActaArchaeologica (København) 67 (1996) 175-181.

= N. ChIDIOŞAN-I. ORDENTLICH: Un templu-megaron din epoca bronzului descoperit la Sălacea. Ein in Sălacea entdeckter Megaron-Tempel der Bronzezeit. Crisia (1975) 19.

= W. DAVID: Zu den Beziehungen zwischen Donau-Karpatenraum, osteuropäischen Steppengebieten und ägäisch-anatolischem Raum zur Zeit der mykenischen Schachtgräber unter Berücksichtigung neuerer Funde aus Südbayern. In: Anodos. Studien of Ancient World. 1: Mittelmeergebiet und Mitteleuropa in Kontakten und Konfrontationen. Trnava 2001, 51-80.

= W. DAVID: Studien zu Ornamentik und Datierung der bronzezeitlichen Depotfundgruppe Hajdúsámson-Apa-Ighiel-Zajta. 1. Alba Iulia 2002.

= L. Dietrich-O. DiETrich: Wietenberg ohne Mykene? Gedanken zu Herkunft und Bedeutung der Keramikverzierung der Wietenberg-Kultur. PZ 86 (2011) 67-84.

= V. FuRMÁNEK-L. VELIAČIK-J. VlAdÁR: Die Bronzezeit im slowakischen Raum. Prähistorische Archäologie in Südosteuropa 15. Rahden/Westf. 1999.

= B. HÄNSEL-P. MEDOviĆ: Vorbericht über die jugoslawisch-deutschen Ausgrabungen in der Siedlung von Feudvar bei Mošorin von 1986-1990. BRGK 72 (1991) 48-204+ Taf. 63.

= A. Harding: European Societies in the Bronze Age. Cambridge 2000.

= A. Harding-R. ŠumberovÁ-Ch. KnÜSEL-A. Outram: Velim. Violence and Death in Bronze Age Bohemia. Prague 2007.

= G. ILON: A bronzkori halomsíros kultúra temetkezései Nagydém-Középrépáspusztán és a hegykői edénydepot - Die Bestattungen der bronzezeitlichen Hügelgräberkultur in Nagydém-Középrépáspuszta und das Gefäßdepot von Hegykő. Savaria Pars Archaeologica 24/3 (1999) 239-276.

= G. ILON: A Halomsíros kultúra rituális (?) „edénydepója” Veszprém határából - The ritual “vessel hoard" of the Tumulus culture in the vicinity of Veszprém. In: J. Kisfaludi (ed.): Régészeti kutatások Magyarországon 2010 (Archaeological Investigations in Hungary 2010). Budapest 2012, 19-54.

= P. JELínEK: Nálezi detských skeletov v sídliskových objektoch z neolitu, eneolitu a doby bronzovej z juhozápadného Slovenska. Funde der Kinderskelette in den Siedlungsobjekten aus Neolithikum, Äneolithikum und der Bronzezeit aus der Südwestslowakei. ŠtZ 42 (2007) 71-98.

= V. Kiss: The Middle Bronze Age in the western part of Hungary (An overview). In: G. Tiefengraber (Hrsg.): Studien zur Mittel- und Spätbronzezeit am Rande der Südostalpen. UPA 148. Bonn 2007, $15-35$.

$=$ V. KISS: Central European and southeastern Alpine influences upon Western Transdanubia's Early and Middle Bronze Age. In: P. Anreiter et al. (eds): Archaeological, Cultural and Linguistic Heritage. Festschrift for Erzsébet Jerem in Honour of her $70^{\text {th }}$ Birthday. Archaeolingua 25. Budapest 2012, 321-335. 
KMEŤOvÁ-HLADÍKOVÁ-GREGOR 2010

KovÁcs 1994

KovÁCs 1997

KRISTIANSEN-LARSSON 2005

LICHARDUS-VLADÁR 1996

MAKKAY 1999

MARAN 2004

MARKOVÁ-SAMUEL 2008

MetZneR-Nebelsick 2009

Mozsolics 1967

MÜLLER-KaRPE 2003

Neugebauer 1994

PATEK 1968

PAULÍK 1962

PEŠKA 2012

PRIMAS 2008

ROMSAUER 2003

SALAŠ 2007

SÁNTA 2009

SAVA-HuREZAN-MĂRgINEAN 2011

STUCHLÍK 2006

TIEFENGRABER 2007

TočÍK 1964

VLADÁR 1973
= P. KMEŤOvÁ-K. HLAdíKOvÁ-M. GREGOR: Plasticky zdobená mazanica z Levíc-Géne (Der plastisch verzierte Hüttenlehm aus Levice-Géna). In: Popolnicové polia a doba halštatská. Nitra 2010, 139-160.

$=\mathrm{T}$. KovÁcs: Chronologische Fragen des Überganges von der mittleren zur Spätbronzezeit in Transdanubien. ZalaiMúz 5 (1994) 159-172.

= T. KovÁcs: Das Grab von Ménföcsanak. Ein Beitrag zu transdanubischen Denkmälern der Vorhügelgräberzeit. In: C. Becker-M.-L. Dunkelmann-C. Metzner-Nebelsick et al. (Hrsg.): X@óvos. Beiträge zur prähistorischen Archäologie zwischen Nord- und Südosteuropa. Festschrift für Bernhard Hänsel. Internationale Archäologie. Studia honoraria 1. Marburg 1997, 297-301.

= K. Kristiansen-T. B. Larsson: The Rise of Bronze Age Society. Travels, Transmissions and Transformations. Cambridge 2005.

= J. Lichardus-J. VladÁR: Karpatenbecken - Sintašta - Mykene. Ein Beitrag zur Definition der Bronzezeit als historischer Epoche. S1A 44 (1996) 25-93.

= J. MakкAY: The Mycenaean World, the Mycenaean Periphery and the Carpathian Basin. In: H

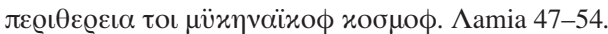

= J. MARAN: Wessex und Mykene. Zur Deutung des Bernsteins in der Schachtgräberzeit Südgriechenlands. In: B. Hänsel-E. Studeniková (Hrsg.): Zwischen Karpaten und Ägais. Neolithikum und ältere Bronzezeit. Gedenkschrift für Viera Němejcová-Pavúková. Rahden/Westfalen 2004, 54-56.

= K. MarkovÁ-M. SAmuEL: Nálezy zo staršej a začiatku strednej doby bronzovej z Ponitrianskej Galérie v Nitre. Funde aus der älteren und dem Anfang der mittleren Bronzezeit aus der Ponitrianska galéria in Nitra. ŠtZ 43 (2008) 63-91.

= C. Metzner-Nebelsick: Symbole der Macht in der Bronze- und Eisenzeit Europas. Beiträge zur Vorgeschichte Nordostbayerns 7 (2009) 13-26.

= A. Mozsolics: Bronzefunde des Karpatenbeckens. Budapest 1967.

= H. MÜLLER-KARPE: Zur religiösen Symbolik von bronzezeitlichem Trachtschmuck aus Mitteleuropa. In: Anodos. Studies of the Ancient World. 3: Proceedings of the International Symposium Ancient Jewellery and Costume in Course of Time. From the Bronze Age to the Late Antiquity. Trnava 2004, $145-154$.

= J.-W. Neugebauer: Bronzezeit in Ostösterreich. St. Pölten-Wien 1994.

= E. PATEK: Die Urnenfelderkultur in Transdanubien. ArchHung 44. Budapest 1968.

= J. PAUlík: Mazanica s plastickou výzdobou v dobe bronzovej na Slovensku. Lehmbewurf mit plastischer Verzierung aus der Bronzezeit in der Slowakei. ŠtZ SAV 10 (1962) 27-57.

= J. PEŠKA: Beispiele der absoluten Chronologie der Frühbronzezeit in Mähren und ihrer Verknüpfungen mit der Ägäis. In: R. Kujovský-V. Mitáš (Hrsg.): Václáv Furmánek a doba bronzová. Zborník k 70. narodeninám. Nitra 2012, 297-314.

= M. Primas: Bronzezeit zwischen Elbe und Po. Strukturwandel in Zentraleuropa 2200-800 v. Chr. UPA 150. Bonn 2008.

= P. ROMSAUER: $\pi \dot{U} \varrho \alpha u v o r$. Prenosné piecky a podstavce z doby bronzovej a doby železnej. Summary. Nitra 2003.

= M. SALAŠ: Starobronzový kostrový pohřeb v nádobě z Vedrovic (Frühbronzezeitliche Skelettbestattung im Vorratsgefäß von Vedrovice). Pravěk NŘ 17 (2007) 121-161.

= G. SÁNTA: A halomsíros kultúra Domaszék-Börcsök-tanyai településének legkorábbi szakasza és a telep szerkezete (Die früheste Phase und die Struktur der Siedlung der Hügelgräber-Kultur in Domaszék-Börcsök Gehöft). Tisicum 19 (2009) 255-280.

= V. SaVA-G. P. HureZAN-F. MĂRginean: Şagu Sit A1_1: A Late Bronze Age settlement on the Lower Mureş. Cluj-Napoca 2011.

= S. STUCHLíK: Borotice. Mohylové pohřebiště z doby bronzové. Borotice. Ein bronzezeitliches Hügelgräberfeld. Brno 2006.

= G. TIEFENGRABER:Zum Stand der Erforschung der Mittel- und Spätbronzezeit in der Steiermark. In: G. Tiefengraber (Hrsg.): Studien zur Mittel- und Spätbronzezeit am Rande der Südostalpen. UPA 148. Bonn 2007, 67-113.

= A. Točík: Opevnena osada z doby bronzovej vo Veselom. Befestigte bronzezeitliche Ansiedlung in Veselé. ASF 5. Bratislava 1964.

= J. VLADÁR: Osteuropäische und mediterrane Einflüsse im Gebiet der Slowakei während der Bronzezeit. SIA 21 (1973) 253-357. 